\title{
Aftershock sequences of some large earthquakes in the region of Greece
}

\author{
B. Papazachos - N. Delizisis - N. Llapis - G. Moumoulidis - \\ G. PURCaRU
}

Ricevuto il 17 Settembre 1966

Riassunto. - Vengono qui studiate dagli A. le caratteristiche delle deformazioni, la magnitudo e la distribuzione dei tempi delle repliche dei grandi terremoti avvenuti in Grecia dal 1926 al 1964 . Sono state trovate relazioni approssimative fra il numero delle repliche, la magnitudo e la profondita focale della scossa principale, e fra la magnitudo della replica più forte e la magnitudo e profonditì focale della scossa principale.

La replica più forte avviene entro quattordici giorni dalla scossa principale; in molti casi "ultime repliche" forti si hanno uno o più mesi dopo le scossa principale. Nel $40 \%$ dei casi la magnitudo di una o più scosse premonitrici è maggiore di 3,5 ; la probabilità che un terremoto sia prece. duto da una forte scossa premonitrice non molto più piccola di quella principale ò del $10 \%$.

Viene dimostrato che dallo studio della distribuzione della magnitudo e delle caratteristiche delle deformazioni delle repliche, si possono dedurre alcune proprietà dei materiali terrestri che si trovano nella regione delle repliche prese in esame.

SUMmarr. - Deformation characteristies, magnitude and time distribution of the aftershocks of the large earthquakes, occurred in the region of Greece from 1926 till 1964 are investigated. An approximate relation between the number of aftershocks and the magnitude and focal depth of the main shock has been found. Also, an approximate relation has been derived between the magnitude of the largest aftershock and the magnitude and focal depth of the main shok. The largest aftershock occurs within fourteen days after the main shock. In many cases large "late aftershocks" occur one or more months after the main shock. One or more foreshocks of magnitude larger than 3.5 occurred in forty per cent of the cases. The 
probability for an earthquake to be preceded hy a large foreshock not much smaller than the main shock is $10 \%$. It is shown that some properties of the Earth's material in the aftershock region can be derived by studying the magnitude distribution and deformation characteristics of the aftershocks.

\section{INTRODUCTION.}

It is well known that the earthquales have a tendency to occur at certain space domains. There is also a tendency of the earthquake activity to concentrate in time. Terms like "seismic zone" and "seismic period" related to these properties of earthquake occurrence have been used by seismologists. Very frequently, series of earthquakes occur in a relatively small space and short time.

A single large earthquale is usually preceded and followed in short time by other earthquakes of considerably smaller magnitude than the large one. These small shocks have their foci near the focus of the large earthquake. The conspicuously larger earthquake of the series is called main or principal shock and the earthquakes preceding and following the main shock are called fore- and aftershocks respectively. The whole series is called foreshock-aftershock sequence. There are cases when a series of earthquakes occurs in a small space and short time but no one of these shocks is conspicuously larger. Such a series is usually called swarm of carthquakes.

In this paper we shall investigate the foreshock and mainly the aftershock sequences all of the normal earthquakes (focal depth smaller than about $70 \mathrm{~km}$ ) of minguitude $M \geqq 6$ occurred in the region of and near Grecee from 1926 till 1964 . The region is bordered by the $34^{\circ} \mathrm{N}$ and $42^{\circ} \mathrm{N}$ parallels and $19^{\circ} \mathrm{E}$ and $29^{\circ} \mathrm{E}$ meridians. The study includes the time and magnitude distribution of the aftershocks, the deformation characteristies and some properties of the material in the space domain of several aftershock sequences.

The study of fore- and aftershock sequences is very usefull for many purposes. Investigations of this kind can contribute to the problem of earthqualke prediction. Formulas [40], [t1], [45] and [t6], for 'xample, ean be used to determine approximately the magnitude of the largest aftershock and the number of aftershocks with $M \geqq 4$ which will follow an earthquake of normal depth when the magnitude and the focial depth of the main shock is known. Also, the tendency of foreshocks to procede large earthquakes that originate from a certain regrion may be used to predict earthquakes in those regions. After- 
shocks of the artificial explosions probably differ from aftershocks of natural seismic events in their time and spacial distribution. Study of these distribution can be used 10 distinguish between natural and artificial seismic events. The difference in magnitudes of the main shock and the largest aftershock might be used additionally for detection of artificial erents. Deformation and stress characteristies of the aftershock volume and characteristics of magnitude distributions "an be used to investigate some poperties of the earth's material in the aftershock region.

The Seismological Institute of the National Observatory of Athens in cooperation with the Seismological Laboratory of the University of Athens has undertaken a program to study the foreshock and aftershork sequences in the region of Greece under terms of a contract between our Seismological Institute and the U.S. Air Foree. Since this is the first paper on this program we shall give a brief review of the results of some of the basic works on this problem.

\section{Time Distribution of Aftershocks.}

The time distribution of aftershocks have been studied by many, mainly Japanese, inrestigators. The original Omori's law was modified by Utsu $\left({ }^{15}\right)$ into:

$$
n(t) d t=K(t+C)^{-h} d t
$$

where $t$ is the time after the main shock, $n(t) d t$ is the number of aftershocks occurring in the time between $t$ and $(t+d t)$ and $K, C$ and $h$ constants chosen to fit the data. When $h=1$, the equation [1] expresses the Omori's law.

Mogi $\left({ }^{\circ}\right)$ showed that the time distribution of aftershocks in the early stage, when the stress probably decreases, is expressed by the relation:

$$
n(t) d t=n_{1} t^{-h} d t \quad 0<t<t_{o}
$$

while in the late stage, when the stress remains constant, is approximated by the formula:

$$
u(t) d t=n_{2} e^{-p t} d t \quad t>t_{o} .
$$

He found that $h$ is independent of the magnitude of the main shock and it shows a spacial distribution. Its value probably depends on the riscosity of the material in the aftershock regrion. 
The frequency function of the time interval between successive earthquakes has been also investigr.ted by serveral seismologists (Mogi (7), Suzuki et al. (14)). The relation

$$
n(\tau) h(\tau)=.1 r^{-\lambda \tau} \text { tr }
$$

is applied in ordinary earthunakes. and ller relation

$$
n(\tau) d r=n t h
$$

in aftershoek sequences. $T$ is the time interval between suceessive earthquakes and $A, \lambda, a$, and $\vec{p}$ are constants. $p$ and the constant $h$ in [2] are related with

$$
\beta=2-\frac{1}{h}
$$

All large earthquakes of normal focal depth have aftershocks. The number of aftershocks abore a tixed magnitude level, as we shall see later, depends on the magnitude of the main shock and on the depth, i.e. on the mechanical strueture of the material in the focal region. On this ground one might expect that all large aftershocks have their own aftershocks. These shocks are called second order aftershocks. The rule however, is that no aftershocks of the second order are often experienced (Matuzawa $\left({ }^{5}\right)$ ). In rare cases aftershocks of large aftershorks exist or can be distinguished.

There are cases when one or more large shocks oceur in one or a few months after the main shock when aftershocks have subsided. Following Richter (13) whe shall call these shocks large "late aftershocks". They usually hare their own aftershocks. It is not always known whether they are real aftershorks or not. But we shall see more about that later.

\section{Spacial Distribution of Foreshocks and Aftershocks.}

The main shock is not situation in the center of the active segment but close to one end. In all big earthquakes which occurred in Japan from 1923 till 1964 and had many aftershocks this phenomenon has been observed (Matuzawa $\left(^{5}\right)$ ). The domain of the epicentres of aftershocks takes approximately an elliptical form with the long axis parallel to the active fault segment. The epicenters of the aftershocks are usually concentrated near the two ends and the epicenter of the largest aftershock is close to one end but in the opposite side of the epicenter of the main shock (Richter $\left({ }^{13}\right)$ ). The area $S$ (in $\left(\mathrm{cm}^{2}\right.$ ) 
covered by the epicenters of the aftershocks is roughly given, aceording Bath and Duda ('), by the relation:

$$
\log S=4.95+1.21 M .
$$

The aftershock volume $r$ (in $\left(\mathrm{cm}^{3}\right)$, aceording to the same writers, is given by the relation:

$$
\log V^{r}=9.58+1.47 M
$$

where $M$ is the magnitude of the main shock.

The problem of the space distribution of foreshorks has not been fully investigated yet. In some cases the epicenters of the foreshocks are close to the epicenter of the main shock but in the opposite directions of the place where the subsequent faulting takes place (Richter $\left({ }^{13}\right)$ ).

\section{Frequency Function of the Magnitude of Eearthquakes.}

The frequency function of the maximum trace amplitude $a$ of earthquakes recorded at an observatory is expressed in most cases by the known Ishimoto-Iida's statistical relation:

$$
n(a) d a=k a^{-m} d a
$$

where $n(a) d a$ is the number of earthquakes confined to a certain domain and recorded with maximum amplitudes between $a$ and $(a+d a)$, and $k, m$, are constants. Gutenberg and Richter $\left({ }^{+}\right)$used the form:

$$
\log n(M)=A+b(8-M)
$$

to express the frequency function of the magnitude $I T$ of the earthquakes originated from a certain space domain. The $n(M) d M$ is the number of earthquakes with magnitudes between $M$ and $(M+d M)$ and $A$ and $b$ are constants.

Since $M \simeq \log a$ for epicentral distance equal to $100 \mathrm{~km}$ and $d a=a$ $d M$, it can be shown that the constants $m$ and $b$ in the formulas [8] and [9] are related by the:

$$
b=m-1 .
$$

The relations [8] and [9] hold also for aftershock and foreshock sequences but the value of constant $b$ is higher by about 0.3 for aftershocks than for foreshocks or other earthquakes of the same region (Mogi $\left({ }^{9}\right)$ ). An explanation of this will be given later. 
The physical meaning of the constant $b$ has been discussed very much, but is not yet very celear. Some investigators relate it with the tectonic structure of the seismic regions. MIogi $\left({ }^{7}\right)$ studied experimentally the elastic shocks caused by the fracture of brittle malerial under constant and under increasing with time stress. He found that the Ishimoto-Iida's relation holds when the structure of the malerial is irregular or when the applied stress is not uniform. The values of $b$ which Mogri found for the elastice shocks in granite speciments lie between 0.5 and 1.0 , and are almost the same as in arthquakes. The value of $b$ incereases as the degree of heterogeneity increases and as the degree of symmetry of the applied stress decreases. Values of $b$ up 10 2.0 have been found experimentally as well as from seismic data. Even values up to 3.0 have been found for some volcanic arthruakes.

When the structure is regular and the stress is applied uniformly the relation $\log n=f(\lambda)$ is a concavely downwards curre which is represented by two or more straight liness.

T'heories on the Aechanism of Generation of Aftershochs.

'Two main irleas are known to us on the mechanism of generation of aftershocks. The one is due to Beniofi and the other to Mogri. Both irleats are based on experimental and observational results as well as on theoretical considerations. Attempts also have been made to explain the process of generation of aftershocks by the rheological equations of Maxwell and Kolvin.

Benioff $\left(^{2}\right)$ presented experimental as well as theoretical evidence that aftershocks are produced by ereep of the fault rocks. He found that at the beginning for some time interval after the main shock the rerep is compressional and the following equation derived by Griggs from laboratory experiments fits this data:

$$
\Sigma \varepsilon_{i}=\xi=a+b \log t,
$$

where $\varepsilon$ is the strain and $\xi$ is the cumblative crece st 1 ain in (ergs) $1 / 2$, $t$ is the time measured from the main shock in days and $a$ and $b$ are constants. After some time interval from the main shock a second phase follows. The following equation represents satisfactorily this pliase:

$$
\sum \varepsilon_{i}=\xi=A+B[1-\exp (-\gamma \sqrt{t-T})],
$$

where $T$ is the time when the second phase starts, $A$ is the strain released in the time between the main shock and the start of this phase, 
$B$ is the strain released in the second phase and, $\gamma$ is a constant related to the relaxation time $\tau$ (the time in which the strain drops to $1 / e$ of the initial value) by the:

$$
\gamma=\frac{1}{\sqrt{\tau}} .
$$



Fig. I - Index map of the epicenters of the shallow earthquakes of $M \quad 6$ occurred in the region of Greece from 1926 till 1964.

Originally this second phase of the strain release was characterized as shearing on the basis of experiments by Michelson but later Lomnitz gave the same type of strain-release characteristic for shear as for compression (Richter, $\left({ }^{13}\right)$ ). To calculate $\varepsilon$, the following formula was used:

$$
\sqrt{J}=\sqrt{\frac{\mu}{2} p \varepsilon^{2}}=K \varepsilon
$$


where $p$, is the fraction of the stored energy in the volume $V$ of the rock which is converted into seismic wave energy $J$ and $\mu$ is an elastic constant. The quantity $K$ was considered constant and equal for all the aftershocks independently of their mingnitude. That means that the focal rolume of each aftershock was considered equal to the whole volume in which aftershock foci exist.

Bath and Duda (') assumed that the constant $K$ in the formula [14] depends on the magnitude of each aftershock because they found that the volume $Y$ of an earthquake is related to its magnitude $M$ by [7]. Then, they used [14], [7] and

$$
\log J=12.21+1.44 M(J \text { in }(r-s s),
$$

to derive the following relation between the deformation $D-\varepsilon V$ (in $\left(\mathrm{m}^{3}\right)$ and the magnitude of the earthquakes:

$$
\log D=5.17+1.46 M
$$

By the use of this formula they calculated the cumulative deformation in the aftershock zone and ploted it as a function of time. In their plots the compressional and the supposed shear phase are also observed.

Mogi $\left({ }^{6}\right),\left({ }^{7}\right),\left({ }^{8}\right),\left({ }^{8}\right),\left({ }^{10}\right)$ in a series of palpers presented his results derived from studying experimentally the elastic shocks caused by the fracture of solid materials. He also used his experimental results to study the fore and aftershock sequences and the swarms. According to him the foreshocks (and other small aarthquakes) occur at structurally irregular points in the Earth's crust where stress concentration takes place and local fractures occur at a stress lower than the normal strength of the material. At the time of a principal earthquake not all of the accumulated strain energy is released. The remaining part of the energy concentrates around the focus at many weak points in the region which has been fractured by the main shork. The number of aftershocks is larger than the number of foreshocks because the main shock causes new cracks and thus the number of irregular points increases. Mogi showed that no foreshorks oceur when the structure is homogeneous and the stress is applied uniformly. Swarms are observed in the case of very irregular structure and / or concentrated stress. In the intermediate case (moderately irregular structure and or not uniform stress) both foreshocks and aftershorks occur. 
The process of relaxation of stress in the aftershock zones may be studied by the rheologieal theory and mainly by applying the Maxwell's equation:

$$
\frac{d \varepsilon_{i j}}{d t}=\frac{1}{2 \mu} \frac{d \sigma_{i j}}{d t}+\frac{\sigma_{i j}}{\eta}, \quad i \neq j
$$

as well as by the Kelvin's equation:

$$
\sigma_{i j}=2 \mu \varepsilon_{i j}+2 \eta \frac{d \varepsilon_{i j}}{d t}, \quad i \neq j
$$

where $\varepsilon$ is the strain, $\sigma$ the stress, $\mu$ the coefficient of rigidity and $\eta$ the coefficient of viscosity. The relaxation time under some conditions is given by

$$
\tau=\frac{\eta}{\mu}
$$

Pshennikov $\left({ }^{22}\right)$ assumed that in the case of aftershocks $\varepsilon$ can be considered almost constant, that is $\frac{d \varepsilon}{d t}=0$. Then from [17] we can receive:

$$
\sigma==\sigma_{o} e e^{-\frac{l}{\tau}}
$$

where $\sigma_{n}$ is the total stress released by all the aftershocks of the sequence. To calculate $\sigma_{o}$ he used the relation:

$$
\sigma_{o}=\sum_{i=1}^{n} \sqrt{E_{i}}
$$

where $n$ is the total number of aftershocks and $E_{0}$ is the energy of each aftershock given by

$$
\log E_{i}=11.8+1.5 . H_{i}
$$

$\sigma$ is the stress remained in the strained region at time $t$ measured from the occurrence of the main shock and is given by the:

$$
\sigma=\sigma_{o}-\sigma_{k}=\sigma_{o}-\sum_{i=1}^{k} \sqrt{E_{i}},
$$


where $l_{i}$ is the number of all aftershocks which oceur during the interval from 0 to $t$. From [20] we can get:

$$
\tau=\frac{t \log e}{\log \frac{\sigma_{o}}{\sigma}} .
$$

Taking a fix time unit e.g. 1 day, $\tau$ is determined as a function of $t$. Pshemikor found a linear relation between the relaxation time $\tau$ and t. That is:

$$
\tau=a+b t .
$$

Then, he found that the relation:

$$
\sigma=\sigma_{0}(\operatorname{xx})\left(-\frac{t}{a+u}\right)
$$

fits the observational data well.

THE DATA.

The aftershock sequences of 40 earthquakes of normal focal depth ( $h \leqq 70 \mathrm{~km}$ ) and magnitude $6.0 \leqq M \leqq 7.5$ occurred in the region of Greece from 1926 till $196 t$ are investigated. Code numbers, dates, origin times, focal depths, magnitudes and locations of these earthquakes are listed in Table I. These data, except the focal depths, have been taken from " $\triangle$ Catalogue of Shocks with $I_{0} \geq$ VI or $M \geqq 5$ " by A. G. Galanopoulos and from the Bulletins of the Seismological Institute of the National Observatory of Atheres. An index map which shows the epicenter's of these earthquakes is given in Figule 1. The 'picenter's of three earthquakes, one elose to the southern coast of 'Turkey and the other two in northern Turkey, are not shown in this map.

\section{Determination of Focal Depths.}

Many quantities calceulated in this study vary with the depth of the focus of the main shock. Consequently, it was necessary to ealculate depths as accurately as possible. In dealing with focal depths the first problem from us faced, was the distinction between normal and intermediate earthquakes since no dee'p focus arthquakes are known to occur in this region. Galanopoulos separates the normal from the 
intermediate earthquakes in his tables by giving focal depths for the intermediate earthquakes on the basis of macroseismic data and data taken from ISS, BCIS and CSCGS. Some additional repiteria have been applied in this study for this distinction: chalacteristics of the seismograms and the existence of aftershockis.

The records of all the arthqualies of $M \geq 6$ oceurred from 1926 till 1964 in the region considered, have been examined very carefully for $P c P$ and sos phases and the focal depths were calculated by using the Jeffreys- Bullen tables. In all the cases when large focal depths were found the amplitudes of the beginning of the $P$ waves were large in the rertical component and the general alpperance of the seismograms was verg different from that of the shallow shocks. In the case of intermediate earthquakes very few small or no aftershocks have been recorded by the Wiechert seismographs. Thus, the depths calculated by using $\operatorname{PcP}$ or ScS phases, the appearance of the seismograms and the existence of aftershocks have been used as additional criteria to separate the normal from the intermediate earthquakes. The lesult is that from all the eathquakes examined only those which are listed in Table I have their foci above a depth of about $70 \mathrm{~km}$. The problem then was to determine the focal depthis of these normal earthquakes with some aceuracy.

Focal depths for some of these earthquakes are given by ISS, BCIS and USCGS, but in calculating these depths they do not take into account the complex structure of this region. Little was known up to few months ago about this structure. Some basic propereties of the crustal structure of the region of Greece have been derived reecently by members of our Institute by using the refraction and reflection methods as well as surface ware techmiques. On the basis of these results, most of the focal depths of the arthquakes which have their foci in the crust $(H \leqq 40 \mathrm{~km}$ ) have been calculated by using ralrious methods and mainly the time difference between arrivals of several phases. The mean erustal thickness from six provinces in the region of Greeces to several stations has been calculated from data given by Papazachos, Comminakis and Drakopoulos ( $\left.{ }^{11}\right)$. Thus, the foral depth of aach arthquake has been alculated by using data of many stations. In the cases when the deviation of one value from the mean was large this value was discarded. The focal depths for some earthqualies bellow the crust have been taken from, ISS, BCIS and LSCGS. These focal depths have been used to derive formulas [40] and [41] which relate the number of aftershocks of $M \geqq 4$ with the focal depth and inagnitude 
of the main shock. These two formulas have been used to calculate focal depths when no other methods could be applied for this purpose. The depths calculated by using formula [40] or [41] are noted by an asterisk in Table $\mathrm{T}$.

\section{Determination of the Magnitudes of the shochs of each Sequence.}

The trace amplitudes of all the foreshocks and aftershocks of each sequence have been measured on the same component of one seismograph at the station in Athens. The measurements have been made on the records of the horizontal Mainka seismograph from 1926 till 1928 and on the verical Wiechert seismograph from 1928 till 1964. To calculate the magnitude $W^{\prime}$ of each shock of the sequence for which an amplitude $A^{\prime}$ was masured the following relation was used:

$$
M^{\prime}=\log A^{\prime}+M-\frac{\sum_{i=1}^{n} \log A_{i}}{n}
$$

where $M$ is the mean value of the magnitude of all the large shocks of the sequence and $A_{i}$ and $n$ are the amplitude and number of these large shorks. The magnitudes of the largest shocks are known from other sources.

The daties, arrival times in Athens and magnitudes of all the shocks of each sequence are in Table III. In Table II the magnitudes of the largest aftershocks are given for thirty nine earthquakes of magnitude between 5.2 and 6.0 . The data of this Table have been taken from Galanopoulos' Tables and from the Bulletins of the Institute.

\section{Proceuere For INVeSTIGation.}

After the determination of the magnitude of each aftershock, the formula [16] was used to calculate the deformation corresponding to each aftershock. The cumulative deformation was plotted versus time on semilogarithmic paper. The parameters of the relations [11] and [12] were determined, when possible, by using $D_{i}$ instead of $\varepsilon_{i}$. In the same semilogarithmic paper the two curves were drawn to show the goodness of fit. To calculate the relaxation time for the "shear phase" the following method was applied.

Taking as zero point of the time axis the time when the "shear" phase" starts the deformation $D_{i}$ which oceurred rach day has been 
computed. The deformation $D_{k}$ which oceurred after the $t_{k}$ day $(k-1$, 2. ...) has been caleulated by using the formula:

$$
D_{k}=D_{o}-\sum_{i=1}^{k} D_{i}
$$

where $D_{o}$ is the total deformation oceurred in the aftershock region. Assuming that

$$
D_{k}=D_{o} \exp \left(-\frac{t_{k}}{\tau_{k}}\right)
$$

the relaxation time $\tau_{k}$ for each day was calculated by the formula:

$$
\tau_{k}=\frac{t_{k} \log ^{2} e}{\log ^{2} \frac{D_{o}}{D_{k}}}
$$

$\tau_{k}$ was plotted against $t_{k}$ and it was found almost independent of it in all cases. Then the formula:

$$
\tau=\frac{\sum_{k=:}^{n} \tau_{k}}{n}
$$

was applied to find the mean relaxation time for each sequence.

The relations [20] and [26] have been also applied. The formula [26] fits the data fairly well in many cases but the data were fitted better by the [29]. That is why the relaxation time calculated by [30] and [31] was finally adopted for the "shear phase".

The equation of the cumulative frequency of the magnitude has been determined. This equations is of the form:

$$
\log N=A-b^{\prime} M
$$

where $N$ is the number of aftershocks which have magnitudes equal to and larger than $M$, and $A$ and $b^{\prime}$ are constants ehosen to fit the data.

The constant $b^{\prime}$, is not the same as the constant $b$ in the relation [9] but it also expresses how the number of small aftershocks increases with decreasing magnitude and consequently it is a measure of the heterogeneity of the material in the aftershock region or of the uniformity of the stress. 
The cumulative time distribution:

$$
N(t)=\int_{t}^{t_{o}} n(t) d t
$$

is then studied. It was found that the relation

$$
\log N=B-A \log t
$$

holds in most of the cases up to certain time $t_{1}$. Assuming that the relation [2] is valid, we have

$$
N(t)=\int_{i}^{t_{0}} n(t) d t=\int^{t_{0}} n_{1} t^{-h} d t=\frac{n_{1}}{h-1}\left(t^{1-h}-t_{0}^{1-h}\right)
$$

Mogi $\left({ }^{\circ}\right)$ gives values for the constant $h$ between about 1.0 and 2.0 . Therefore $(h-1)>0$. This means that for $t_{0} \gg t$, we receive

$$
N(t)=B t^{-I I}
$$

where

$$
H=h-1, \quad B=\frac{\omega_{1}}{h-1}
$$

The formula [36] was applied for all the aftershocks which have magnitude equal to and larger than 4 and it fitted the data well up to a certain time $t_{1} \ll t_{0}$ in almost all the cases when enough data were available.

'The number of aftershocks with $M \geqq 4$ and the magnitude of the largest aftershock were related with the magnitude and focal depth of the main shock. The spacial distribution of the constant $b^{\prime}$ in the relation [32] was also examined.

In the following, a description is made for aach sequence. Plots of the data have not been made in all cases. No large aftershorks followed the earthquakes with code numbers, $12 \mathrm{~b}, 36 \mathrm{~b}, 42$ and 43 . There is evidence that these earthquakes are rery shallow.

1. - Aftershocks of the Southern Sporades Earthquale of March 18, 1926.

The epicenter of this earthquake is in the Eastern Mediterranean Sea, about $170 \mathrm{~km}$ SE of Rhodes and $120 \mathrm{~km}$ off the South coast of Turkey. Its magnitude is 6.9 . It caused considerable damage and 
casualties in the Asia Xinore. Eighteen aftershocks of magnitude $3.9 \leqq \lambda \leqq 5.7$ have been recorded at the Seismological Station in Athens by a Mainka seismograph. The dates, arrival times and the magnitudes of these aftershocks are listed in Table III (1).

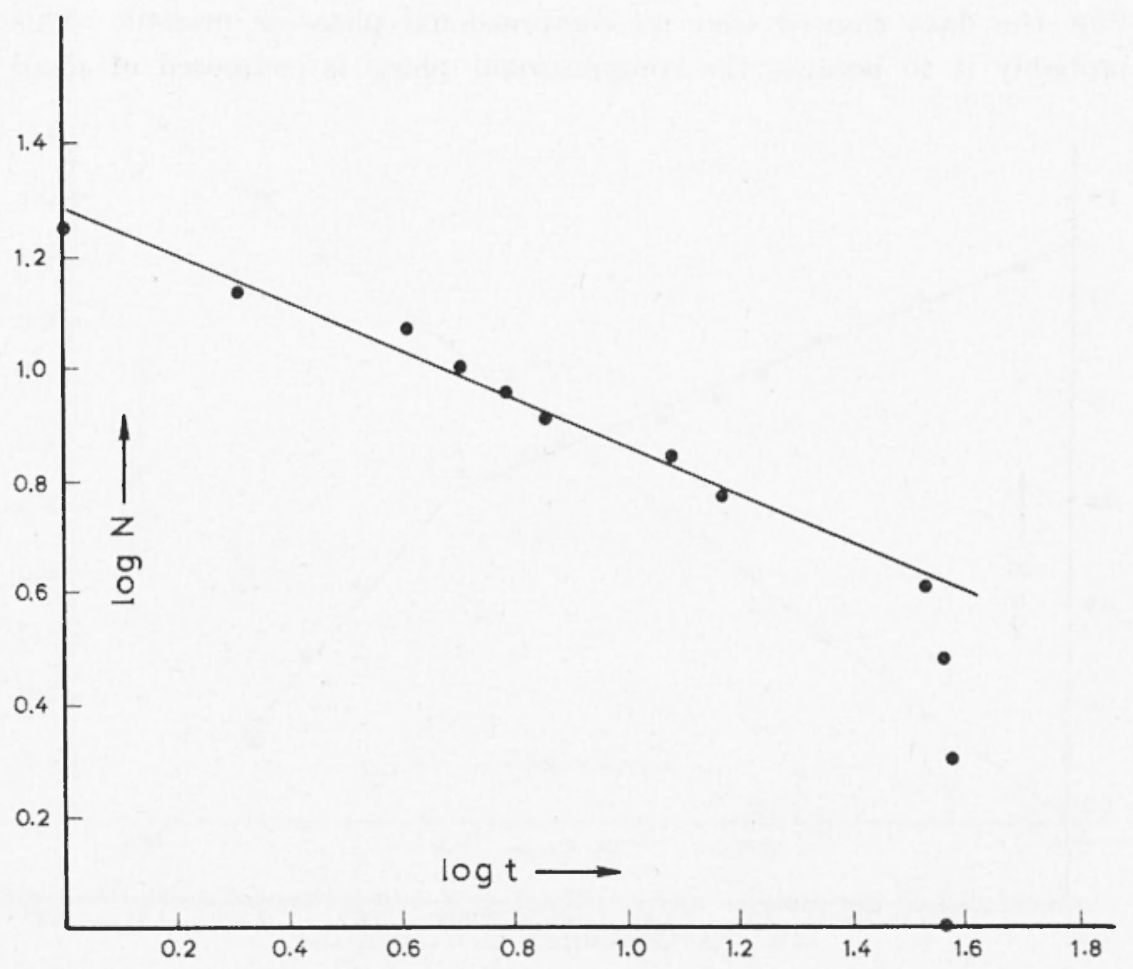

Fig. 2 - Time distribution of the aftershocks of the Southern sporades Earthquake of March 18, 1926.

The logarithm of the number $N$. of aftershocks which oceurred after $t-1$ days after the main shock is plotted against the logarithm of $t$ in Figure 2. The following relation fits the data, in the least square sense:

$$
\log N=1.28-0.43 \log t . \quad t \leqq 33 \text { days }
$$

The logarithm of the cumulative frequency function of the magnitude is plotted against $M$ in Figure 3 . We see that this plot is a concavely downward curve composed of two straight lines with equations:

$$
\begin{array}{ll}
\log N=2.85-0.40 M & 3.8 \leqq M \leqq 5 \\
\log N=6.96-1.22 M & 5 \leqq M \leqq 5.7 .
\end{array}
$$


The deformation characteristic of the supposed shear phase is roughly expressed by the

$$
\text { ¿ } D=\left\{1.12+5.78\left[1-\exp (-0.69 \sqrt{t-0.16)}] \times 10^{13} \mathrm{~cm}^{3} .\right.\right.
$$

Plot the data showed that uo compressional phase is present. This probably is so because the compressional phase is composed of small

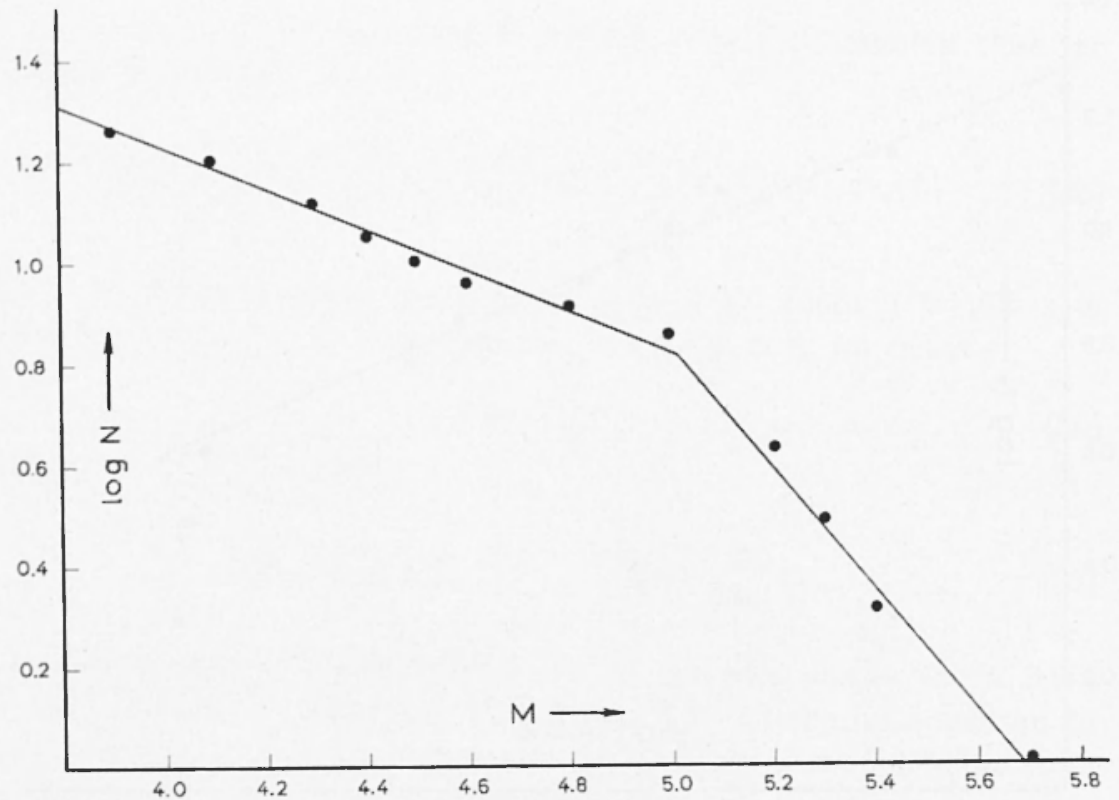

Fig. 3 - Distribution of the Magnitudes of the aftershocks of the Southern Sporades Earthquake of March 18, 1926.

earthquakes which have not been recorded by the Mainka seismograph at that time since the epicentral distance is more than $600 \mathrm{~km}$. The relaxation time is 2.0 days.

2. - Aftershocks of the Messinia Earthquake of September 19, 1926.

The epicenter of this shock is olf the south coast of Peloponnesus. Its magnitude is 6.2 . Eleven aftershocks of magnitude $3.5 \leqq M \leqq 5$ have been recorded in Athens. The dates, arrival times and magniturles are listed in Table III - (2). The logarithm of the number of 
aftershocks of magnitude $M$ and larger is plotted against, $M$ in Figure 4 . This relation is expressed by the:

$$
\log N=3.82-0.77 M .
$$

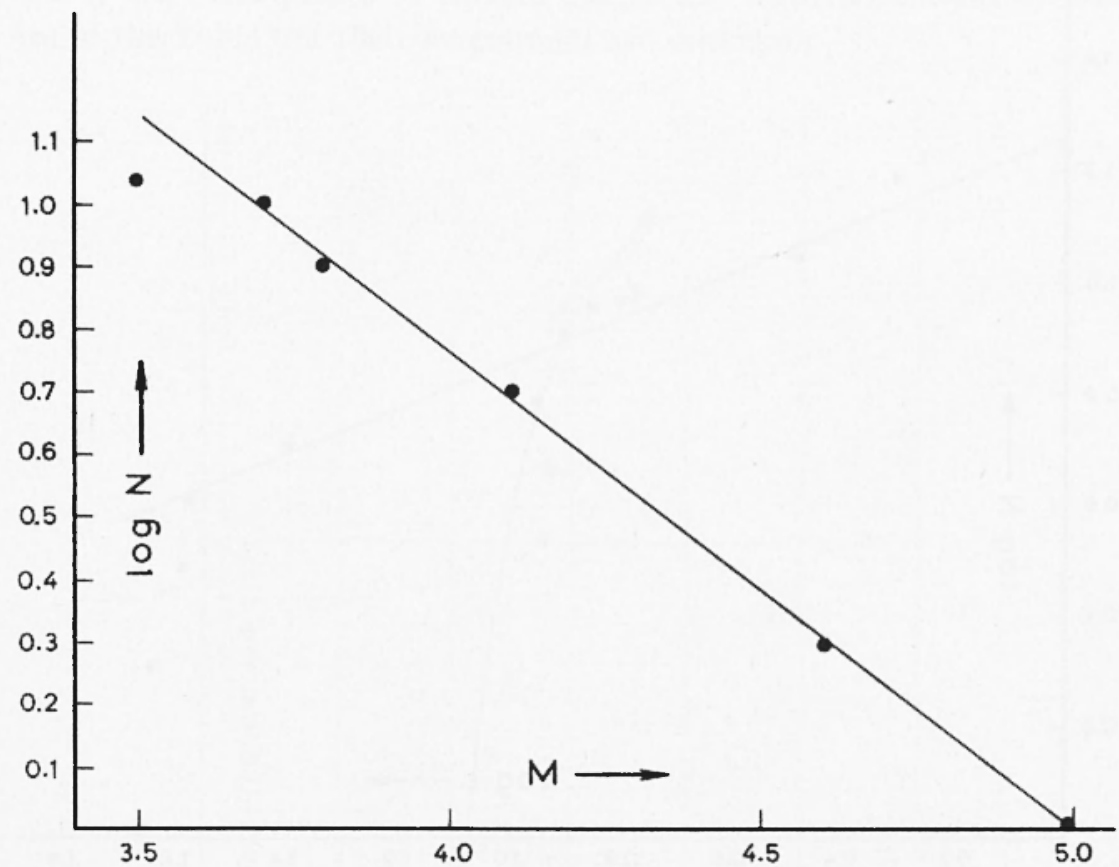

Fig. 4 - Distribution of the Magnitudes of the aftershocks of the Messinia Earthquake of September 19, 1926.

3. - Aftershocks of the Corinth Earthquake of A pril 22, 1928.

This earthquake caused extensive property damage and casualties in Corinth. Its magnitude is 6.2. Eighteen aftershocks of magnitude $4.2 \leqq M \leqq 5.2$ have been recorded by the Wiechert seismographs in Athens. Some smaller earthquakes which are probably aftershocks have been recorded but they were omitted because the uncertainty in measuring the amplitudes is big. Only one foreshock with magnitude larger than 4.1 has been recorded. Its magnitude is 5.3. The dates, arrival times and magnitudes of these aftershocks are listed in Table III -(3). The time distribution of the aftershocks of $M \geqslant 4$ is roughly expressed by the:

$$
\log N=1.26-0.41 \log t, \quad t \leqq 36 \text { dilys }
$$


where $N$ is the number of aftershocks which occurred in the $t$ day after the main shock and after that day. This distribution is shown in Figure 5.

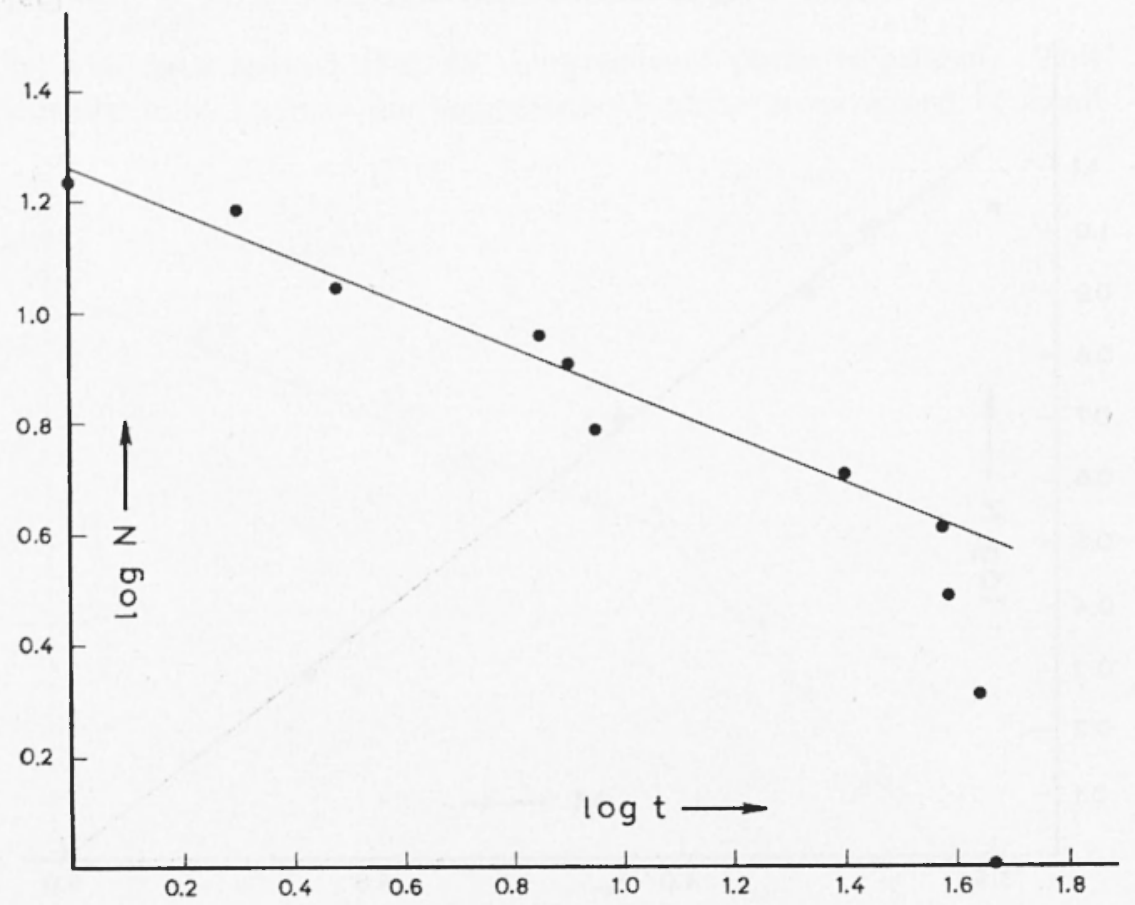

Fig: 5 - Time distribution of the aftershocks of the Corinth Earthquake of April 22, 1928.

The deformation characteristics are shown in Figure 6 . The equation for the "shear phase" is:

$\Sigma D=\mid 0.60+3.60[1-\exp (-0.55 \sqrt{t-1.0})] \times 10^{13} \mathrm{~cm}^{3}$.

The relaxation time for the "shear phase" is 3.4 days.

4. - Aftershocks of the Chalkidike Earthquake of September 26, 1932.

The epicenter of the main shock is probably in the Gulf of Hierissos. Its magnitude is 6.9. Extensive damage has been caused by the main shock as well as by many large aftershocks in the region of Chalkidike. Two of these aftershocks have magnitudes 6.2 and 6.3 . This aftershock sequence probably lasted till the beginning of 1934 but the aftershocks 
after July 19, 1933 were very few and of small magnitude. The dates, arrival times and magnitudes of the aftershocks are listed in Table III-(4). The total number of aftershocks of magnitude $3.9 \leqq M \leqq 6.3$ is 63 . Thirty six earthquakes of smaller magnitude have been recorded and are in the Table but their magnitudes are uncertain.

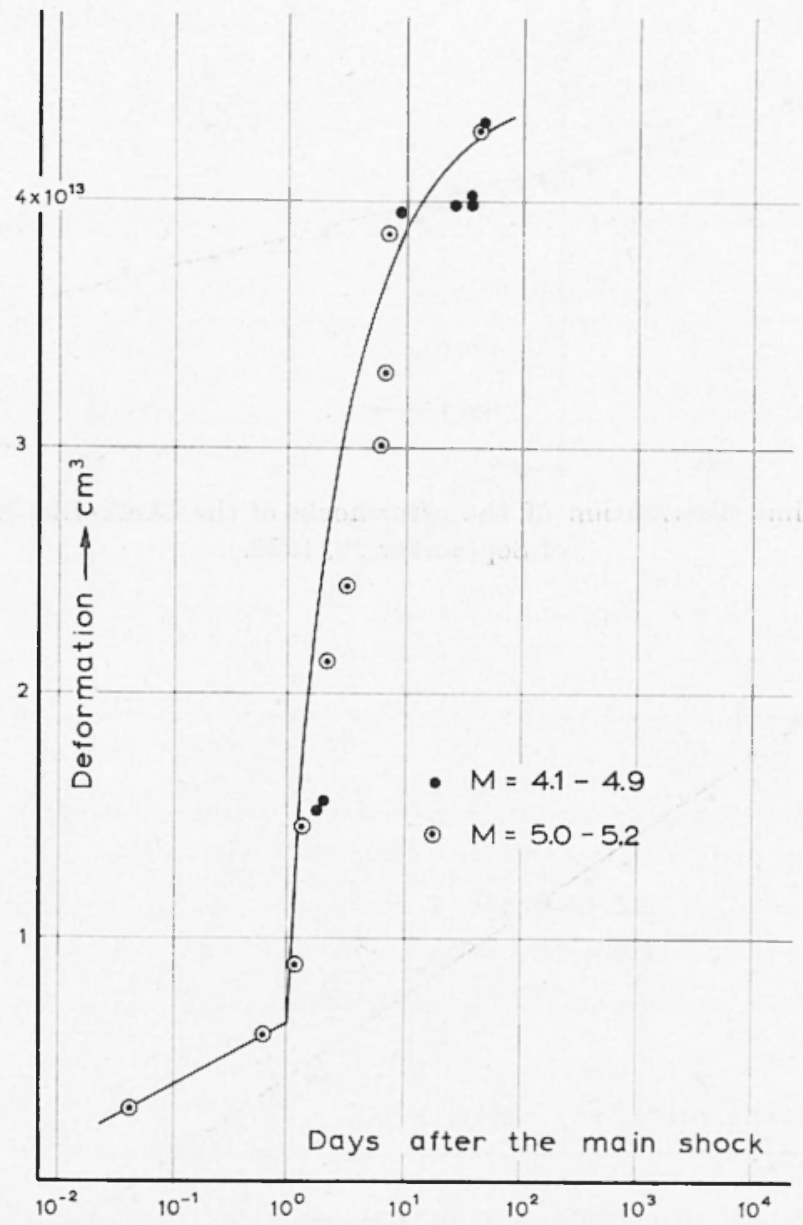

Fig. 6 - Deformation characteristics of the aftershock sequence of the Corinth Earthquake of April 22, 1928.

One can see in the Table III-( 4 ) and in Figure 9 that the sequence is divided in two groups. The first lasted till December 29, 1932. After that no aftershocks of magnitude larger than about 3.8 has been 


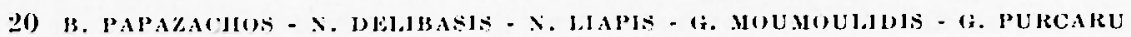

recorded till May 8, 1933, when an aftershock of magnitude 5 occurred. The second group started after a large "late aftershock" of magnitude 6.3 which occurred on May 11, 1933. This shock is responsible for

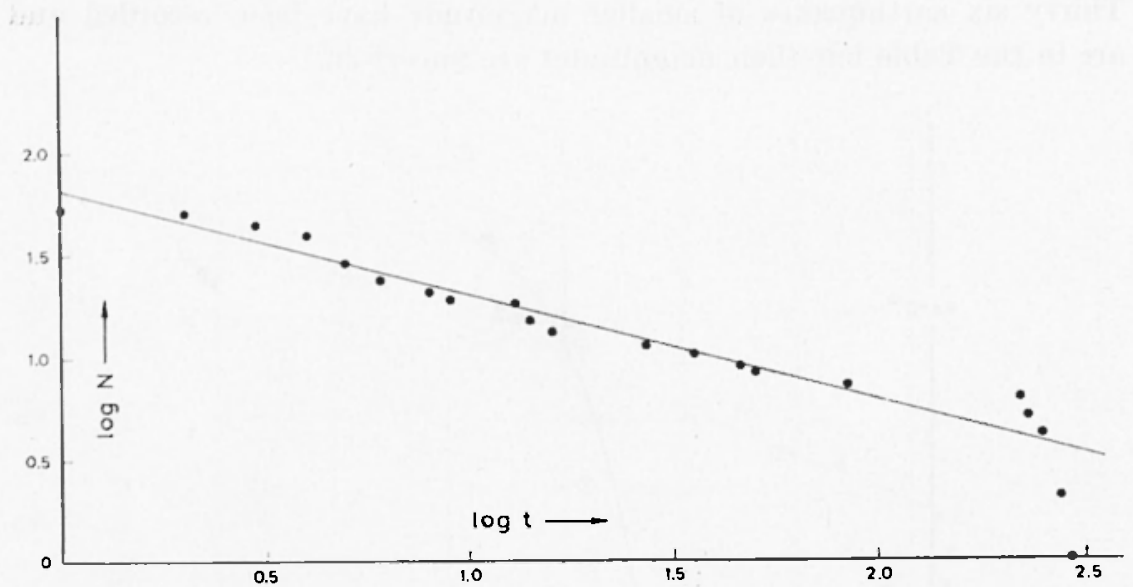

Fig. 7 - Time distribution of the aftershocks of the Chalkidike Earthquake of September 26, 1932.

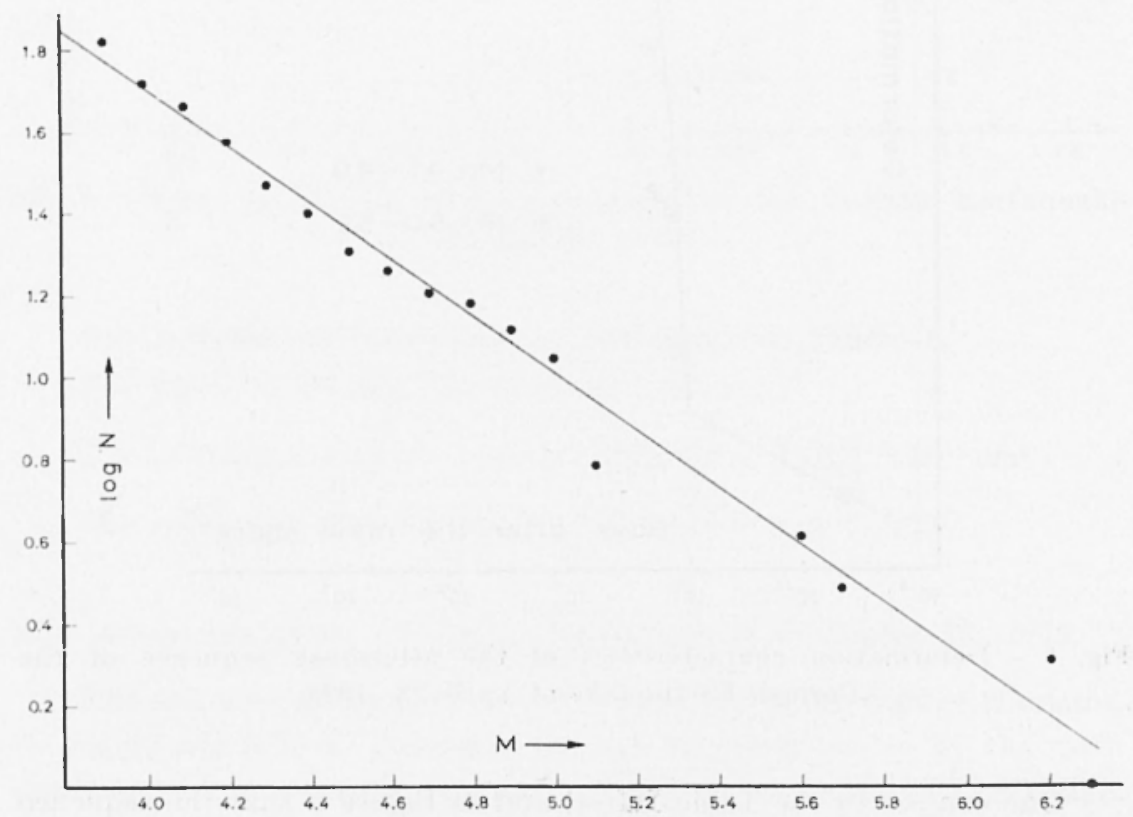

Fig. 8 - Distribution of the Magnitudes of the aftershocks of the Chalkidike Earthquake of September 26, 1932. 
the second group of aftershocks. The fact that this earthquake has its own aftershocks probably means that the foci of this large "late aftershock" and its aftershorks are not in the aftershock volume of the main shock. However, we have no other evidence, in this case, that this is so.

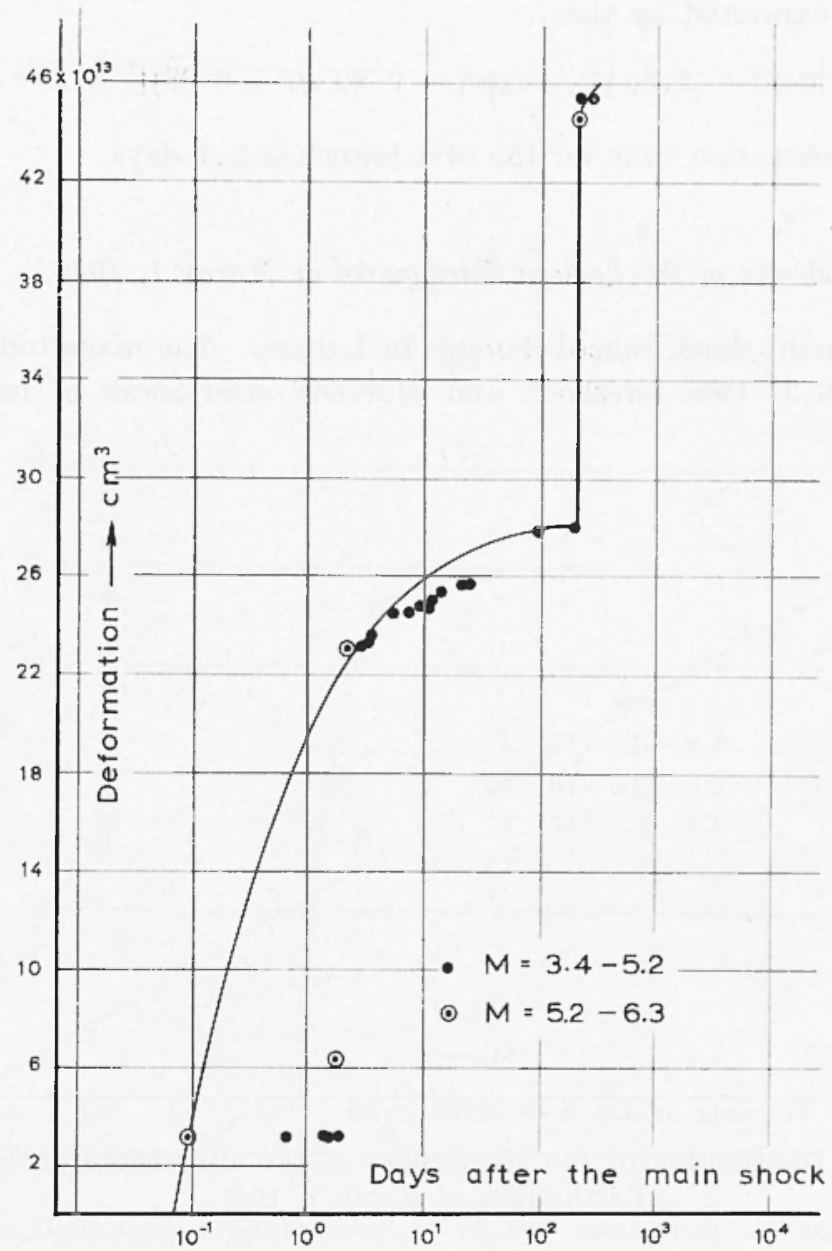

Fig. 9 - Deformation characteristics of the aftershock sequence of the Chalkidike Earthquake of September 26, 1932.

The logarithm of the number of aftershocks of magnitude $M \geqq 4$ occurred in the $t$ day after the main shock and after that day is plotted in Figure $T$ against the $\log t$. This relation is expressed by the:

$$
\log N=1.80-0.52 \log t \quad t \leqq 250 \text { days } .
$$


The cumulative magnitude distribution is expressed by the:

$$
\log N=4.50-0.70 . M
$$

and is shown in Figure 8 .

The deformation chanceteristies are shown in Figure 9. The first bianch is expressed by the:

$$
\Sigma D=\left\{0.31+2.50[1-\exp (-0.89 \sqrt{t-0.08})] \times 10^{14} \mathrm{~cm}^{3}\right. \text {. }
$$

The relaxation time for the first branch is 2.1 days.

\section{5. - Aftershocks of the Larissa Earthquake of Murch 1, 1941.}

The main shock caused damage in Larissa. The magnitude of this shock is 6.3. One foreshock and nineteen aftershocks of mignitude

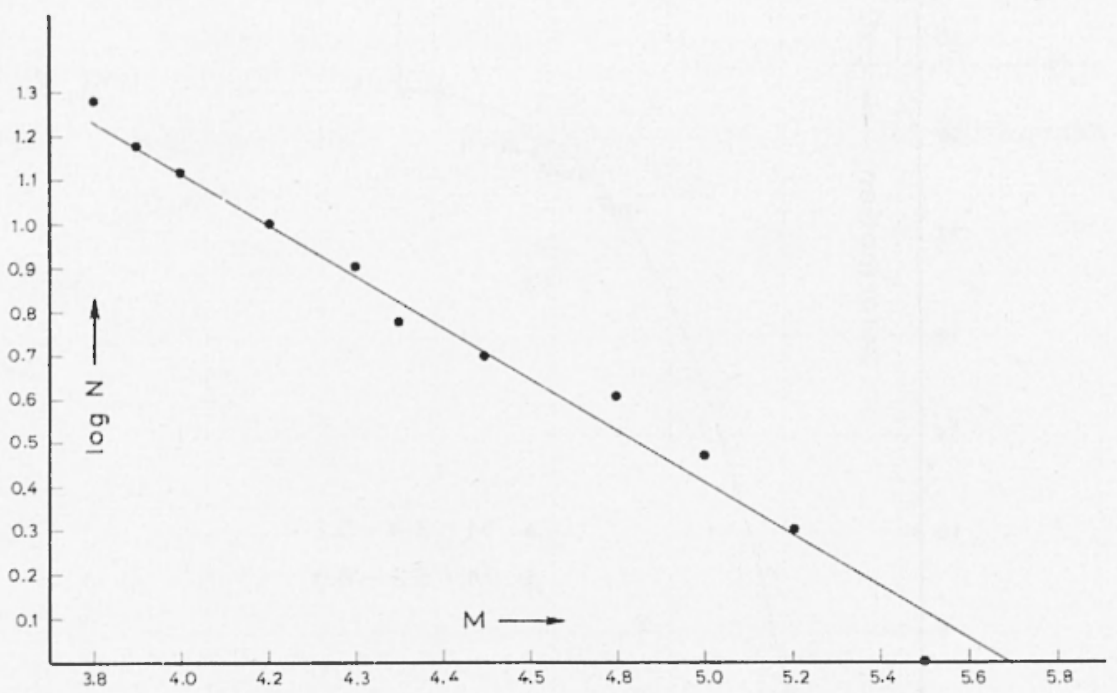

Fig. 10 - Distribution of the Magnitudes of the aftershocks of the Larisaa Earthquake of March 1, 1941.

$3.8 \leqq M \leqq 5.2$ were recorded till March 18 , and no other aftershocks of $M \geqq 3.8$ have been recorded till Maly 14 , when one "late aftershock" of magnitude $M=5^{1} / 2^{-} 5^{3} / 4$ occurred. Another shock of magnitude $5^{1} / x^{-}-5^{1} / 2$ was recorded on May 16 . The epicenter of these two "late aftershocks" is about $25 \mathrm{~km}$ southeast of the epicentel of the main shock. The dates, arrival times and magnitudes of the earthquakes of 
this sequence are listed in Table III-(5). The cumulative magnitude distribution is shown in Figure 10 and is expressed by the:

$\log N=3.56-0.61 M$.

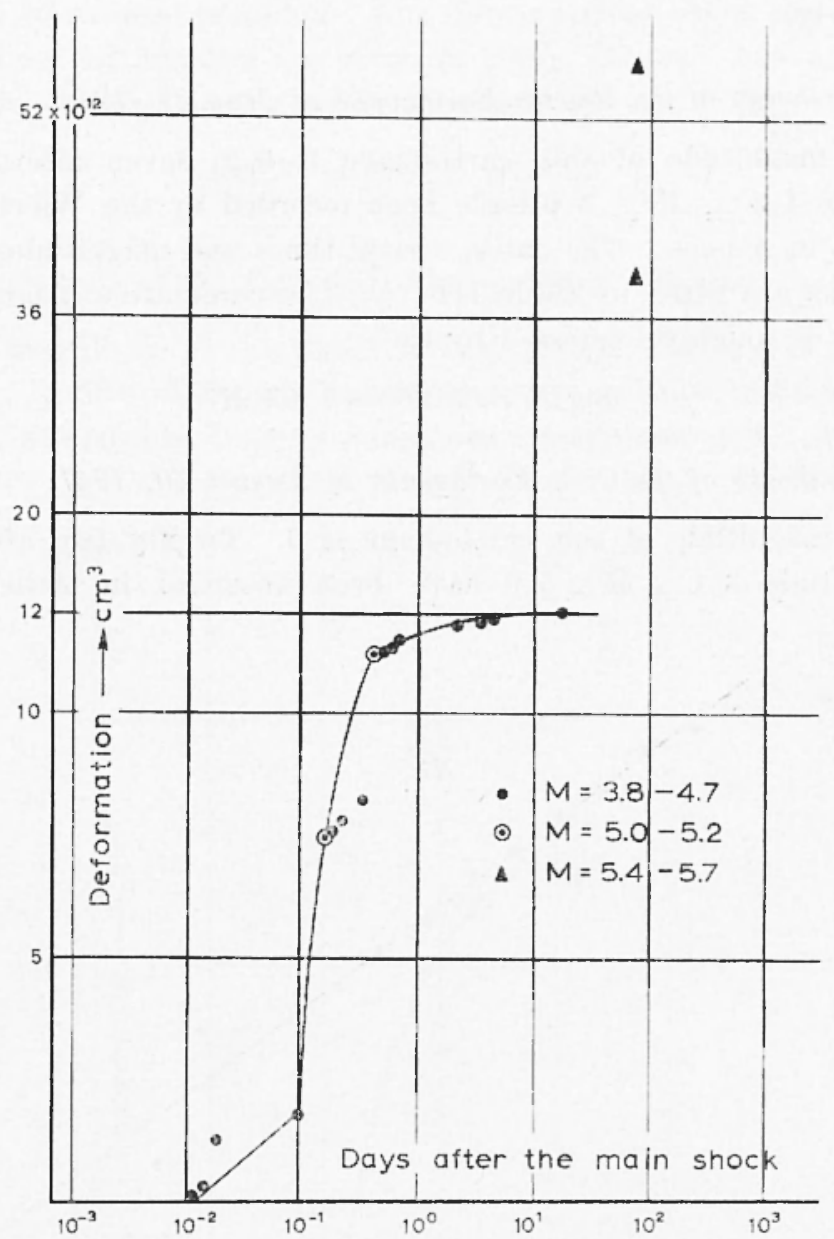

Fig. 11 - Deformation eharacteristies of the aftershock sequence of the Larissa Earthquake of March 1, 1941.

The deformation characteristies are shown in Figure 11. Three branches are observed. The equation for the second branch is:

$$
\Sigma D=[12.0-10.2 \exp (-3.2 \tau \sqrt{t-0.10})] \times 10^{12} \mathrm{~cm}^{3} \text {. }
$$

The relaxation time for the serond phase is 0.2 days. 
6. - Aftershocks of the Kephallenia Earthquake of February 14, 1943.

The magnitude of the main shock is 6. Two aftershocks of magnitude 5.2 and 4.3 occurred at $09^{\mathrm{n} 2} 26^{\mathrm{m}}$ and $14^{\mathrm{n}} 02^{\mathrm{m}}$ on Febrlury 14 , respectively.

7. - Aftershocks of the Rhodes Earthquake of May $2 \pi, 1944$.

The magnitude of this earthquake is 6.2 . Seven aftershocks of magnitude $4.3 \leqq M \leqq 5.0$ have been recorded by the Wiechert seismographs in Athens. The dates, arrival times and magnitudes of these aftershocks are listed iu Table III-(7). The cumulative magnitude distribution is roughly expressed by the:

$$
\log N=5.20-1.03 M \text {. }
$$

8. - Aftershocks of the Crete Earthquake of August 30, 1947.

The magnitude of this earthquake is 6 . Twenty two aftershocks of magnitude $3.1 \leqq M \leqq 5.0$ have been recorded in Athens. The

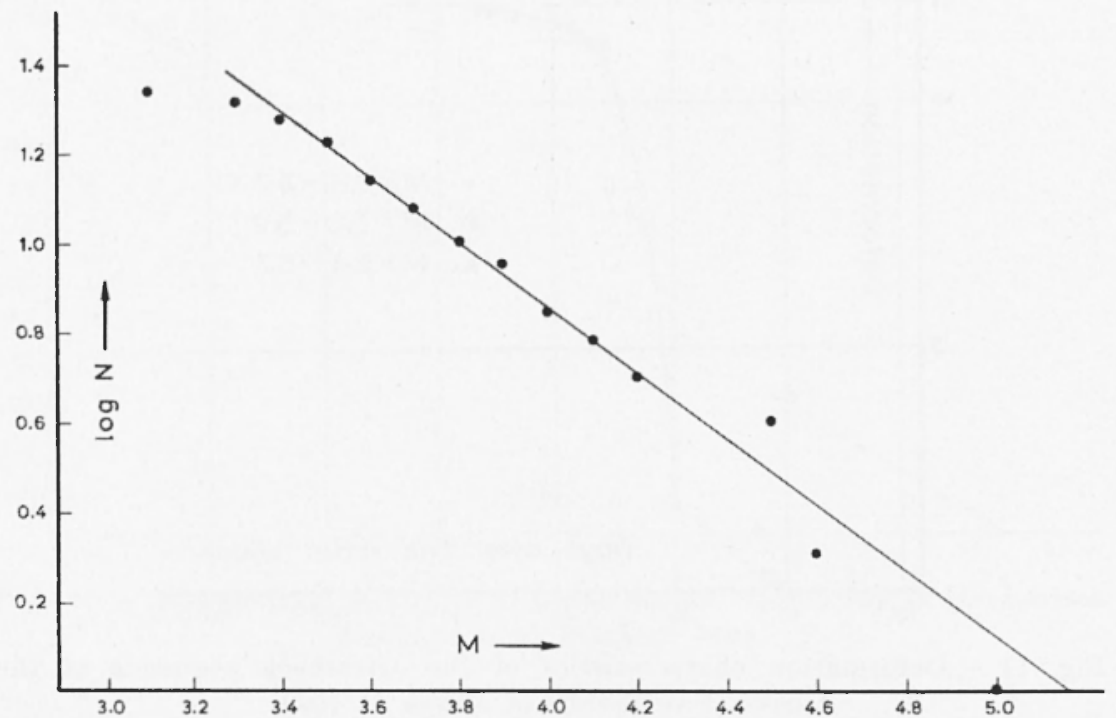

Fig. 12 - Distribution of the Magnitudes of the aftershocks of the Crete Earthquake of August 30, 1947.

dates, arrival times and magnitudes are listed in Table III-(8). The magnitude distribution is shown in Figure 12 and is expressed by the:

$$
\log N=3.77-0.73 M \text {. }
$$


9. - Aftershocks of the Messinia Earthquake of October $6,191 \%$.

The magnitude of the main shock is $i$. This earthquake caused damage and casualties in Messinia. Only ten aftershocks of magnitude $\boldsymbol{U} \geqq 3.5$ have been recorded. The dates, arrival times and magnitudes of these earthquakes are given in Table III-(9). The cumulative magnitude distribution is roughly expressed by the:

$$
\log N=2.81-0.54 M .
$$

10. - Aftershocks of the Karpathos Earthquake of February 9, 1948.

The magnitude of this shock is 7.1 . Thirty aftershocks of magnitude 4.4 . $\leqq M \leqq 5.8$ have been recorded in Athens. Three of them are "late aftershocks" one of which has a magnitude 5.8 . The dates,

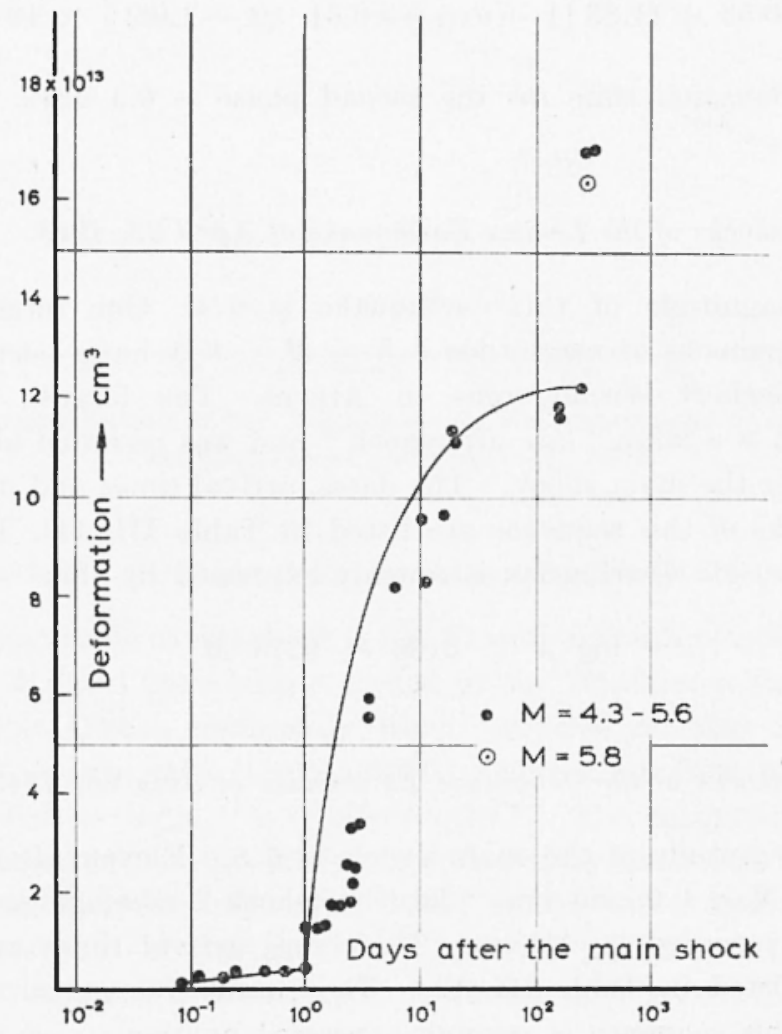

Fig. 13 - Deformation characteristics of the aftershock sequence of the Karpathos Earthquake of February 9, 1948. 
arrival times and magnitudes of these shocks are given in Table III-(10). The time distribution is roughly expressed by the:

$$
\log N=1.50-0.71 \log t \text {. }
$$

The ('umulative magnitude distribution is expressed by the:

$$
\log N=4.40-0.68 \mathrm{H} \text {. }
$$

The deformation characteristic's are shown in Figure 13. 'The equation for the compressional phase is:

$$
\Sigma I I=(0.52+0.41 \log t) \times 10^{13} \mathrm{~cm}^{3} .
$$

The equation for the second phase is:

$$
\Sigma I=\left\{0.53+11.83[1-\exp (-0.51 \sqrt{t-1.06)}]\} \times 10^{13}\left(\mathrm{~m}^{3} .\right.\right.
$$

The relaxation time for the second phase is 6.5 days.

11. - Aftershocks of the Leukas Earthquake of April 22, 1948.

The magnitude of this earthquake is 6.4 . One foreshock and twenty aftershocks of magnitude $3.8 \leq M \leq 6.3$ have been recorded by the Wiechert seismographs in Athens. The largest aftershock $\left(M_{1}=6.3\right)$ is a large "late aftershock" and was recorded about three months after the main shock. The dates, arrival times and magnitudes of the shocks of this sequence are listed in Table III-(11). The cumulative magnitude distribution is roughly expressed by the:

$$
\log N=3.96-0.73 \mathrm{~N} \text {. }
$$

12. - Aftershocks of the Ocnoussae Earthquake of July 23, 1949.

The magnitude of the main shock is 6.8. Eleven aftershocks of magnitude $M \geqq 4.0$ and one "late aftershock" of magnitude $M=6$, have been recorded in Athens. The dates, arrival times and magnitudes are listed in Table III-(12). The cumulative magnitude distribution of this sequence is roughly expressed by the:

$$
\log N=4.24-0.81 . M \text {. }
$$


13. - Aftershocks of the SW Crete Earthquake of December 17, 195\%.

The magnitude of the main shock is $6 \frac{3}{4}$. Ten aftershocks of magnitude $4.1 \leqq M \leqq 6.0$ have been recorded by the Wiechert seismographs in Athens. The dates, arrival times and magnitudes of these earthquakes are listed in Table III-(13). The cumulative magnitude distribution is shown in Figure 14 and is expressed by the:

$$
\log N=2.34-0.33 \mu .
$$

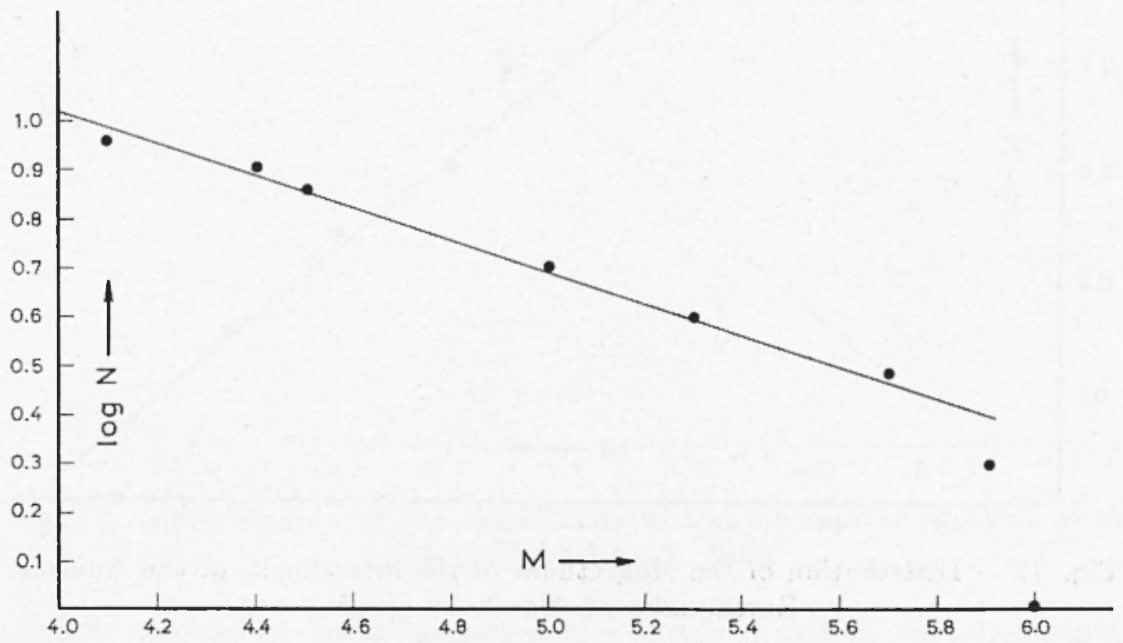

Fig. 14 - Distribution of the Magnitudes of the aftershocks of the SW Crete Earthquake of December $17,1952$.

14. - Aftershocks of the Anatolia Earthquale of March 18, 1953.

The magnitude of this shock is 7.2 . Twenty one aftershocks of magnitude $4.1 \leq M \leq 5.7$ have been recorded by the Wiechert seismographs in Athens. The Lesbos earthquake which oceurred on May 2, 1953 and the Anatolia earthquake $\left(40^{\circ} 0 \mathrm{~N}, 28^{\circ} 0 \mathrm{E}\right)$ occurred on June 3,1953 , can be considered as large "late aftershocks". The magnitude of both these carthquakes is 6.0. They are followed by their own aftershocks and are studied separately. The dates, arrival times and magnitudes of the aftershocks of this sequence are listed in Table III-(14). The cumulative magnitude distribution is shown in Figure 15 and is expressed by the:

$$
\log N=4.64-0.78 \mu .
$$




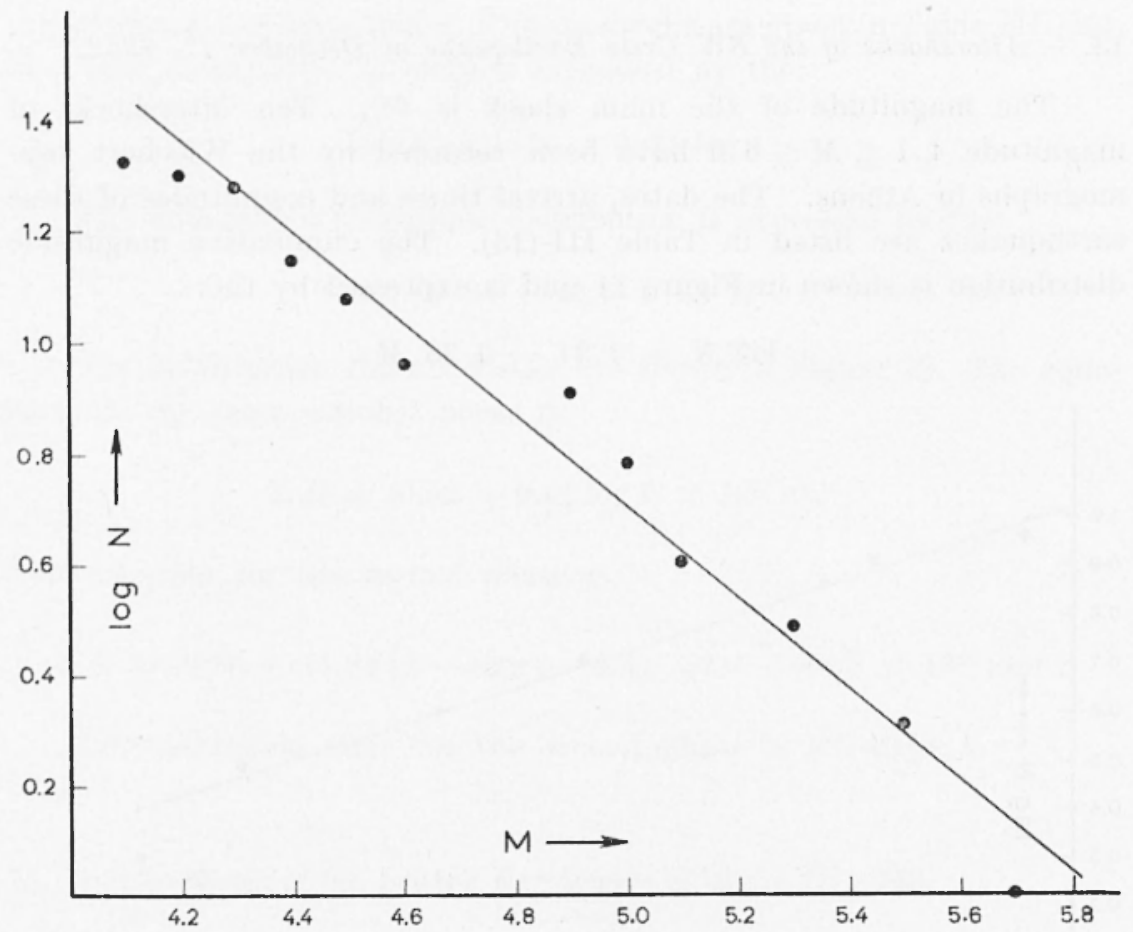

Fig. 15 - Distribution of the Magnitudes of the aftershocks of the Anatolia Earthquake of March 18. 1953.

15. - Aftershocks of the Lesbos Earthqualie of May 2, 1953.

The magnitude of the main shock is probably a little less then 6 . Its epicenter is about $20 \mathrm{~km}$ south of Mytilene. Three foreshocks and nine aftershocks of magnitude $4.1 \subseteq M \leqq 5.1$ have been recorded in Athens. The dates, arrival times and magnitudes are listed in Table III-(15). The time distribution of the aftershocks with $U \geqq t .1$ is roughly expressed by the:

$$
\log N=0.96-0.37 \log t \quad t \leqq 10 \text { days . }
$$

The magnitude distribution is shown in Figure 16 and is represented by the:

$$
\log N=4.25-0.84 M .
$$

The deformation has been plotted against time but it is not shown here. The rompressional phase lasted about 12 days. After that an 


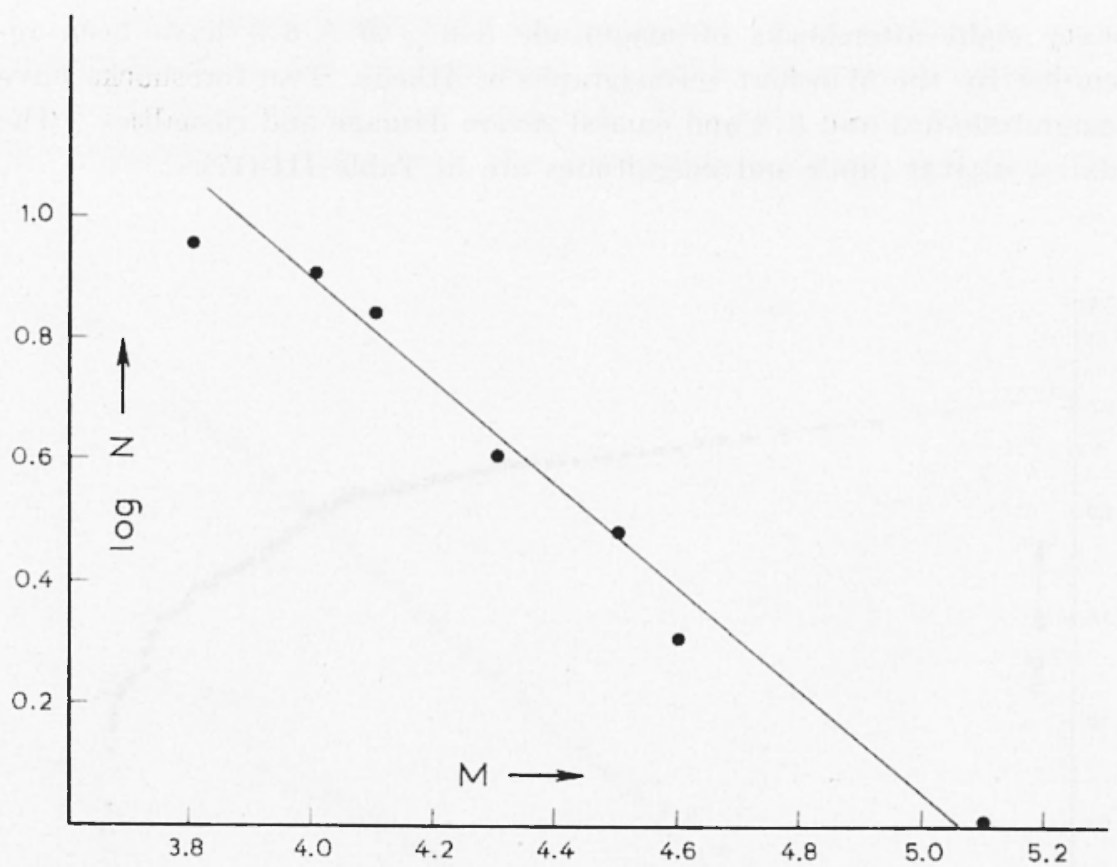

Fig. 16 - Distribution of the Magnitudes of the aftershocks of the Lesbos Earthquake of May 2, 1953.

abrupt increase of the deformation was observed due to the occurrence of the largest and last aftershock of magnitude 5.1. The deformation characteristic of the compressional phase is expressed by the:

$$
\Sigma D=(9.28+9.66 \log t) \times 10^{12}\left(\mathrm{~m}^{3} .\right.
$$

16. - Aftershocks of the Anatolia Earthquake of June 3, 1953.

The magnitude of the main shock is 6.0. Three aftershocks of magnitude $4.2 \leqq M \leqq 5.2$ have been recorded by the Wiechert Seismographs in Athens. The dates, arrival times and magnitudes of these earthquakes are listed in Table III-(16).

17. - Foreshocks and Aftershocks of the Kephallenia Earthquale of August 12, 1953.

The magnitude of this earthquakes is $7 / 4$. Extremely high foreand aftershock activity was observed for more than seven months. Fifty foreshocks of magnitude $3.9 \leqq M \leqq 6.8$ and four hundred and 
sixty eight aftershocks of magnitude $3.6 \leqq M \leqq 6.5$ have been recorded by the Wiechert seismographs in Athens. Two foreshocks have magnitude 6.3 and 6.8 and caused severe damage and casualties. The dates, arrival times and magnitudes are in Table III-(17).

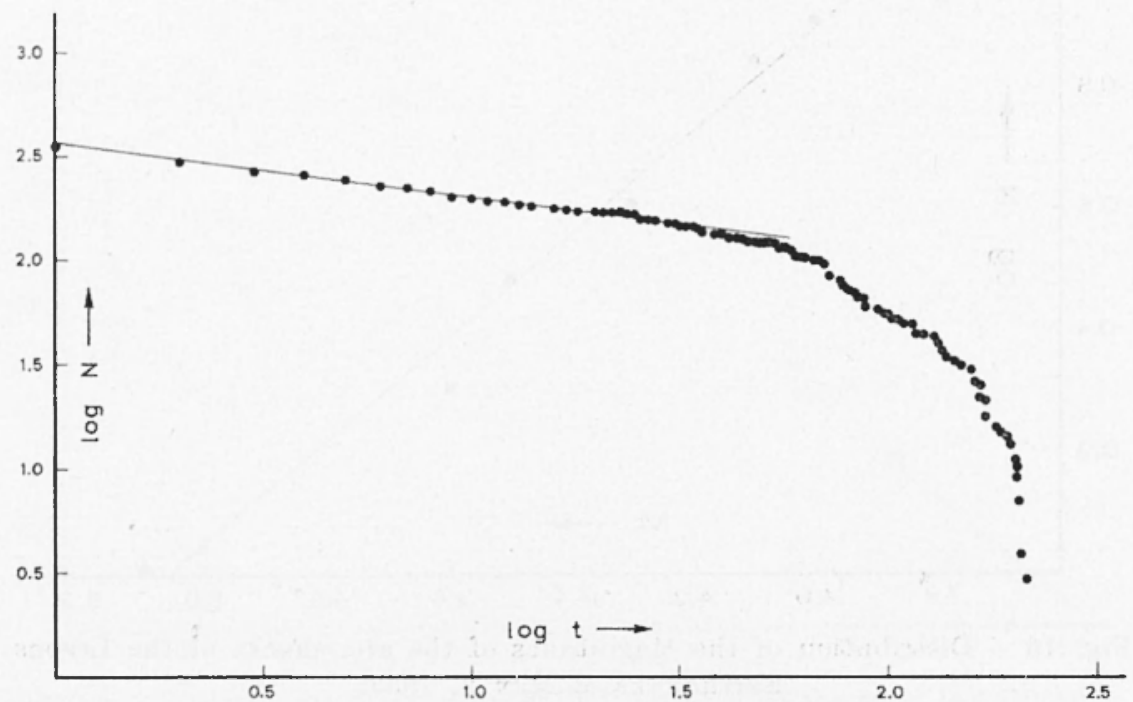

Fig. 17 - Time distribution of the aftershocks of the Kephallenia Earthquake of August 12, 1953.

The time and magnitude distribution of this aftershock sequence are shown in Figures 17 and 18 and are expressed by the:

$$
\begin{aligned}
& \log N=2.56-0.26 \log t \quad t \leq 50 \text { days } \\
& \log N=5.91-0.85 \mathrm{M} .
\end{aligned}
$$

The eumulative distribution of the foreshocks is also shown in Figure 18 and is expressed by the:

$$
\log N=3.99-0.61 M .
$$

The deformation characteristics are shown in Figure 19. We can see three branches. The second phase starts at 0.8 days and lasts about one month. This phase is expresses by the:

$$
\Sigma D=10.50+9.34[1-\exp (-5.06 \sqrt{t-0.09})]_{1}^{1} \times 10^{14} \mathrm{~cm}^{3}
$$


A third phase begins with the occurrence of an earthquake with magnitude $M=\mathbf{5 . 9}$ on September 14, 1953. This phase includes a larges "late aftershock" of magnitude $M=6.5$. Immediately after the occurrence of this shock the earthquake activity increased. It

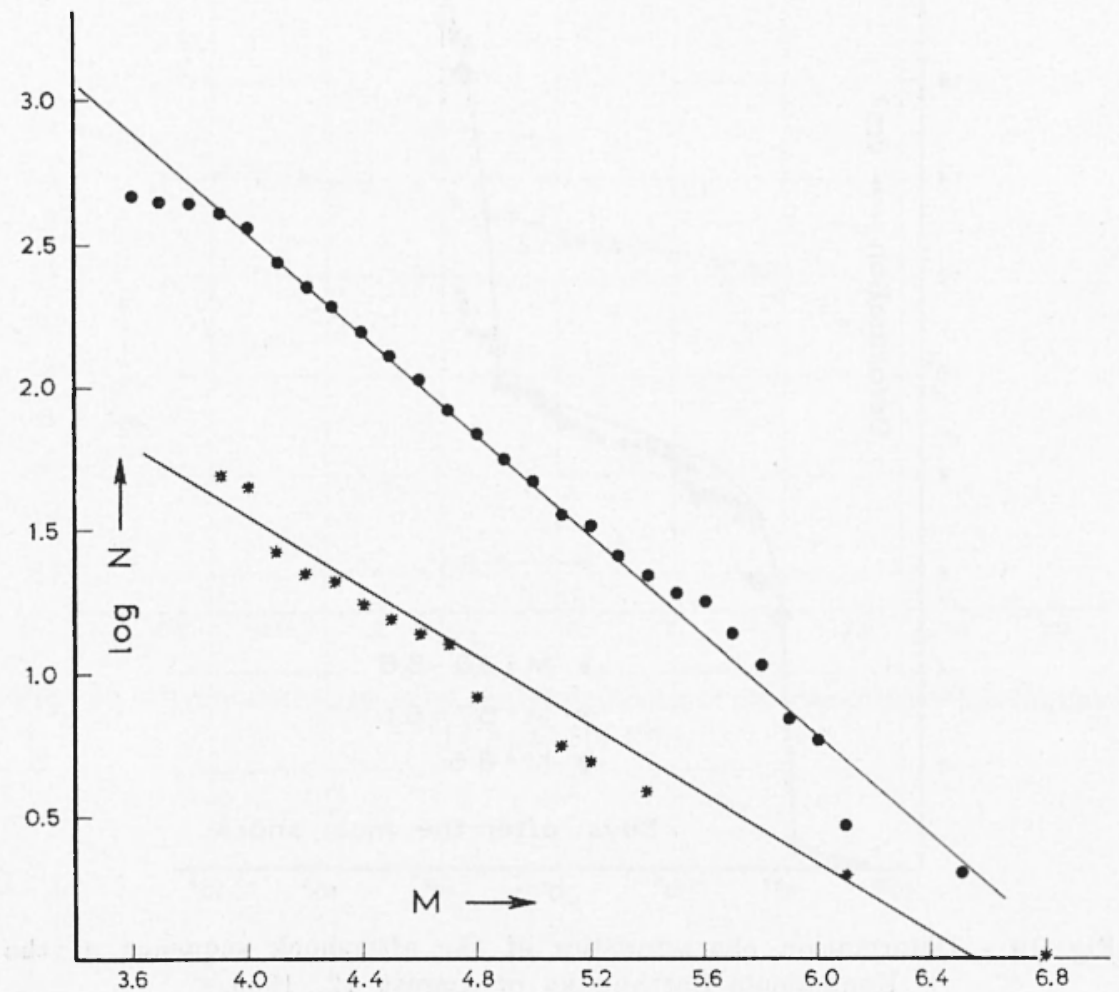

Fig. 18 - Distribution of the Magnitudes of the aftershocks and foreshocks of the Kephallenia Earthquake of August 12, 1953.

means that this shock las its own aftershocks. From this we can probably conclude that most of the shocks of the third branch come from a different seismic volume. This is supported by the fact that the macroseismic epicenter of the large "late aftershock" differs from the epicenter of the main shock. The third phase can be expressed by the:

$$
\Sigma L=\left\{9.85+10.39[1-\exp (-0.10 \sqrt{t-32.07})\}^{\prime} \times 10^{14} \cdot \mathrm{m}^{3} .\right.
$$

The relaxation time for the serend phase is 0.3 days. 


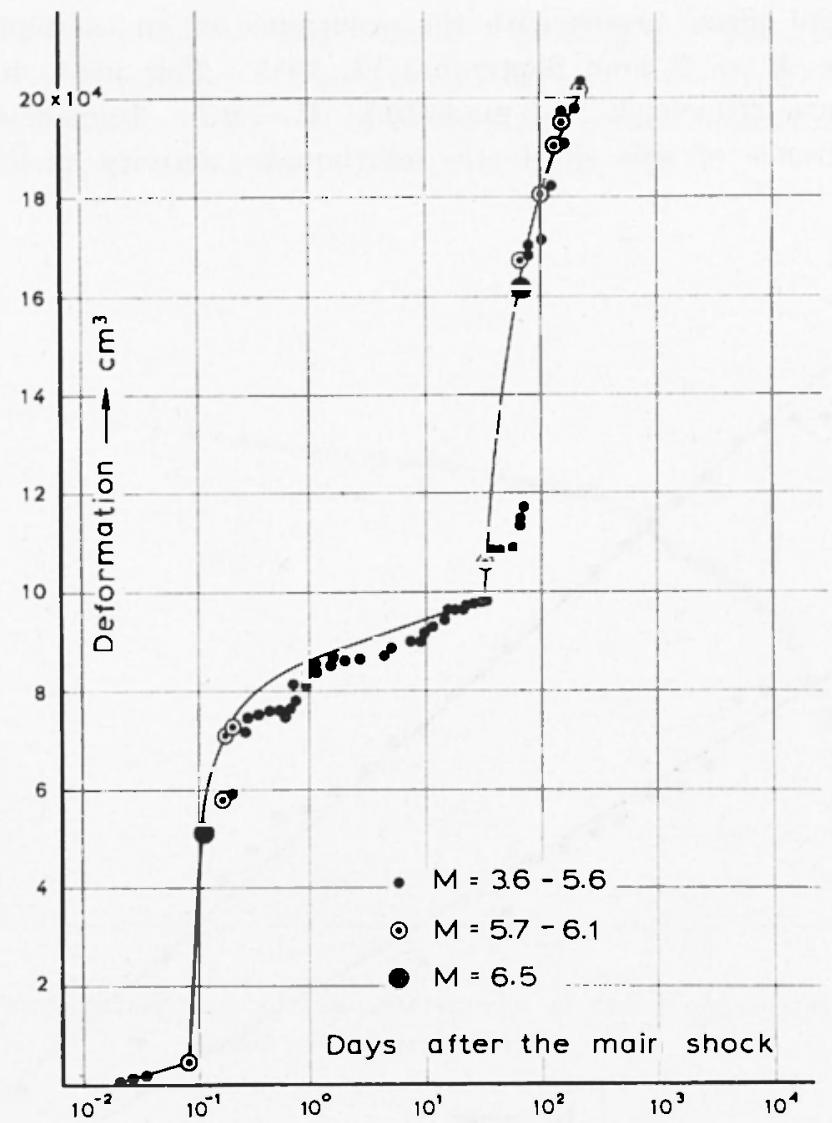

Fig. 19 - Deformation characteristics of the aftershock sequence of the Eephallenia Earthquake of August 12, 1953.

18. - Aftershocks of the Shophades Earthquake of April 30, 1954.

The epicenter of this earthquake is very close to the town of Sophades in the Western Thessaly. It caused severe damage and casualties. Its magnitude is 7 . Ten foreshocks and two hundred ninety nine aftershocks of magnitude $3.2 \leq M \leq 5.9$ have been recorded by the Wiechert seismographs in Athens. Their dates, arrival times and magnitudes are in Table III-(18).

The time distribution for the aftershocks of $M \geqq 4$ is shown in Figure 20 and is expressed by the:

$$
\log N=1.97-0.41 \operatorname{lot} t \quad t \leqq 27 \text { days } .
$$


The magnitude distribution of the aftershocks is shown in Figure 21 and is expressed by the:

$$
\log N=5.92-1.00 M .
$$

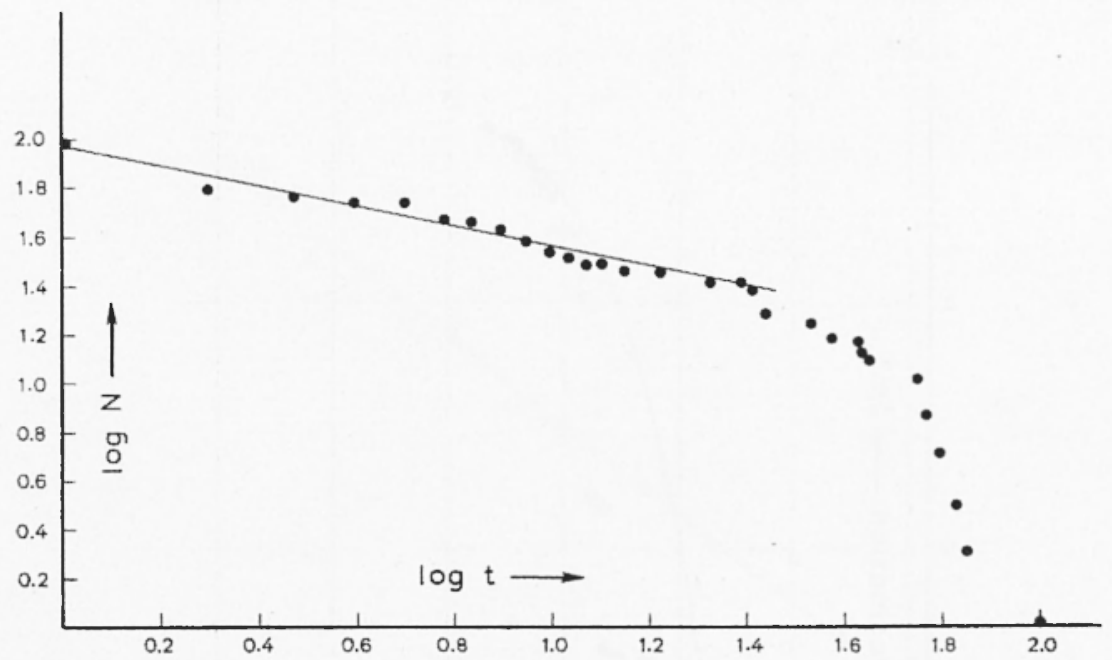

Fig. 20 - Time distribution of the aftershocks of the shophades Earthquake of April 30, 1954.

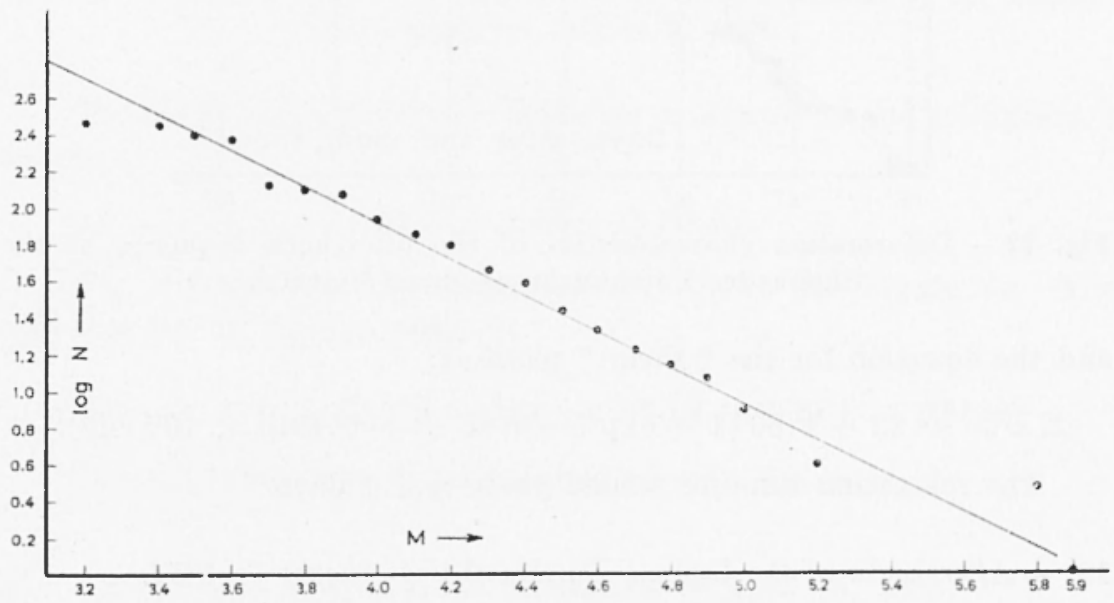

Fig. 2] - Distribution of the Magnitudes of the aftershocks of the shophades Earthquake of Apri 30,1954 
The deformation characteristics are shown in Figure 22. The compressional phase is expressed by the:

$\Sigma D=(0.17+0.10 \log t) \times 10^{14} \mathrm{~cm}^{3}$,

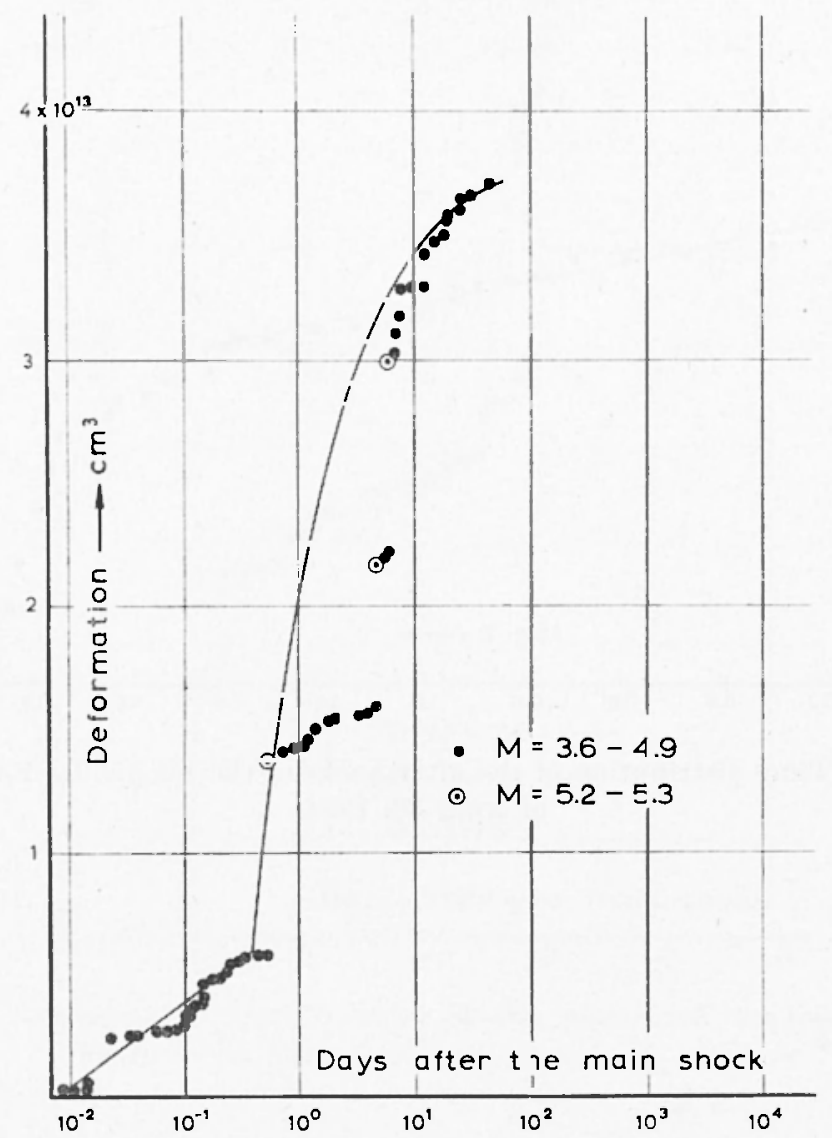

Fig. 22 - Deformation characteristics of the aftershock sequence of the Shophades Earthquake of April 30, 1954.

and the equation for the "shear" phase is:

$$
\Sigma D=\left\{0.22+1.80\left[1-\exp (-0.86 \sqrt{t-0.40)}] \times 10^{14} \mathrm{~cm}^{3}\right. \text {. }\right.
$$

The relaxation time for second phase is 3.4 days.

19. - Aftershocks of the Lemnos Earthquake of August 3, 1954.

The epicenter of the main shock is close to the Northern coast of the Lemnos island. Its magnitude is 6.1. Twenty one aftershocks 
of magnitude $4.0 \leqq M \leqq 5.5$ have been recorded in $A$ thens. The dates, arrival times and magnitudes are listed in Table III-(19). The time distribution of the aftershocks of this sequence is expressed by the:

$$
\log N=1.33-0.54 \log t \quad t \leqq 80 \text { days } .
$$

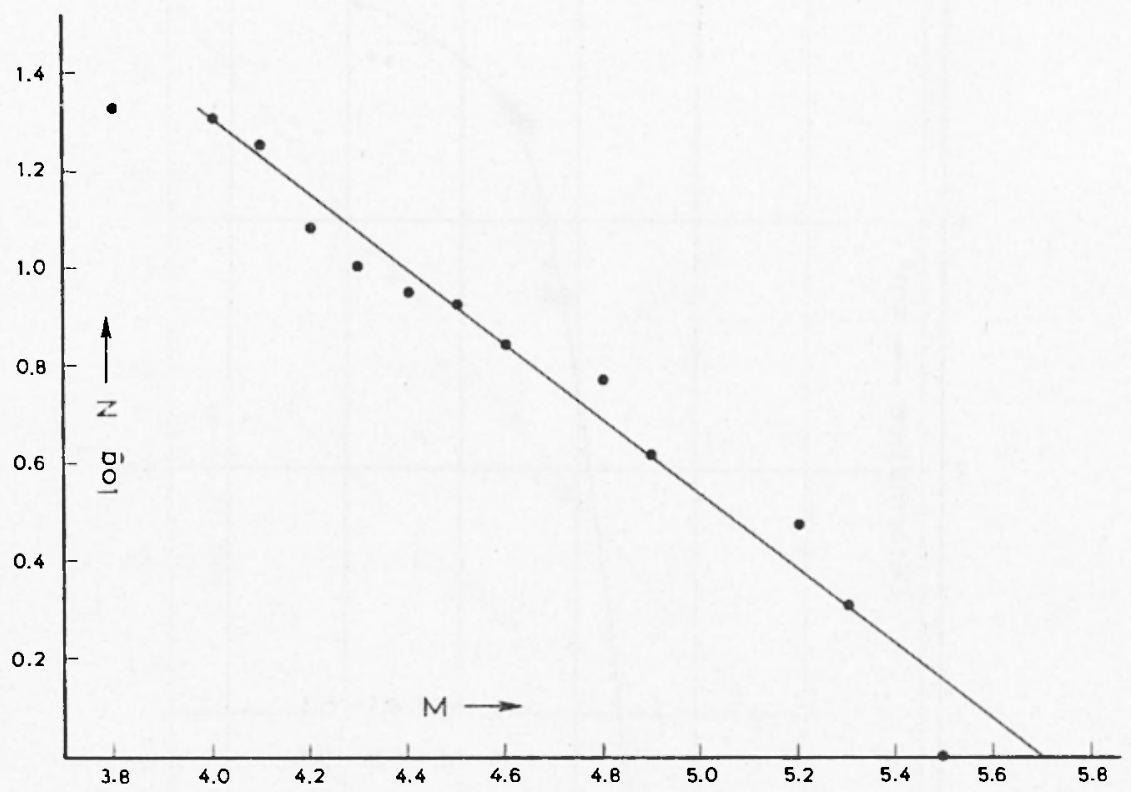

Fig. 23 - Distribution of the Magnitudes of the aftershocks of the Lemnos Earthquake of August 3, 1954.

The magnitude distribution is shown in Figure 23 and is expressed by the:

$$
\log N=4.68-0.86 M .
$$

The deformation characteristics are shown in Figure 24. The equation for the second phase is:

$$
\Sigma D=\left\{0.32+3.59[1-\exp (-0.96 \sqrt{t-0.29)}]\} \times 10^{13} \mathrm{~cm}^{3} .\right.
$$

The relaxation time for the second phase is 0.8 days.

20. - Aftershocks of the Laconia Earthquake of April 13, 1955.

The magnitude of this shock is 6 . The largest aftershock has a magnitude of 4.3 and occurred at $04^{\mathrm{n}} 22^{\mathrm{m}}$ on April 14. This probably 
is the only aftershock of $M \geqq 4$. The records of this earthquake show that its focus must be below the Mohorovicic discontinuity.

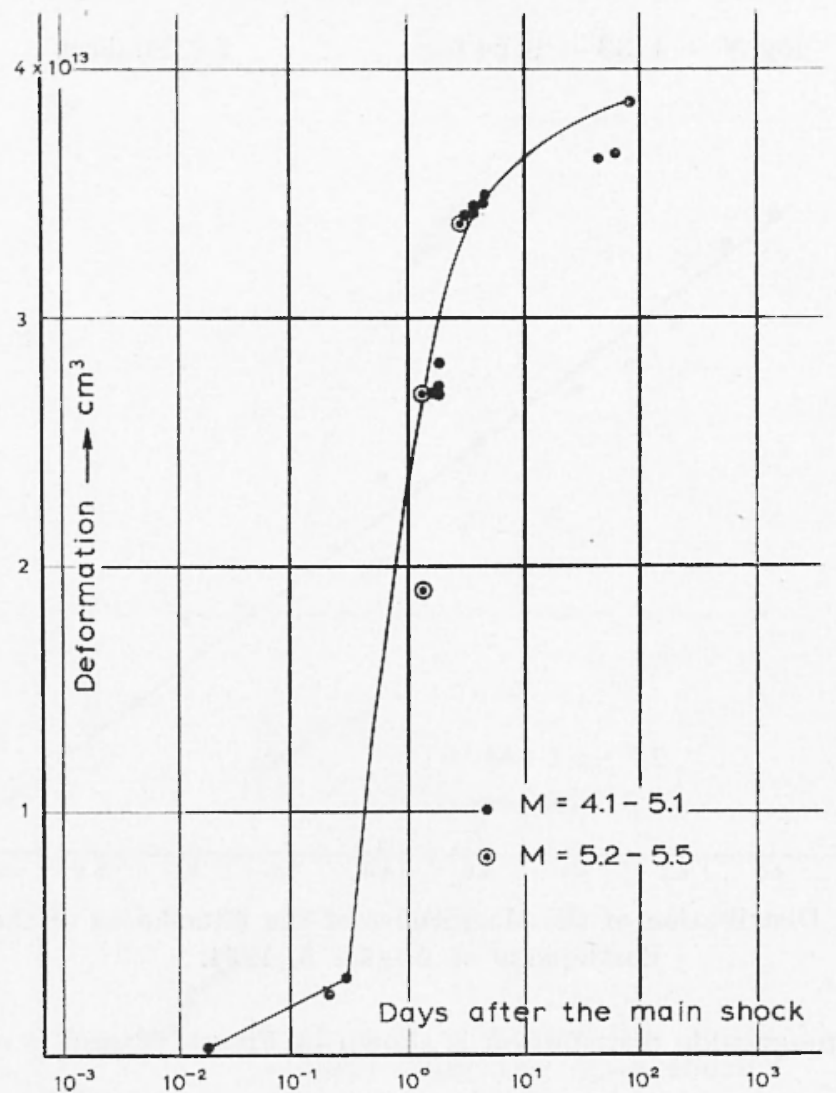

Fig. 24 - Deformation characteristic of the aftershock sequence of the Lemnos Earthquake of August 3, 1954.

21. - Aftershocks of the Volos Earthquake of April 19. 1955.

The epicenter of the main shock is in the Pagasitikos Gulf. It caused extensive damage in Magnesia. Its magnitude is $6^{1} /$. Seven foreshocks and forty two aftershocks of magnitude $3.3 \leqq M \leqq 5.9$, have been recorded in Athens. The dates, arrival times and magnitudes are listed in Table III-(21). In the same Table three " late aftershocks" are included. 
The time distribution for all the aftershocks with magnitude $M \geqq 4$ is expressed by the:

$$
\log N^{\top}=1.01-0.40 \log t \quad t \leqq 11 \text { days } .
$$

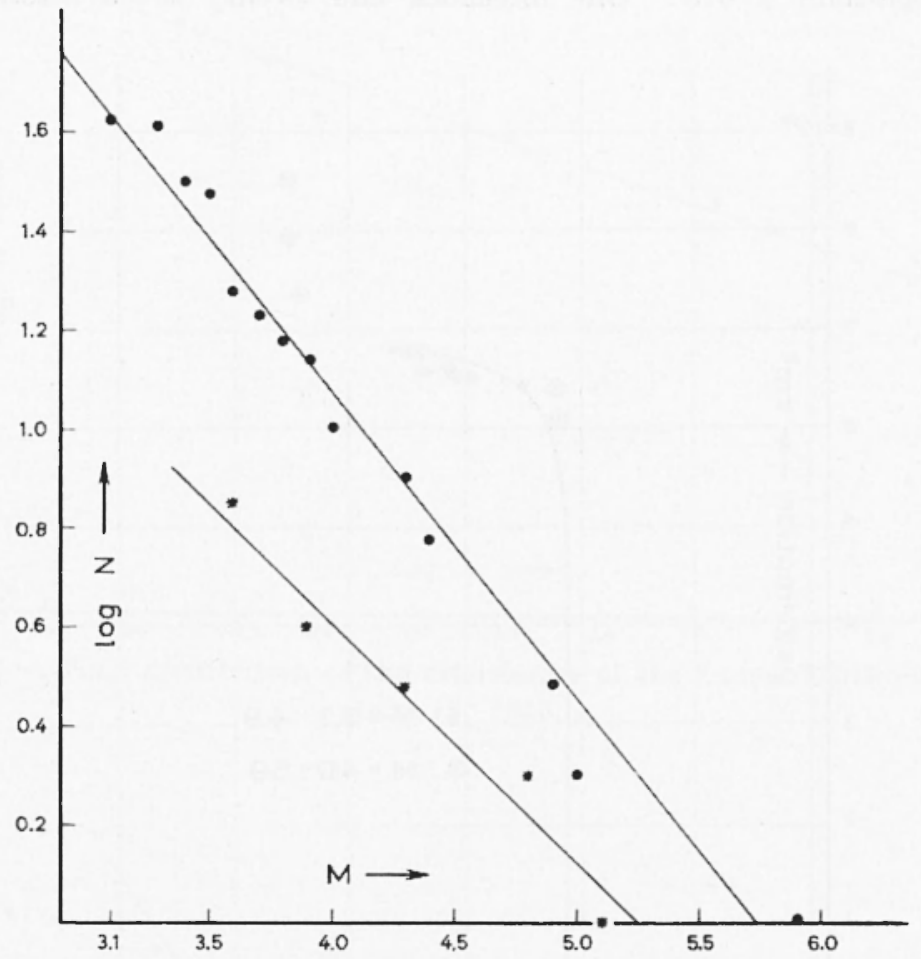

Fig. 25 - Distribution of the Magnitudes of the foreshocks and aftershocks of the Volos Earthquake of April 19, 1955.

The magnitude distribution of the aftershocks and foreshocks are shown in Figure 25 and are expressed by the:

$$
\begin{array}{ll}
\log N=3.61-0.63 M & \text { Aftershocks } \\
\log N=2.28-0.43 M & \text { Foreshocks . }
\end{array}
$$

The deformation characteristics are shown in Figure 26. The equation for the second phase is:

$\Sigma D=\{0.09+6.73[1-\exp (-3.32 \sqrt{t-1.30})]\}^{\prime} \times 10^{13} \mathrm{~cm}^{3}$.

The relaxation time for the second phase was found equal to 0.7 days. 
22. - Aftershocks of the Samos Earthquake of July 15, 1955.

The epicenter of this shock is close to the Western coast of Turkey. Its magnitude is 6.8. One foreshock and twenty seven aftershocks

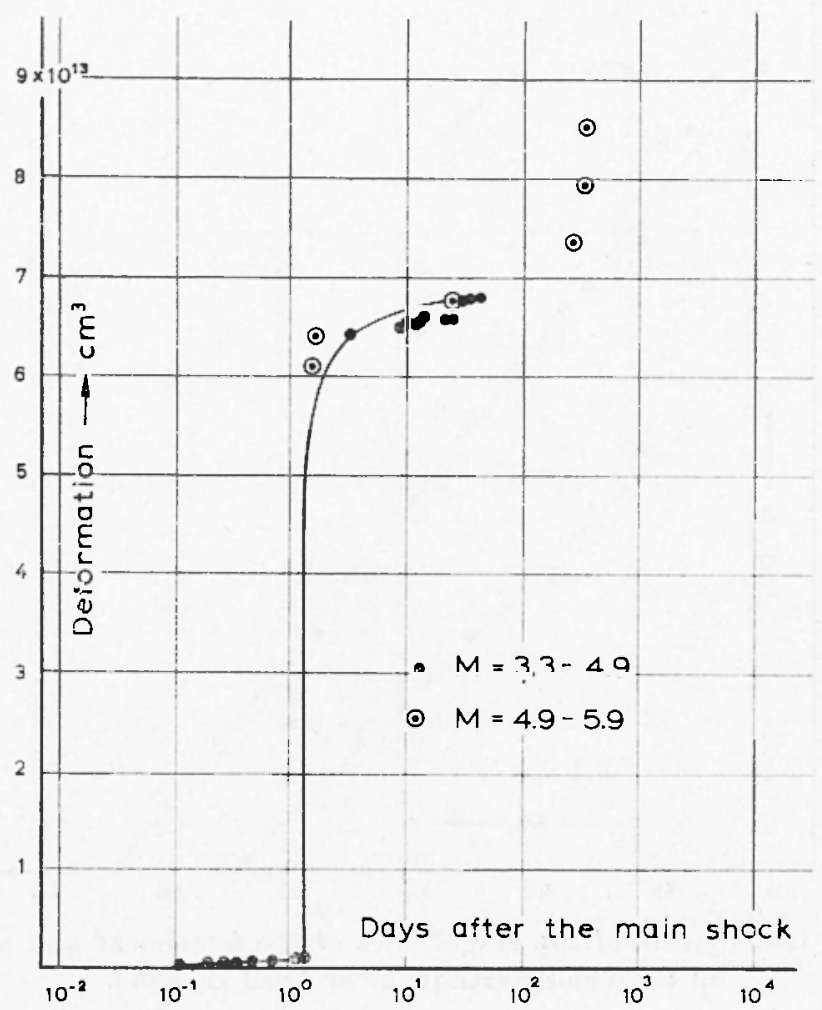

Fig. 26 - Deformation characteristics of the aftershock sequence of the Volos Earthquake of April 19, 1955.

of magnitude $4.0 \leqq M \leqq 5.2$ have been recorded in Athens. The dates, arrival times and magnitudes of these slooks are listed in Table III-(22).

The time and magnitude distribution of these aftershocks are shown in Figure 27 and 28 respectively and are expressed by the:

$$
\begin{aligned}
& \log N=1.42-0.33 \log t \quad t<213 \text { days } \\
& \log N=7.49-1.45 M .
\end{aligned}
$$




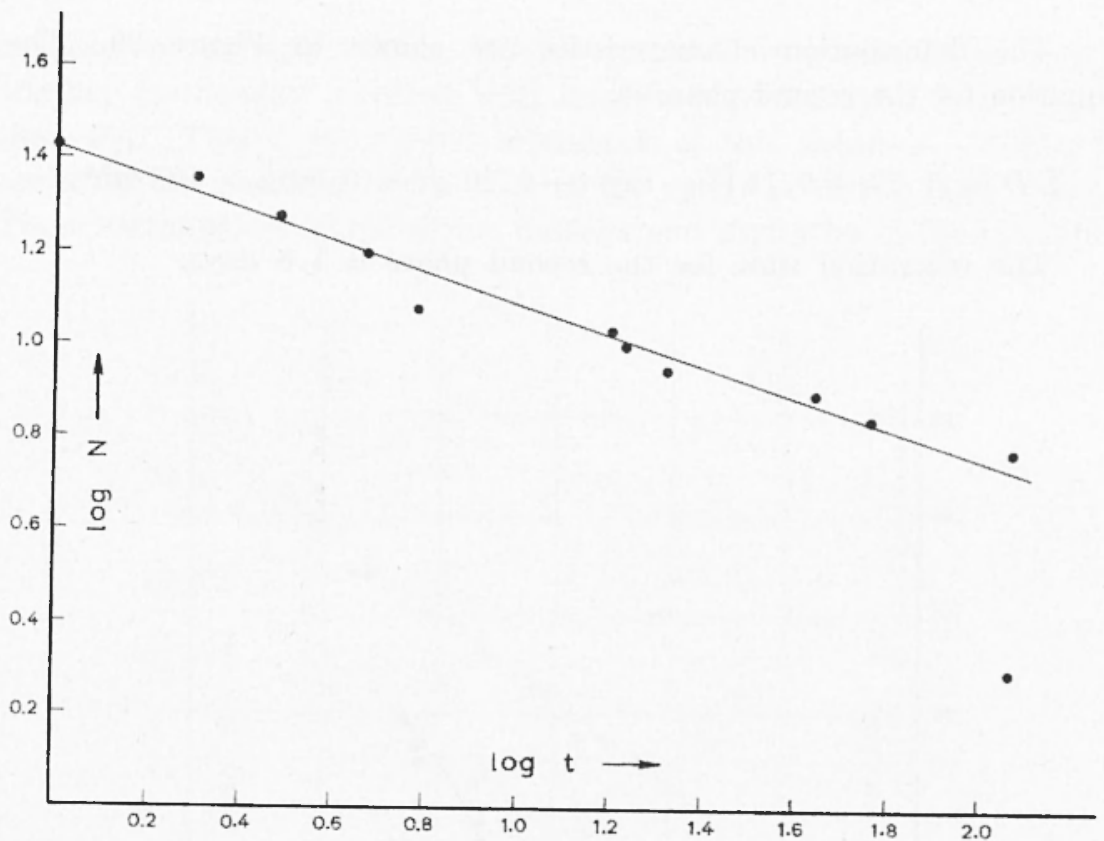

Fig. 27 - Time distribution of the aftershocks of the Samos Earthquake of July 15, 1955 .

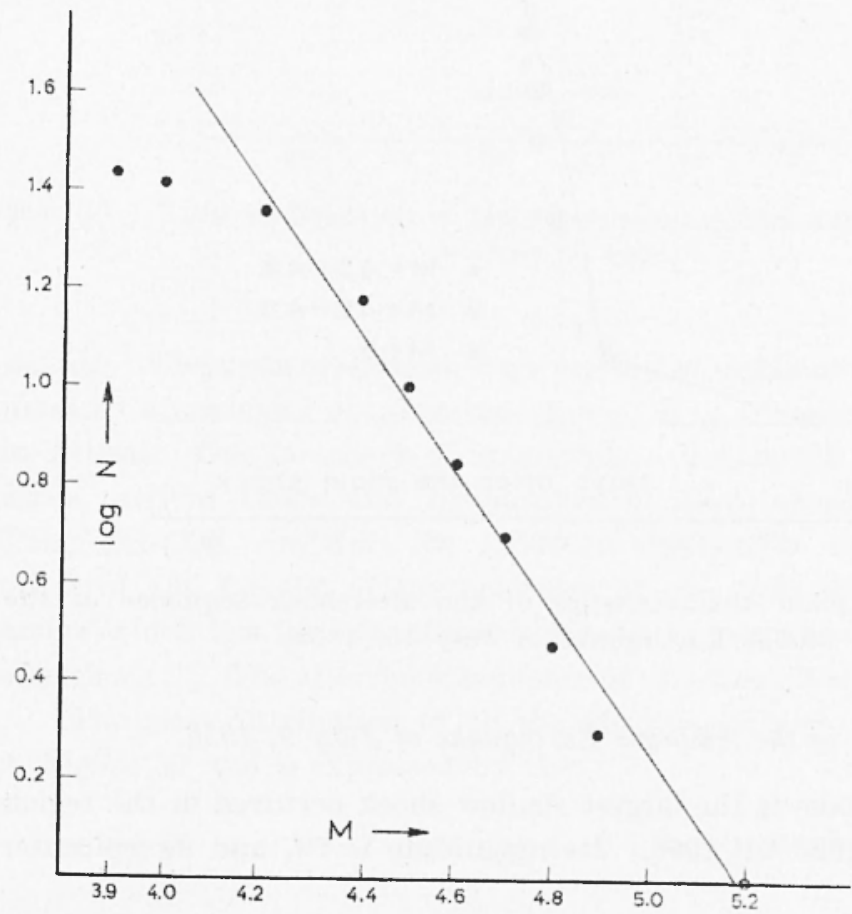

Fig. 28 - Distribution of the Magnitudes of the aftershocks of the Samos Earthquake of July 15， 1955 . 
40 B. Papazacilos - N. Delibasis - N. Liapis - G. moumoulidis - G. PURcaru

The deformation characteristics are shown in Figure 29. The equation for the second phase is:

$\Sigma D=11.73+5.74\left[1-\exp (-0.70 \sqrt{t-0.50)}] \times 10^{13} \mathrm{~cm}^{3}\right.$

The relaxation time for the second phase is 1.8 days.

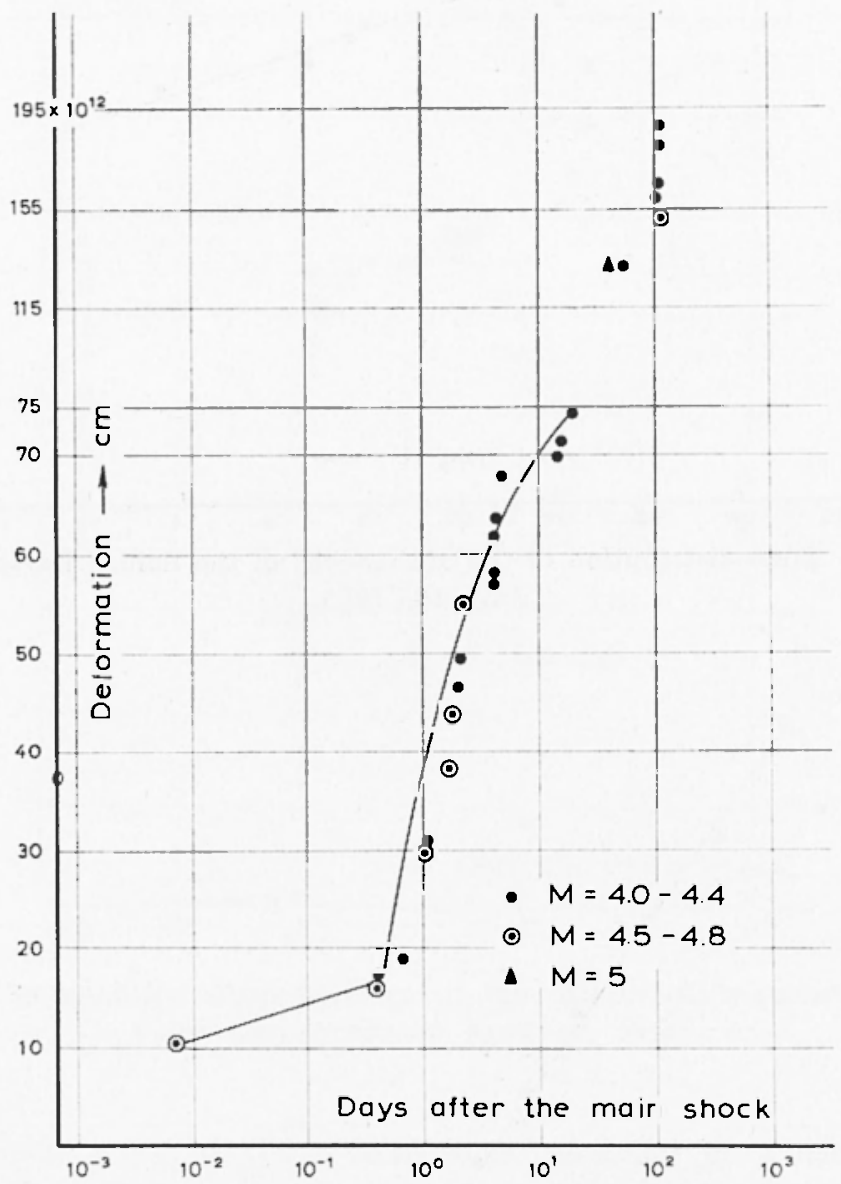

Fig. 29 - Deformation characteristics of the aftershock sequence of the Samos Earthquake of July 15, 1955.

23. - Aftershocks of the Amorgos Earthquake of July 9, 1956.

This earthquake is the largest shallow shock occurred in the region of Greece from 1926 till 1966. Its magnitude is $7^{1 / 2}$ and its epicenter 
is close to Amorgos island. Twelve minutes after the main shock another earthquake occurred with magnitude probably a little larger than $63 / 4$. This is the largest aftershock of this sequence. The epicenter of this shock is $70 \mathrm{~km}$ west of the epicenter of the main shock. These earthquakes caused severe damage and casualties in the Cyclades

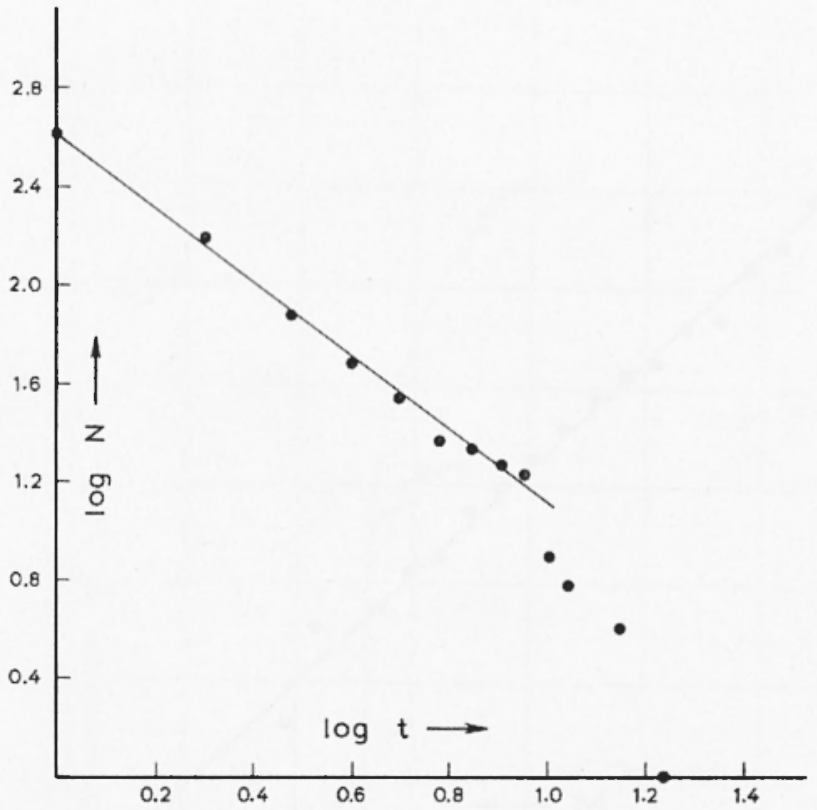

Fig. 30 - Time distribution of the aftershocks of the Amorgos Earthquake of July 9, 1956.

islands. The main aftershock sequence lasted eighteen days only. Four hundred aftershocks of magnitude $3.5 \leqq M \leqq 6^{3} / 4$ have been recorded in Athens. One foreshock of magnitude $\check{5} .0$ occurred on July 8 . The dates, arrival times and magnitudes of these shocks are listed in Table III-(23). On July 30, 19506, an earthquake of magnitude 6.1 occurred $100 \mathrm{~km}$ SE of the epicenter of the main shork. This earthquake which has its own aftershorks, can be considered as large "late aftershock". The aftershock sequence of this shock is st udied separately.

The time distribution of all the aftershocks with $I I \geqq 4$ is shown in Figure 30 and is expressed by the:

$$
\log N=2.60-1.50 \log t \quad t \leqq 10 \text { days. }
$$


The cumulative frequency function of the magnitude is shown in Figure 31 and is expressed by the:

$$
\log N=5.8-0.92 M \text {. }
$$

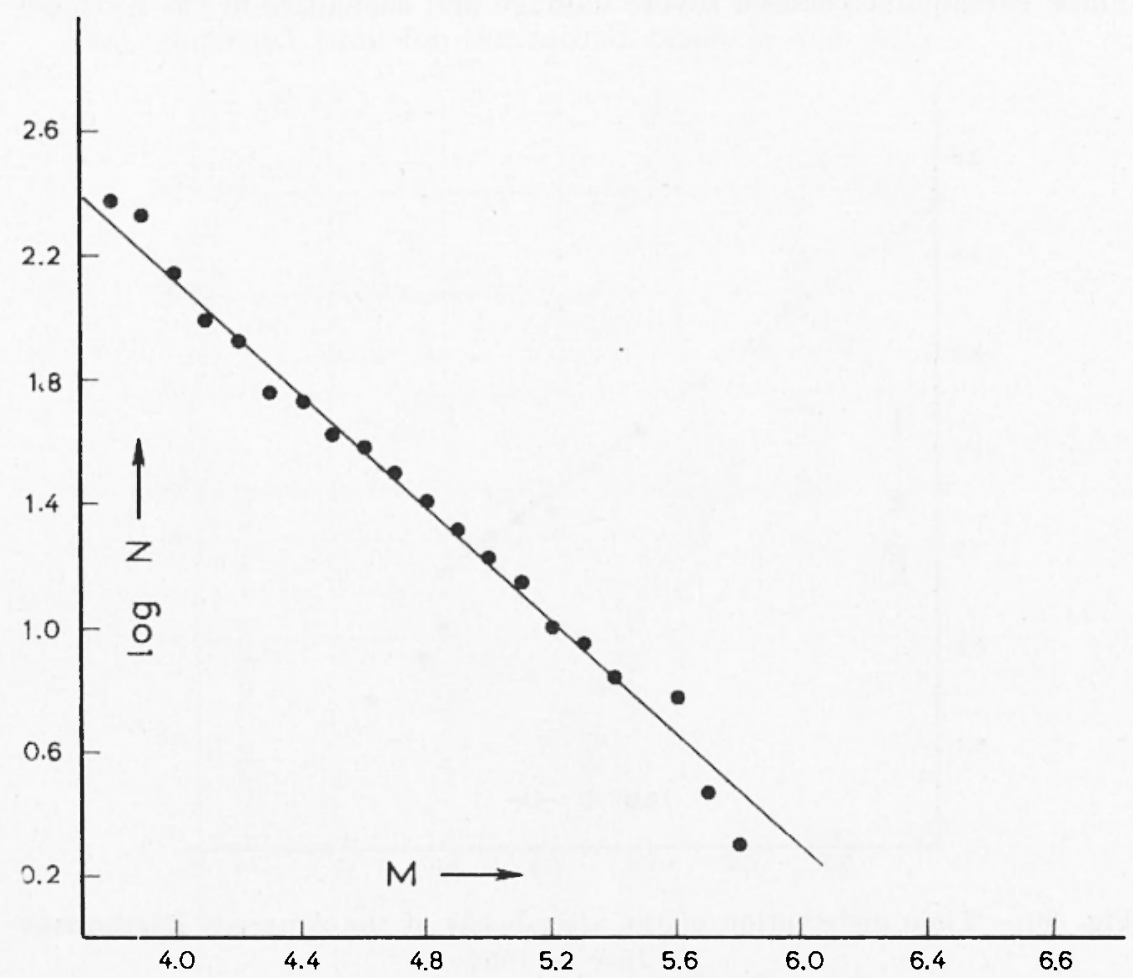

Figr. 31 - Distribution of the Magnitudes of the aftershocks of the Amorgos Earthquake of July 9, 1956.

The deformation characteristics are shown in Figure 32 . The equations for the compressional and second phase are:

$$
\begin{gathered}
\searrow D=(6.51+3.78 \log t) \times 10^{13} \mathrm{~cm}^{3} \\
\sum D=\left\{21.16+3.15\left[1-\exp \left(-2.48 \sqrt{t-0.12)] \times 10^{13} \mathrm{~cm}^{3}}\right.\right.\right.
\end{gathered}
$$

The deformation during the occurrence of the largest aftershock is not plotted in Figure 32 .

The relaxation time of the "shear phase" is 0.4 days. 
24. - Aftershocks of the NE Crete Earthquake of July 30. 1956.

This earthquake can be considered as large "late aftershock" of the Amorgos Earthquake of July 9, 1956. Its magnitude is 6.1. About

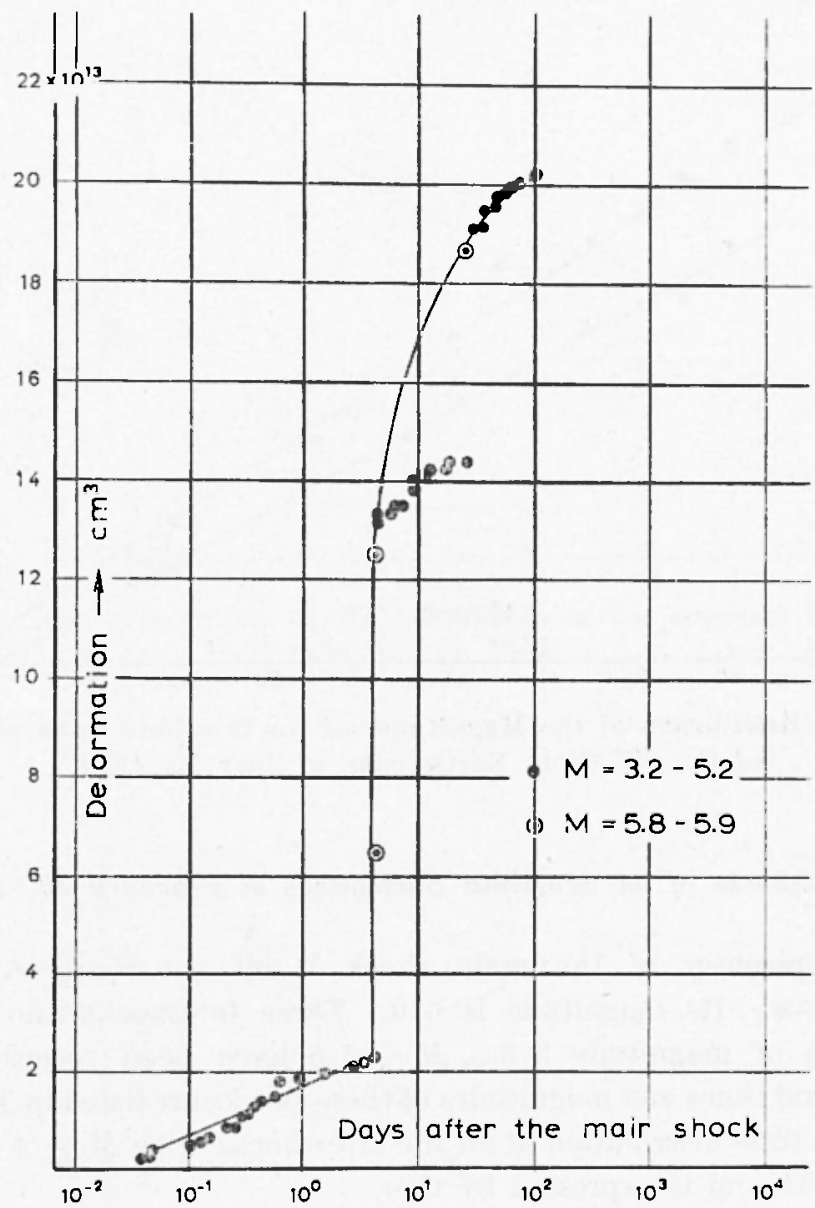

Fig. 32 - Deformation characteristics of the aftershock sequence of the Amorgos Earthquake of July 9, 1956.

eight foreshocks and nineteen aftershocks of magnitude $3.7 \leqq M \leqq 5.7$ have been recorded in Athens. The dates, arrival times and magnitudes 
are listed in Table III-(24). The cumulative distribution of the magnitude are shown in Figure 33 and are expressed by the:

$$
\begin{array}{ll}
\log N=3.64-0.65 M & \text { Aftershocks } \\
\log N=3.08-0.55 M & \text { Foreshocks }
\end{array}
$$

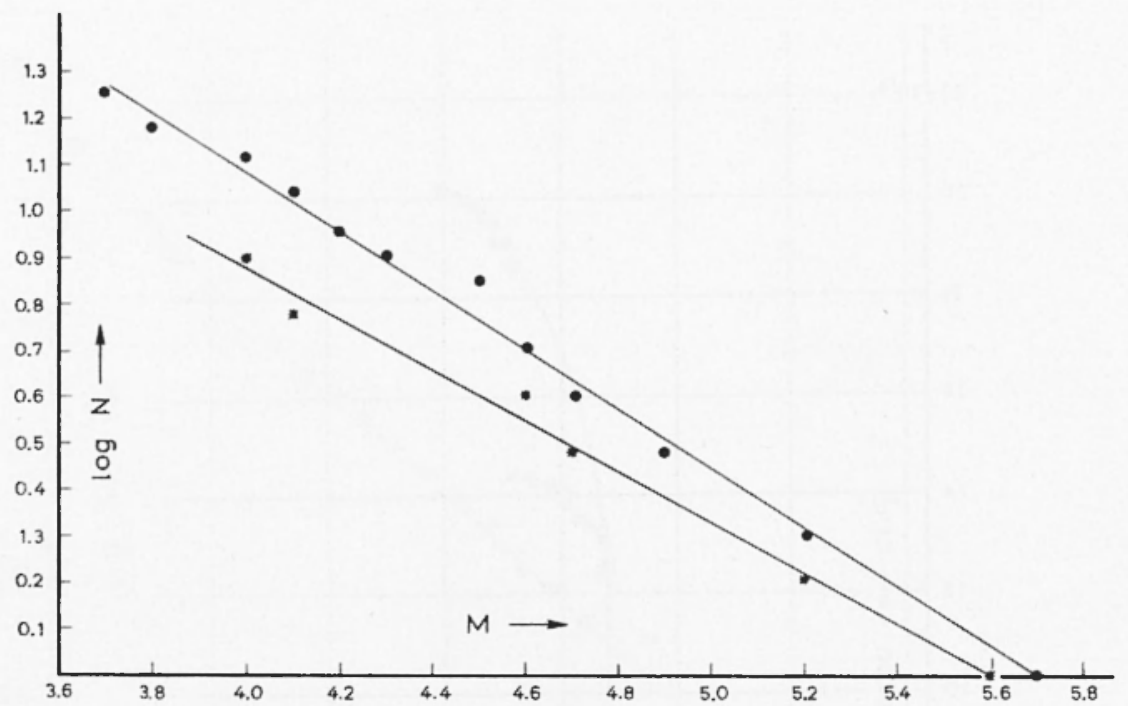

Fig. 33 - Distribution of the Magnitudes of the foreshocks and aftershocks of the NE-Crete Earthquake of July 30, 1956.

25. - Aftershocks of the Messinia Earthquake of February 19, $195 \%$.

The epicenter of the main shock is off the Southern coast of Peloponnesus. Its magnitude is 6.0. Three foreshocks and thirteen aftershocks of magnitude $3.8 \leqq M \leqq 4.5$ have been recorded. The dates, arrival times and magnitudes of these shocks are listed in Table III(25). The time distribution of all the aftershocks with $M \geqq 4$ is shown in Figure 34 and is expressed by the:

$$
\log N=1.14-0.58 \log t \quad t \leqq 14 \text { days }
$$

The cumulative distribution of the magnitude of the aftershocks is shown in Figure 35 and is expressed by the:

$$
\log N=\check{5} .39-1.14 M \text {. }
$$


The deformation characteristics for the second phase is expressed by the:

$\Sigma D=\left\{0.2+2.1[1-\exp (-1.46 \sqrt{t-0.05)}]\} \times 10^{12} \mathrm{~cm}^{3}\right.$.

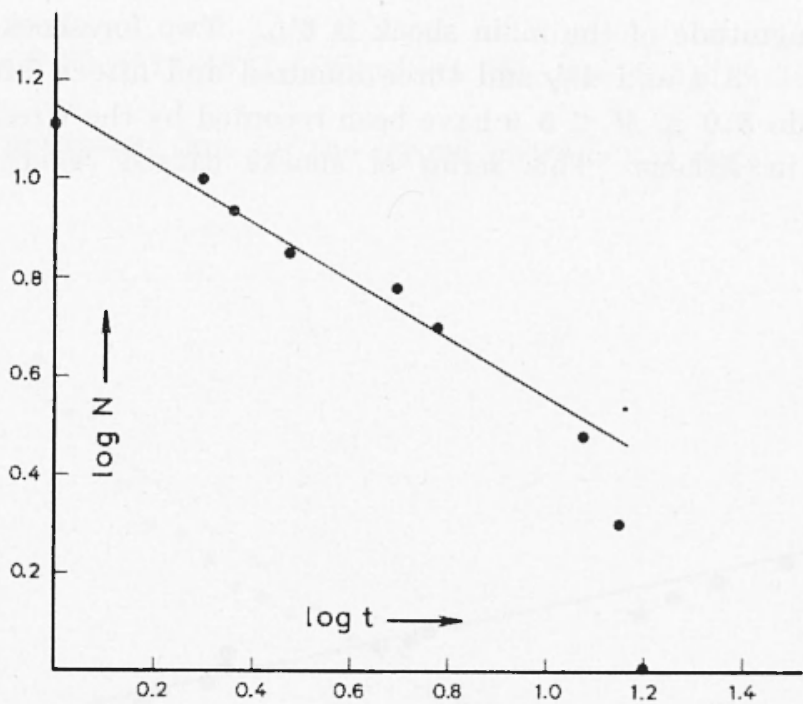

Fig. 34 - Time distribution of the aftershocks of the Messinia Earthquake of February 19, 1957.

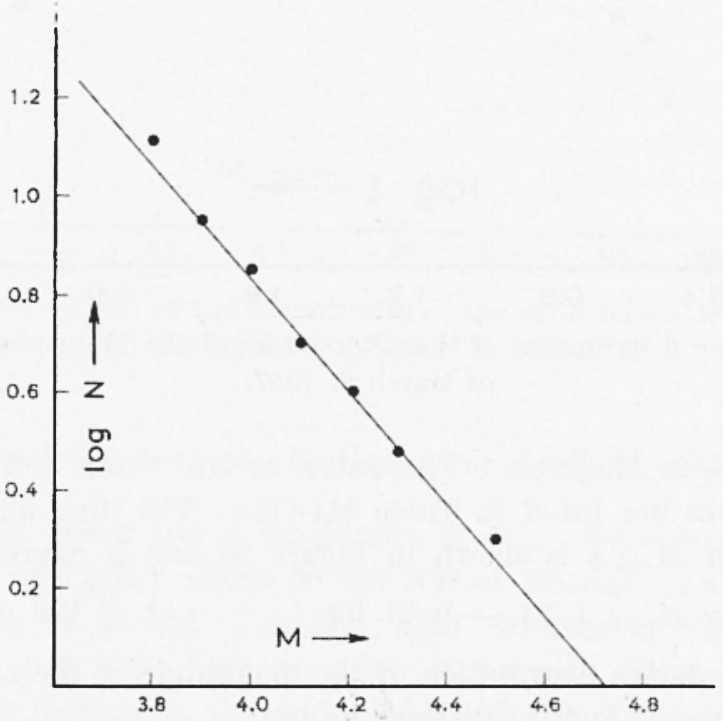

Fig. 35 - Distribution of the Magnitudes of the aftershocks of the Messinia Earthquake of February 19, 1957. 
The relaxation time for the "shear phase" is equal to 1.64 days.

26. - Aftershocks of the Magnesia Earthquake of March 8, 1957.

The ragnitude of the main shock is $6^{3} / 4$. Two foreshocks of magnitude $M=3.4$ and $6^{1 / 2}$ and three hundred and fifteen aftershocks of magnitude $3.0 \leqq M \leqq 5.9$ have been recorded by the Wiechert seismographs, in Athens. This series of shocks caused severe damage

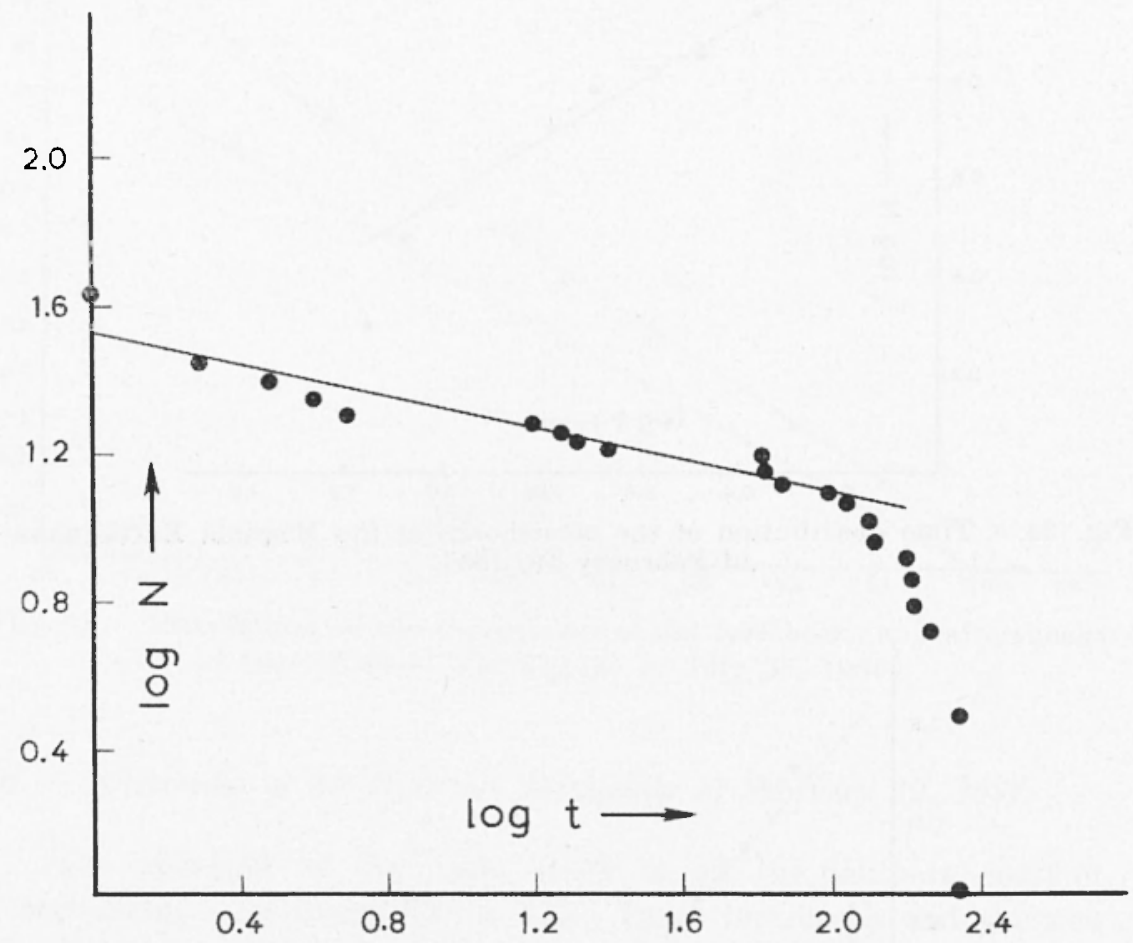

Fig. 36 - Time distribution of the aftershocks of the Magnesia Earthquake of March $8,1957$.

and casualties in Magnesia. The dates, arrival times and magnitudes of these shocks are listed in Table III-(26). The time distribution of aftershocks of $M \geqq 4$ is shown in Figure 36 and is expressed by the:

$$
\log N=1.53-0.21 \log t \quad t \leqq 126 \text { days } .
$$

The cumulative distribution of the magnitude of the aftershocks is shown in Figure 37 and is expressed by the:

$$
\log N=4.61-0.73 M \text {. }
$$


Deformation characteristics are shown in Figure 38. Three phases are observed. The third phase starts with a shock of $M=5.8$ and consists of fifty one late aftershocks. The equation for the second phase is:

$$
\Sigma D=\left\{0.33+12.48\left[1-\exp (-1.45 \sqrt{t-0.3)}\}_{i}^{\prime} \times 10^{13} \mathrm{~cm}^{3} .\right.\right.
$$

The relaxation time for the second phase is 2.2 days.

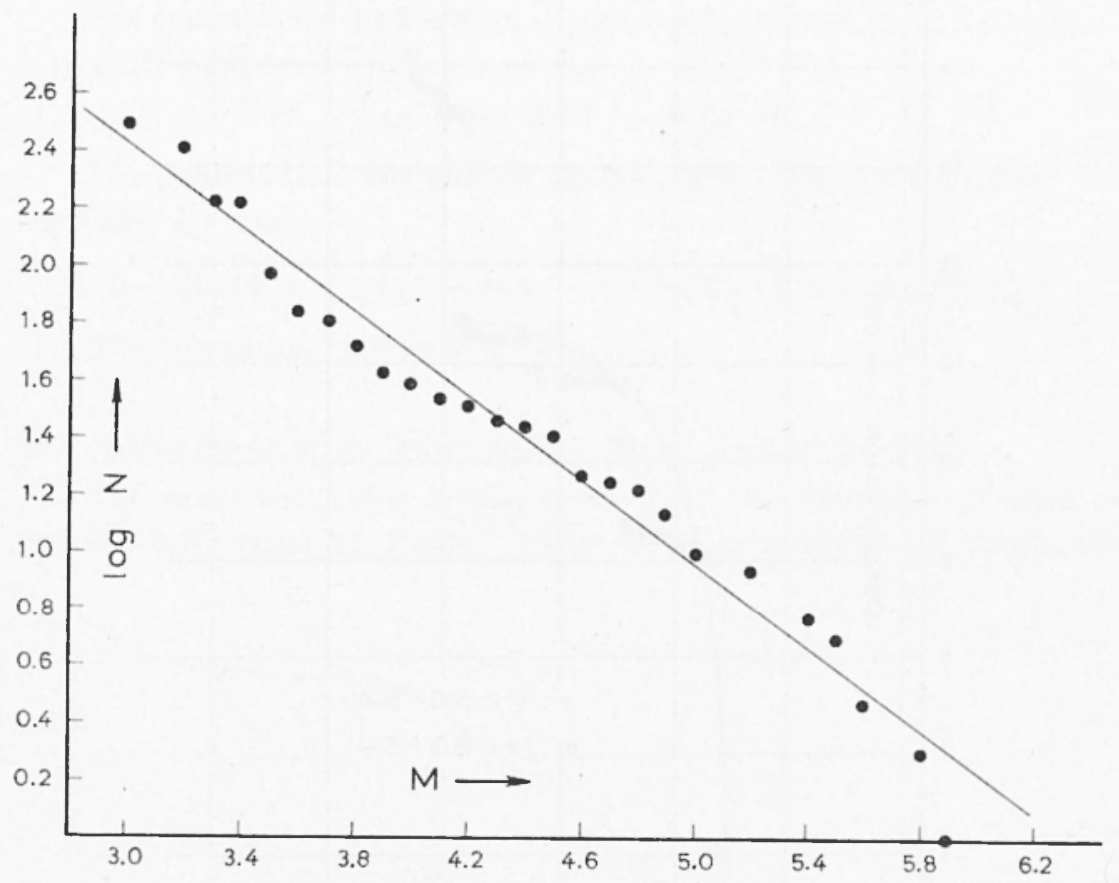

Fig. 37 - Distribution of the Magnitudes of the aftershocks of the Magnesia Earthqualie of March 8, 1957.

27. - Aftershoclis of the Lycia Earthquake of April 25, 195\%.

The main shock has a magnitude of $71 / 4$. Its epicenter is close to the coast of Turkey about $50 \mathrm{~km} \mathrm{NE}$ of Rhodes. Two foreshocks of magnitude 4.6 and 7.0 and nine aftershocks of magnitude $4.3 \leqq M I \leqq 6.3$ have been recorded in $A$ thens. These earthquakes caused severe damage in the region of Fethiye in Turkey. The dates, arrival times and magnitudes of these foreshocks and aftershocks are 
listed in Table III-(27). The time distribution of the aftersbocks is expressed by the:

$$
\log N=1.00-0.18 \log t \quad t \leqq 33 \text { days } .
$$

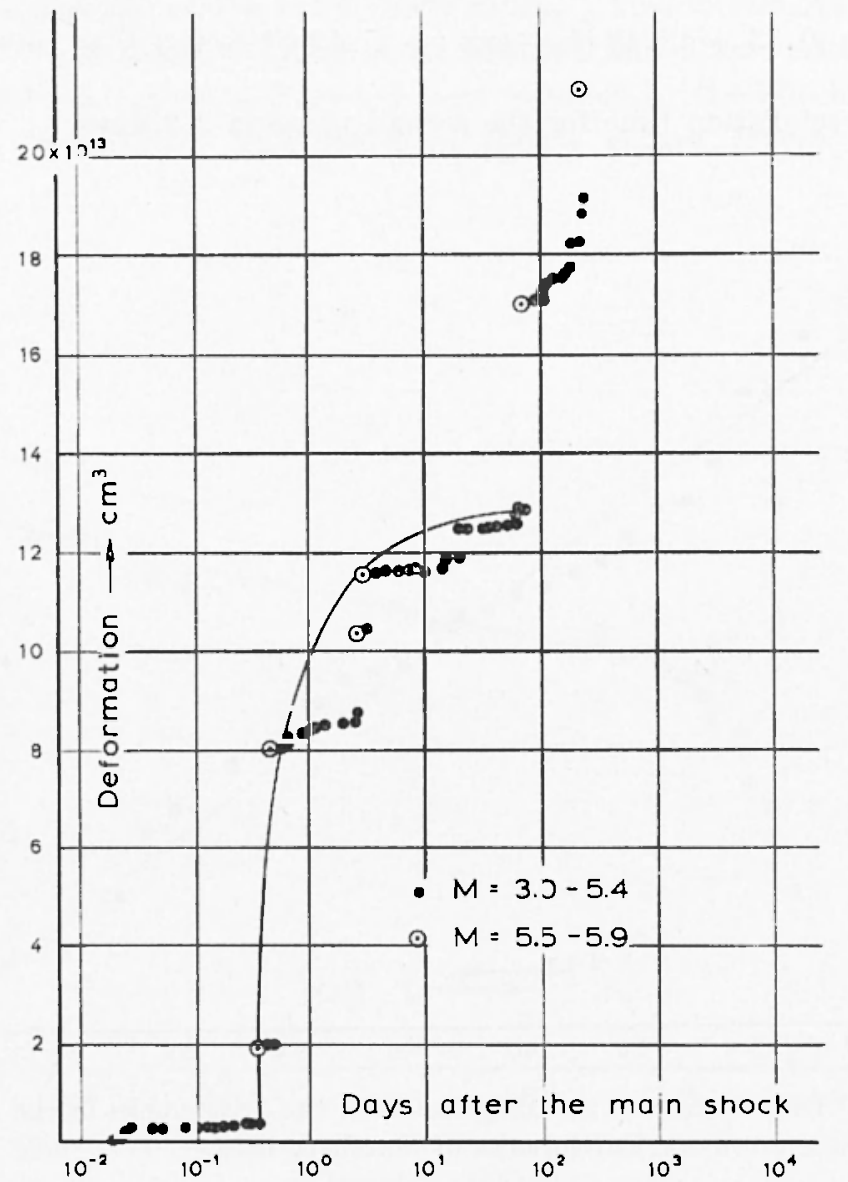

Fig. 38 - Deformation characteristics of the aftershock sequences of the Magnesia Earthquake of March 8, 1957.

The cumulative distribution of the magnitude of the aftershocks is expressed by the:

$$
\log N=3.52-0.59 M .
$$

The relaxation time is 2.3 days. 
28. - Aftershocks of the NE Turkey Earthquake of May 26, $195 \%$.

The magnitude of the main shoek is 7.0 . It caused severe damage in Bolu Province of Turkey. Fifteen aftershorks of magnitude $4.3 \leqq M \leqq 6.0$ have been recorded in Athens. The dates, arrival times and magnitudes are listed in Table III-(28). The time distribution of the aftershocks is approximately expressed by the:

$$
\log N=1.19-0.55 \log t \quad t \leqq 4 \text { dilys } .
$$

The eumulative distribution of the magnitude of these aftershocks is roughly expressed by the:

$$
\log N=3.87-0.64 \mu \text {. }
$$

The deformation was plotted against time. The "shear phase" is expressed by the;

$$
\Sigma D=\left\{0.16+1.08\left[1-\exp (-2.69 \sqrt{t-0.1)}] \mid \times 10^{14} \mathrm{~cm}^{3} .\right.\right.
$$

The relaxation time is 0.2 days.

29. - Aftershocks of the Zante Earthquake of August 27, 1958.

The main shock has a magnitude 6.5. Its epicenter is close to the Western coast of Zante. Fifty three aftershocks of magnitude

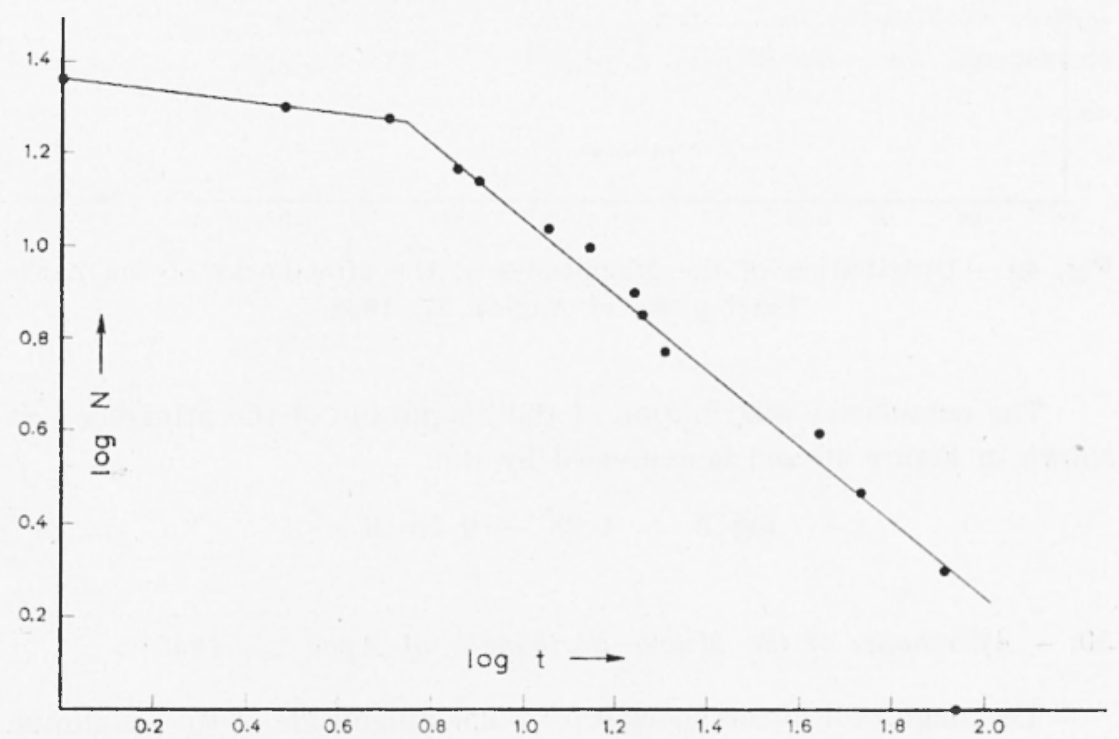

Fig. 39 - Time distribution of the aftershocks of the Zante Larthquake of tugust 27, 1958. 
$3.4 \leq M \leq 5.6$ have been recorded by the Wiechert seismographs in Athens. The dates, arrival times and magritudes are listed in Table III-(29). The time distribution of the aftershocks is shown in Figure 39 and is expressed by the;

$$
\begin{array}{ll}
\log N=1.36-0.13 \log t & t \leqq 6 \text { days } \\
\log N=2.38-1.32 \log t & 6 \cong t \leq 80 \text { days. }
\end{array}
$$

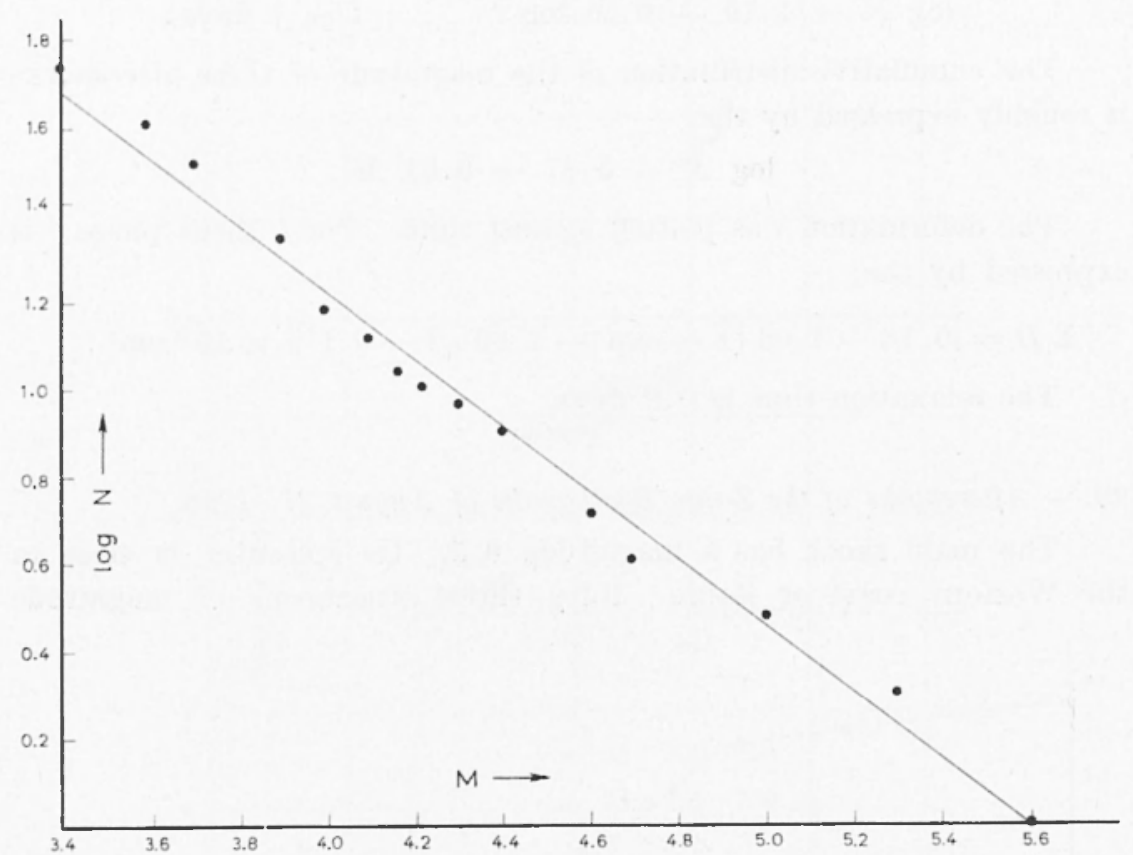

Fig. \pm 0 - Distribution of the Magnitudes of the aftershocks of the Zante Earthquake of August 27, 1958.

The cumulative distribution of the magnitude of the aftershocks is shown in Figure 40 and is expressed by the:

$$
\log N=4.28-0.76 \mathrm{M} \text {. }
$$

30. - Aftershocks of the Mugla Earthquake of April 25, 1959.

The magnitude of this shock is $6^{1} / 4$. The magnitude of the maximum aftershock is 5.6. Other aftershocks of smaller magnitude have been also occurred but some of them have not been recorded in Athens 
because of the large epicentral distance and other have been recorded but they cannot be distinguished from other normal shocks.

\section{1. - Aftershocks of the Crete Earthquake of May 14, 1959.}

The magnitude of the main shock is 6.4. It caused extensive damage and casualties in Crete. One foreshock and six aftershocks are listed in Table III-(31).

32. - Aftershocks of the Albanian Earthquake of September 1, 1959.

The main shock has a magnitude of 6.4 . Three foreshocks and six aftershocks of magnitude $4.1 \leqq M \leqq 6.0$ have been recorded by the Wiechert seismographs in Athens. The dates, arrival times and magnitudes of these shoeks are in Table III-(32). The cumulative magnitude distribution is roughly expressed by the:

$$
\log N=2.40-0.40 \mathrm{M} \text {. }
$$

33. Aftershocks of the Zante Earthquake of November 15, 1959.

The magnitule of the main shock is 7.0 . This earthquake caused darnage in Ionian islands. Eighteen aftershocks of magnitude

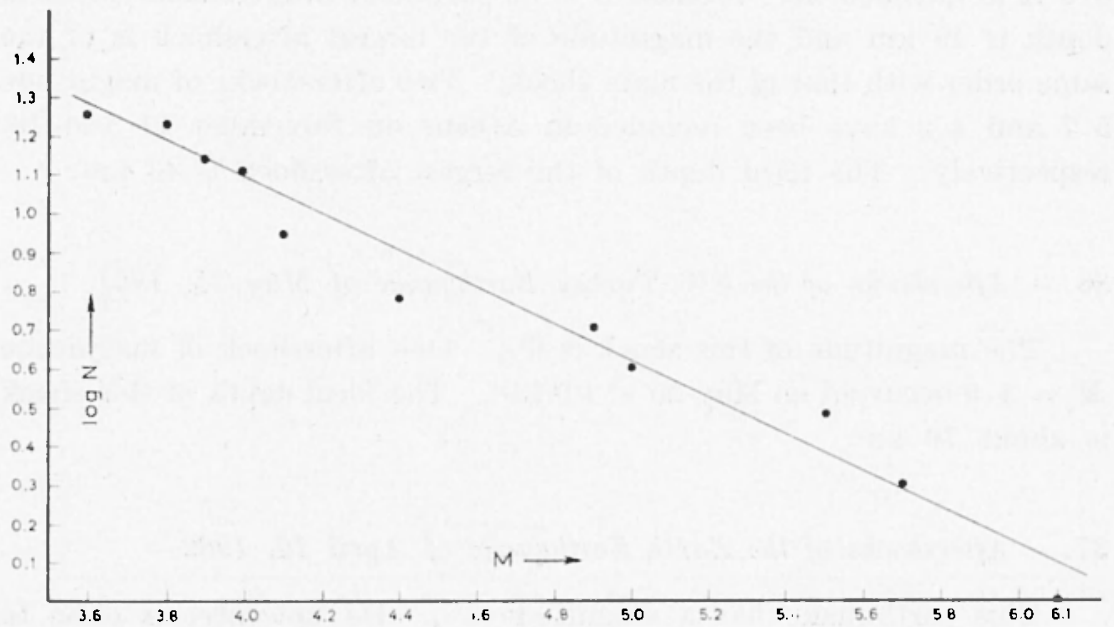

Fig. 1] - Distribution of the Magnitudes of the aftershocks of the Zante Larthquake of November 15, 1959. 
$3.8 \leqq H \leqq 6.1$ have been recorded in Athens. The dates, arrival times and magnitudes of these earthquakes are listed in Table III-(33). The time distribution of all aftershocks of magnitude $M \geqq 4$ is expressed by the:

$$
\log N=1.12-0.23 \log t \quad t \leq 16 \text { days. }
$$

The magnitude distribution is shown in Figure 41 . The curve which has the following equation fits the data:

$$
\log N=2.97-0.47 H .
$$

34. - Aftershocks of the Albanian Earthquake of May 26, 1960.

The magnitude of the main shock is 6.5 . Three foreshocks and six aftershocks of magnitude $4.0 \leqq M \leqq 5.2$ have been recorded in Athens. The dates, arrival times and magnitudes of the shocks of this sequence are listed in Table III-(34). The cumulative distribution of the magnitude is expressed by the:

$$
\log N=2.72-0.52 M .
$$

35. - Aftershocks of the Thesprotia Earthquake of November 4, 1960.

Although the magnitude of this shock is 5.8 , that is, smaller than 6.0 it is included here because it is of particular interest since its focal depth is $49 \mathrm{~km}$ and the magnitude of the largest aftershock is of the same order with that of the main shock. Two aftershocks of magnitude 5.7 and 4.2 have been recorded in Athens on November 11 and 16, respectively. The focal depth of the largest aftershoce is $43 \mathrm{~km}$.

36. - Aftershocks of the SW Turkey Earthquake of May 23, 1961.

The magnitude of this shock is $6^{1} / 2$. One aftershock of magnitude $M=4.9$ occurred on May 25 at $01^{\mathrm{h}} 13^{\mathrm{m}}$. The focal depth of this shock is about $70 \mathrm{~km}$.

37. - Aftershocks of the Zante Earthquake of April 10, 1962.

This earthquake has a magnitude $6 \frac{1}{4}$. Its epicenter is close to the Southern coast of the Zante island. One hundred and thirty nine aftershocks of magnitude $3.6 \leqq M \leqq 5.3$ have been recorded by the 


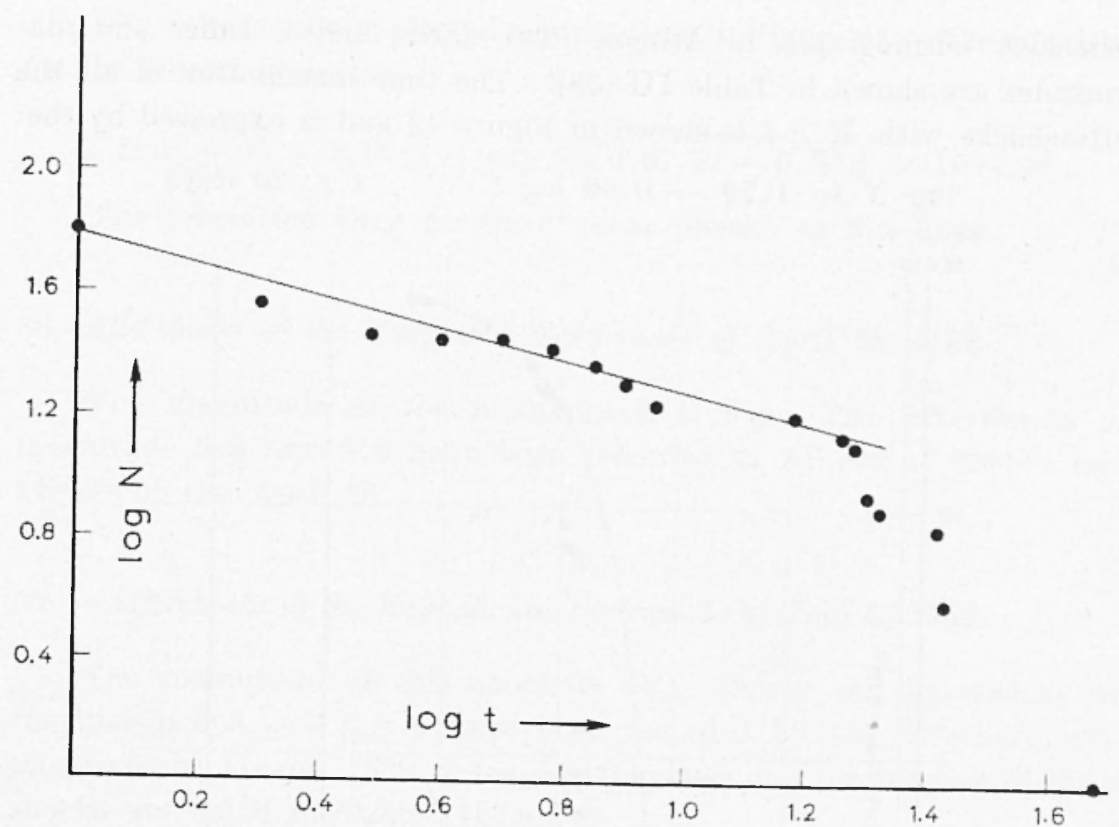

Fig. 42 - Time distribution of the aftershocks of the Zante Earthquake of Avril 10, 1962.

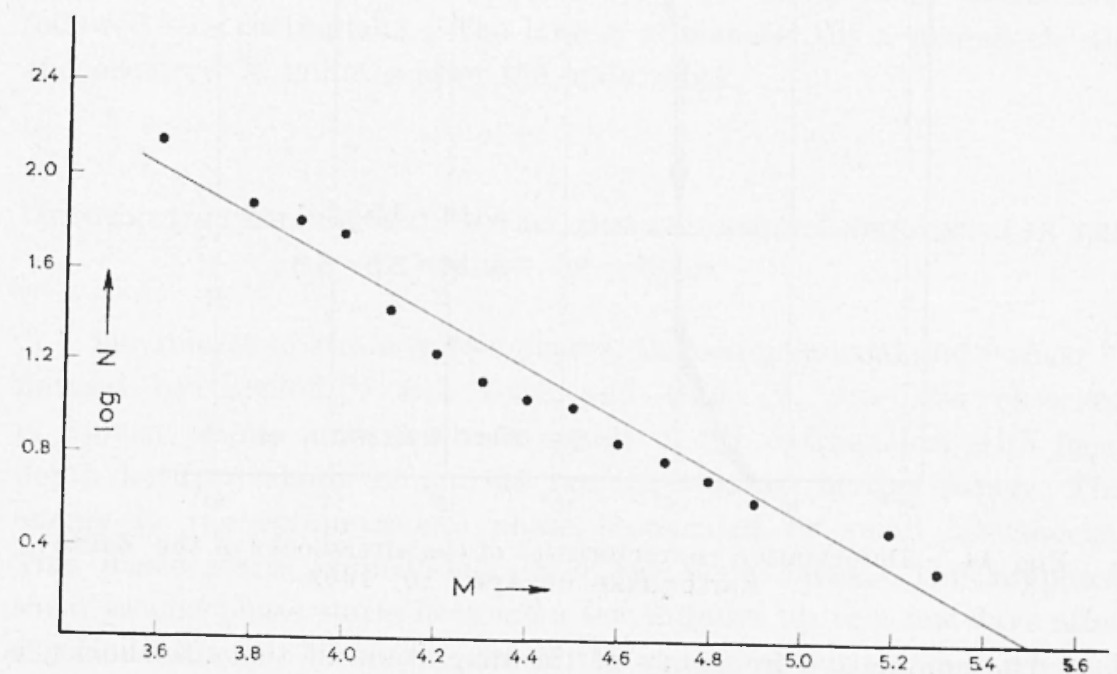

Fig. 43 - Distribution of the Magnitudes of the aftershocks of the Zante Earthquake of April 10, 1962. 
Wiechert seismographs in Athens. The dates, arrival times and magnitudes are shown in Table III-(38). The time distribution of all the aftershocks with $M \geqq 4$ is shown in Figure 42 and is expressed by the:

$$
\log N=1.79-0.50 \log t \quad t \leq 20 \text { days } .
$$

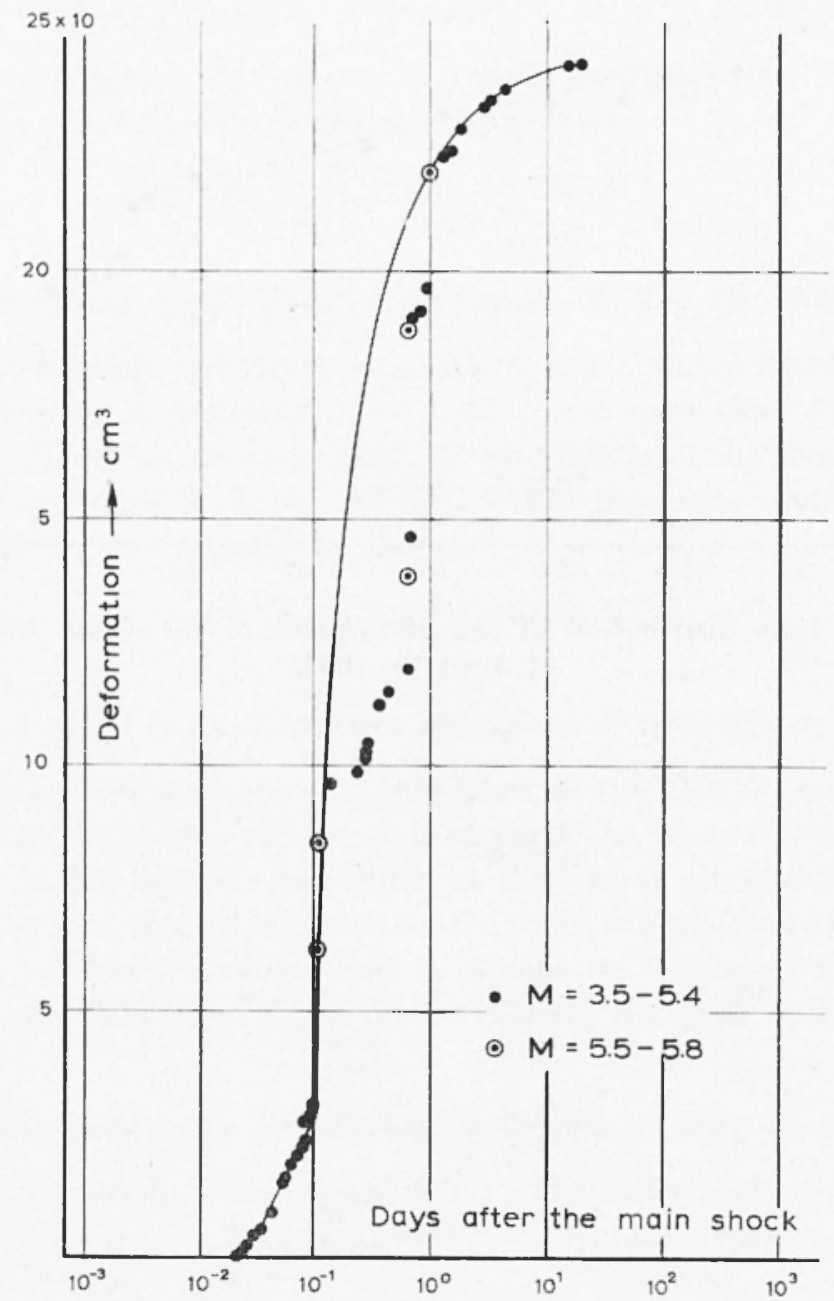

Fig. 44 - Deformation characteristies of the aftershocks of the Zante Earthquake of April 10, 1962.

The cumblative frequency of the magnitude of the aftershocks, is shown in Figure 43 and is expressed by the:

$$
\log N=\check{\mathbf{5}} .88-1.07 M \text {. }
$$


The deformation is plotted against time in Figure 44. The equation for the second phase is:

$$
\Sigma D=10.60+3.15[1-\exp (-0.67 \sqrt{t-0.04})]^{\prime} \times 10^{13} \mathrm{~cm}^{3} \text {. }
$$

The relaxation time for the "shear phase" is 2.5 days.

38. Aftershocks of the Karpathos Earthquale of April 28, 1962.

The magnitude of the main shock is 6.0. Two aftershocks of magnitude 5.8 and 4.5 have been recorded in Athens at $12^{\mathrm{h}} 44^{\mathrm{m}}$ and $14^{\mathrm{n}} 02 \mathrm{~m}$ of the April 28 .

39 - Aftershocks of the Kephallenia Earthquake of July 6, 1962.

The magnitude of this shock is $6^{1 / 4}$. Thirty six aftershocks of magnitude $3.8 \leqq X \leqq 4.5$ have been recorded by the Wiechert seismographs in Athens. The dates, arrival times and magnitudes of these shocks are listed in Table HI-(40).

40. - Aftershocks of the Skopje Earthquake of July 26, 1963.

The marnitude of the main shock is 6.2. Many small earthquakes followed this earthquake. The largest aftershock has a magnitude $4^{3 / 4}$ and oceurred 36 minutes after the main shock.

DEFORMATION CHARACTERISTICS OF THE AFTERSHOCK SEQUENCES IN THE REGION OF GREECE

The release of strain in two phases, the compressional and "shear". noticed by Benioff $\left({ }^{2}\right)$ and Bath and Duda $\left({ }^{1}\right)$, was also observed in almost all the aftershock sequences of the earthquakes with focal depth between about 15 and $50 \mathrm{~km}$ investigated in this paper. The energy in the compressional phase is released by small aftershocks. This phase starts immediately after the main shock. The supposed shear second phase starts between a few minutes up to a few days after the main shock. The most part of the energy in this phase is released by large aftershocks and mainly by the largest aftershock. The largest aftershock, which increases the destructive work of the main shock 
occurs, in all the cases a few minutes up to 14 days after the main shock. The mean value of the time of occurrence of the largest aftershock after the main shock is about 3 days.

The relaxation times of the second phase are distributed between 0.2 days and 6.5 days. The mean value is 2.0 days. Assuming that the relaxation time $\tau$ is related with the coefficient of viscocity $\eta$ and the coefficient of rigidity $\mu$ by the $\tau=\frac{\eta}{\mu}$, a rough value for $\eta$ can be found by applying this formula. The mean value of the focal depth of these earthquakes is about $40 \mathrm{~km}$. The velocity of the shear waves at that depth is approximately equal to $S_{n}$ velocity. If we take this velocity equal to $4.55 \mathrm{~km} / \mathrm{sec}$ (Papazachos et al. $\left({ }^{11}\right)$ ) and the density equal to $3.2 \mathrm{gr} / \mathrm{cm}^{3}$ the value of $\mu$ must be $0.66 \times 10^{2} \mathrm{dynes} / \mathrm{cm}^{2}$. Then the value of the coefficient of viscosity is equal to $10^{17} \mathrm{gr} / \mathrm{sec}-\mathrm{cm}$ at a depth of about $40 \mathrm{~km}$.

In the cases of the earthquakes which are listed in Table I with code numbers $4,5,8,10,11,12,13,14,17,21,22,23,26$, and 32 , that is, in about $30 \%$ of the cases a third phase was observed. The most part of the energy in this phase is released by the so called large "late aftershocks". The largest "late aftershocks" in these fourteen cases occurred $222,74,41,281,69,123,50,75,69,330,43,21,219$, and 36 days after the main shock.

The fact that the large "late aftershocks" have their own aftershocks indicates that they are at least partially, independent of the main shock. That is, the largest part of their aftershock region is not included in the aftershock volume of the main shock. This is supported by the fact that in most of the cases there is strong evidence that the epicenter of the large "late aftershock" differs from the epicenter of the main shock. It is probable that the main shock intervenes in part of the strained region of the large "late aftershock" and reduces the strength of this region by breaking through the barriers of some of its locks. The time when the major "late aftershock" occurs depends on the time needed for further stress accumulation till it reaches the remainder strenght of the material.

The large "late aftershocks" are particularly dangerous because they occur at time when the public believes that the serious danger is over. They usually cause considerable damage and casualties. It is not easy to locate regions which give large "late aftershocks" since as we can notice the earthquakes which have large "late aftershocks" are distributed all over the region considered, i.e. are independent of 
the surface geology. The probability for a major "late aftershock" to occur is greater in the case of large earthquakes. About $50 \%$ of the shallow earthquakes of $M \geqq 63 / 4$ are followed by large "late aftershocks". In most of the cases the mignitude of the major "late aftershock" is of the same order with the magnitude of the largest normal aftershock but it can be smaller or larger.

\section{Dependence OF THE NUMBER OF AFTERShocks ON THE Manitude AND FOCAL DEPTH OF THE MAIN SHOCK}

It is known that the number of aftershocks increases as the magnitude of the main shock increases and depends also on the properties of the materials in the aftershock region and on the distribution of the applied stress. Since the properties of the material and distribution of stress change with depth it is reasonable to expect a dependence of the number of aftershocks on the focal depth of the main shock. Indeed, this number decreases with increasing depth.

An attempt is made here to find a tentative quantitative relation between the number of aftershock of $M \geqq 4$ and the magnitude and focal depth of the main shock. The accuracy of such anempirical relation depends on the accuracy of the focal depths and magnitudes, that are used to calculate the parameters of the relation and on the significance of the omitted terms on which the number of shocks also depend. Such terms depend on the horizontal variations of the properties of the material and the distribution of stress in the seismic region.

The method by which the focal depths and magnitudes were determined have been described previously. It is very difficult or even impossible to determine these quantities with accuracy. The best data that were at our disposal have been used for this purpose. Data were used only in cases when the depths determined from the times of several stations were distributed around one value with small scatter.

By the trial and error method the following two relations have been derived for depths between 14 and $40 \mathrm{~km}$ and between 41 and $70 \mathrm{~km}$ :

$$
\begin{array}{ll}
\log N_{o}=0.95 M-0.025 h-4.22 & 14 \leqq h \leqq 40 \mathrm{~km} \\
\log N_{\circ}=0.95 M-0.035 h-3.75 & 41 \leqq h \leqq 70 \mathrm{~km}
\end{array}
$$

where $N_{0}$ is the number of aftershocks with magnitude $I \geqq 4, M$ is the magnitude of the main shock and $h$ is the focal depth of the main shock 
in kilometers. The RMS error for both relations is \pm 0.13 . For focal depth smaller than about $14 \mathrm{~km}$ and larger than $70 \mathrm{~km}$ the number of aftershocks of $H \geqq t$ is very small. These two relations can be used to predict roughly the number of aftershocks with $I \geqq 4$. When the number of aftershocks and the magnitude of the main shock are known they can be used to determine roughly the depth of focus.

TIME DISTRIBUTION OF 'JHE AFTERSHOCKS IN THE AREA OF GREECE.

The number of aftershocks of $M \geqq t$ which occur after $t-1$ days after the main shock is given in each case by a relation of the form:

$$
N=N_{0} t^{-H} \quad t<t_{1},
$$

where $N_{0}$ is the total number of aftershocks of $Y \geq 4$ and $H$ is a constant. The mean values of $H$ for the cases of earthquake with considerable number of aftershocks is 0.40 with a standard deviation $上 0.12$. Since $H$ does not vary largely the following relation gives roughly the time distribution of the aftershocks of $M \geq 4$ in the region of Greece, when the magnitude and focal depth of the main shock allow the occurrence of a considerable number of aftershocks:

$$
N=N_{0}(H, h) t^{-0.40} \quad t<t_{1} .
$$

$N_{0}$ is given by [40] or [41] and $t$, varies between a few days and a few months.

DEIENDENCE OF THE MAGNITUDE OF THE LARGEST AFTERSHOCK ON THE MAGNITUDF AND FOCAL DEPTH OF THE MAIN SHOCK

The magnitude of the largest aftershock is plotted versus the magnitude of the main shock in Figure 45 for almost all the earthquakes with focal depth between about 14 and $55 \mathrm{~km}$ and magnitude $\mu \geqq 5^{3} / 4$ occurred from 1926 till 1964 in the region considered. The following relation was found between the magnitude $M_{1}$ of the largest aftershock and the magnitude of the main shock:

$$
M_{1}=1.07+0.71 \mu \text {. }
$$

There are listed twenty nine cases in Galanopoulos' tables when earthquakes with magnitudes between $5^{1 / 4}$ and $5^{3} / 4$ were followed by 
aftershocks. This data are also plotted in Figure 45 and are in agreement with the relation [4t]. There are, however, cases when earthquakes with magnitude between $5^{1 / 4}$ and $5^{3 / 4}$ are not followed by recorded aftershocks. It means that when [t+] is applied for this range of magnit ude it gives an estimation of the largest possible expected aftershock. The data taken from Galanopoulos' tables are listed in Table II.

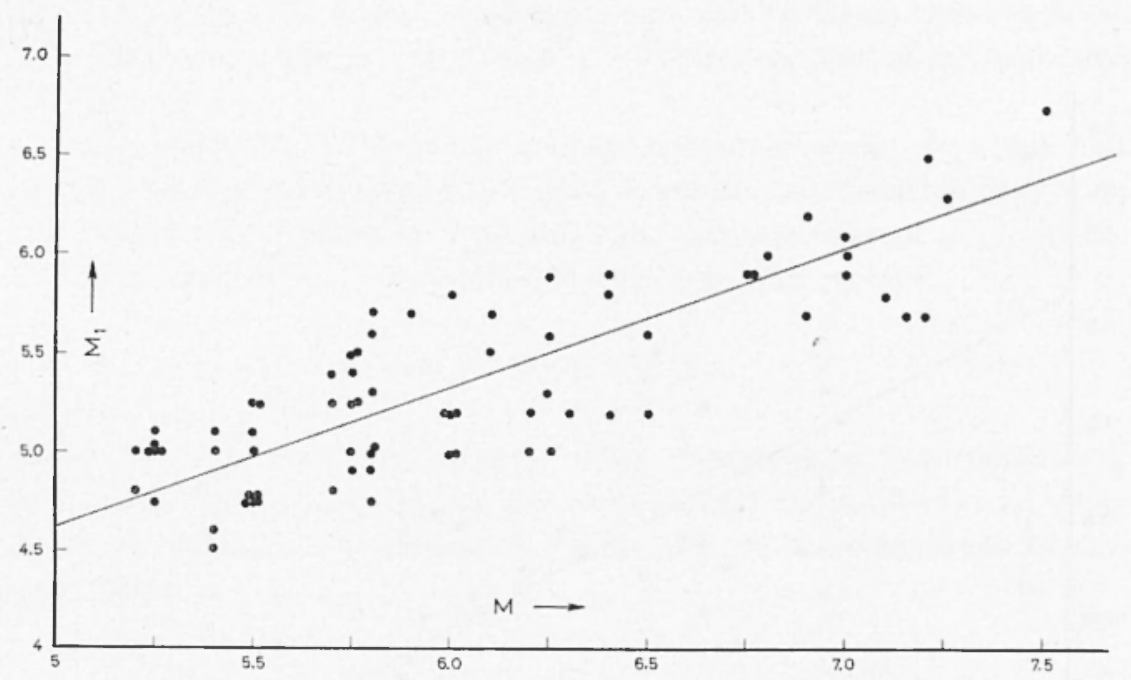

Fig. 45 - Dependence of the magnitude of the largest aftershock. II, on tho Magnitude of the main shock M.

The differenes of the observed values of $M_{1}$ from those calculated by the formula [44] were computed. It was found that these differences are large for very small foeal depth and decreases with depth up to about $15 \mathrm{~km}$. Then it increases gradually up to a depth of about $42 \mathrm{~km}$. At the depth of $42 \mathrm{~km}$ it decreases abruptly and after that it increases again gradually up to a depth of $70 \mathrm{~km}$. For depths larger than $70 \mathrm{~km}$ this difference is very large. Assuming that the rate of change of the magnitude of the largest aftershock with the magnitude of the main shock is independent of the depth, the following two tentative relations have been derived for depths between 15 and $42 \mathrm{~km}$ and between 42 and $70 \mathrm{~km}$ :

$$
\begin{array}{ll}
M_{1}=0.71 M-0.046 h+2.12 & 15 \leqq h \leqq 42 \\
M_{1}=0.71 M-0.068 h+4.53 & 42 \leqq h \leqq 70 .
\end{array}
$$


DISTRIBUTIO: OF MAGNITUDES OF FORESHOCKS AND AFTERSHOCKS IN THE AREA OF GREECE

The number $N$ of aftershocks which have magnitude equal to and larger than $\boldsymbol{M}$ are given by the:

$$
N=10^{a-b^{\prime} s} .
$$

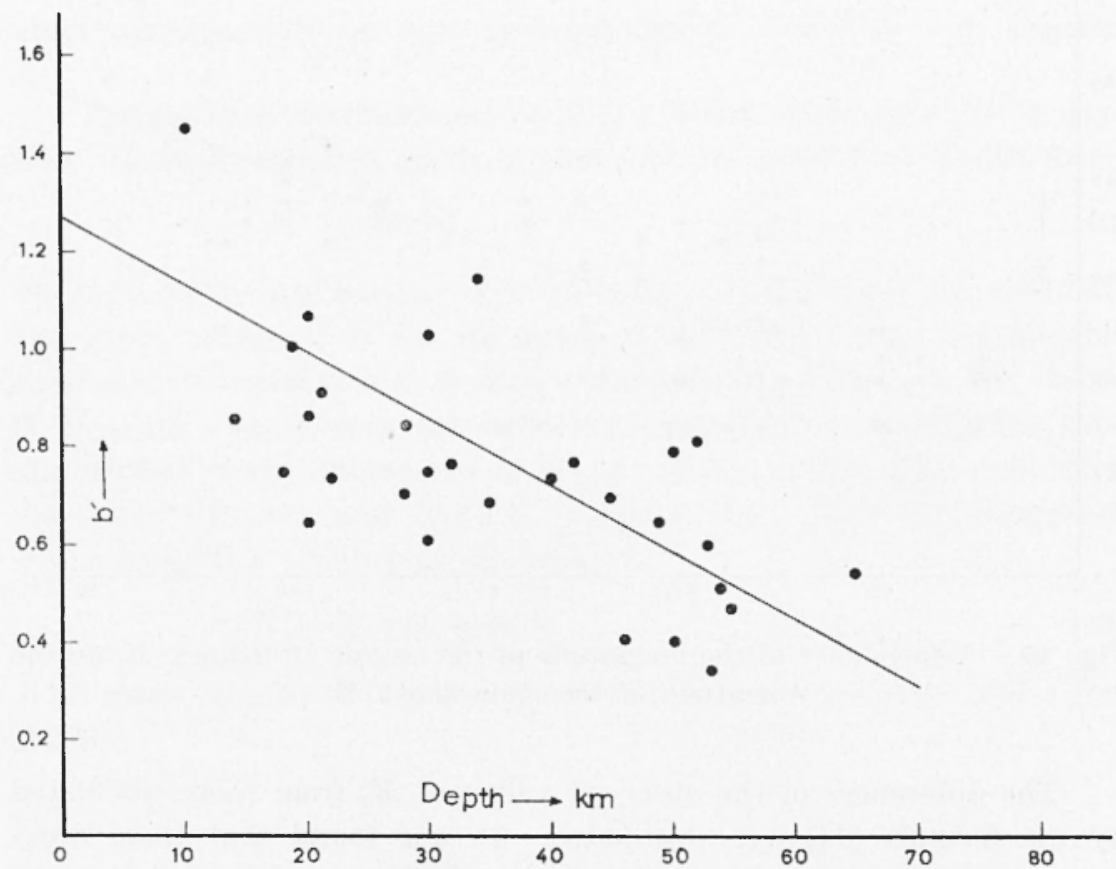

Fig. 46 - Dependence of the constant $b^{\prime}$ of the cumulative frequency function of the magnitude on the focal depth.

The values of the constant $b^{\prime}$ varies between 0.34 and 1.45 . These values are plotted versus focal depth of the main shock in Figure 46 . $A$ clear decerase of the constant $b^{\prime}$ with depth is observed. This dependence of $b^{\prime}$ on the depth $h$, can be very roughly expressed by:

$$
b^{\prime}=1.26-0.0135 h \quad 14<h<70 .
$$

The decrease in $b^{\prime}$ with depth can be interpreted, aceording to Mogi's experimental results, as an increase of homogeneity with depth. Galanopoulos $\left(^{3}\right)$ studied the distribution of the magnitudes of the shallow 
as well as the intermediate earthquakes in the area of Greece. He also found larger values for the constant $b^{\prime}$ in the case of shallow earthquakes $\left(b^{\prime}=0.82\right)$ than in the case of earthquakes with intermediate focal depth $\left(b^{\prime}=0.42\right)$.

Some decrease of heterogeneity with depth is reasonable. The constant $b^{\prime}$ can be used as measure of the variation of the homogeneity of the material with depth. Comparison of this variation between areas with different structure can probably lead to very usefull geotectonical results.

The scattering in Figure 46 is large and can probably be attributed not only to errors introduced in $b^{\prime}$ and $h$ but also to variation of $b^{\prime}$ with the geology of the different regions of the area considered.

If we put $M=t$ in the relation [4] we can receive:

$$
\alpha=4 b+\log N_{o}
$$

where $N_{0}$ is given by [40] or [41]. That means that the constant $\alpha$ of the relation [47] depends on the properties of the material and symmetry of stress in the aftershock regrion and on the magnitude of the main shock.

\section{Foreshocks.}

In the cases of the earthquakes with code numbers $3,5,11,15$, $17,18,21,22,23,24,25,26,27,31,32,34$ one or more foreshocks were observed. This means that $40 \%$ of the large shallow earthquakes are preceded by one or more foreshocks with magnitude $\boldsymbol{y} \geq 3.5$. In the cases of arthquakes with code numbers 17, 2627 and 32 large foreshocks with magnitudes not much smaller than the magnitude of the main shock occurred, $2.0,0.0,0.3$ and 14.5 days before the main shock. This means that when a large shallow earthquake occurs we must not exclude the possibility that this is not the main shock of the sequence and a larger earthquake may shortly follow. However, this probability is less than $10 \%$.

Data for studying the cumulative distribution of the magnitudes of the foreshorks were available in the cases of the arthquakes with code numbers 17,21 and 24 only. The values of the constant $b^{\prime}$ are $0.65,0.43$ and 0.55 , respectively. Their differences from the corresponding values of the aftershocks are $0.20,0.20$ and 0.10 . 
I) InCLission.

Values for the relaxation time could be found easily from the constant $\gamma$ of the relations of the form [12] in each case. However, by the method used above the data are smoothed first and the adopted value of the relaxation time for each secquence is the arithmetio mean of many values.

The formula $\eta=\tau \mu$, is valid for a Maxwell's body when $\varepsilon^{\prime}=0$, or for a Kelvin's body. Thus, the values found in this paper for $\eta$, are approximately right since neither the matelial of the crust and uppermost part of the mantle have the properties of Maxwell's or Kelvin's body, nor the conditions under which this formula is valid are entirely fulfilled.

The areuracy of formulas [40], [41], [45] and [46] which relate the number of aftershocks and the magnitude of the largest aftershock with the magnitude and focal depth of the main shock is not high. The reasons for that are party the errors introduced in calculating focal depths and magnitudes and the fact that terms depending only on these two quantities are not the only ones which determine the number of aftershocks and the magnitude of the largest aftershock. For example, horizontal variation of the properties of the material have an influence on the number of aftershocks and the magnitude of the largest after'shock.

Equation [43] is not valid when the focal depth is smaller than about $15 \mathrm{~km}$ or larger than about $50 \mathrm{~km}$. Even in the cases of focal depths between 15 and $50 \mathrm{~km}$ exceptions are possible. Such an exeeption is the sequence of the Amorgos earthquake of July 9, 1956. In this case $H=1.5$.

The values of $b^{\prime}$ have been calculated with $\Delta M=0.1$. Trials, however, with $\Delta M=1 /$ in miny cases shown that the influence of the choise of $\Delta M$ is not large in comparison with errors introduced from other rources.

The lack of considerable theoretical and laboratory work related to the problem of earthquake secquences, the difficulty to determine the space coordinates of the shocks, the difficulty to separate the small shocks of one sequence from individual small earthequakes and errors in measurements ale the main caluses of some weak points in this stiudy. 


\section{SUMmarT AND CONCLUSIONS.}

The foreshock and aftershock sequences of all the major shallow earthquakes $(I I \geqq 6, h \cong 70 \mathrm{~km})$ which ocrurred in the region of Greece from 1926 till 1964 have been investigated.

In studying the deformation characteristies of the aftershock sequences of these earthquakes the known phases, compressional and "shear", were observed in almost all cases, when the focal depth is between about 15 and $55 \mathrm{~km}$. In about $30 \%$ of the calses a thind phase was noticed. The most part of the encergy in this phase is released by the so called major "late aftershocks" which oceur from about one month up to some months after the main shock. There is evidence that the aftershock region of the large "late aftershocks" is elose to the aftershock region of the main shock but it is not entirely included in it. The mean relaxation time for the "shear phase" was found equal to 2.0 days. This gives a coefficient of riscosity equal to $10^{17} \mathrm{gr} / \mathrm{sec}-(\cdot \mathrm{m}$ in a depth of about $40 \mathrm{~km}$.

The largest aftershock of the "shear" phase which is usually the largest of all the aftershocks of the sequence oreurs between a few minutes up to fourteen days after the main shock and its magnitude $M_{\mathrm{b}}$ can be roughly predeceted by using the formula:

$$
I_{1}=1.07+0.71 \mathrm{M} \text {; }
$$

where $\boldsymbol{H}$, is the magnitude of the main shock. For a more aceurate prediction, knowledge of the depth of the focus is necessary. For constant magnitude of the main shock the magnitude of the largest aftershock has a maximum value in a deptlı of about $15 \mathrm{~km}$ and gradually decreases up to a depth of about $42 \mathrm{~km}$ where it increases abruptly and then it decreases gradually up to a depth of about $70 \mathrm{~km}$. For depths smaller than $15 \mathrm{~km}$ or larger than $70 \mathrm{~km}$ the magnitude of the largest aftershock is small. The magnitude of the major "late aftershock" is usually of the same order with the magnitude of the largest aftershock of the sequence but it can be smaller or larger than that.

The formula $N=N_{0}(I I, h) t^{-0.4}$ where $t<t_{1}$, deseribes roughly the time distribution of the aftershocks with $M \geqq 4$ when the magnitude and focal depth of the main shock is such that a considemble number of large aftershocks occur: $N$ is the number of aftershocks ( $I I \geq 4$ ) which oceur after $(t-1)$ days after the main shock: $N_{0}$ is the total number 
of aftershocks with $I I \equiv 4$, which depends on the magnitude and focal depths of the main shock. $N_{0}$ increases with magnitude. For constant magnitude, $N_{0}$ is the largest in a depth of about $15 \mathrm{~km}$ and it decreases up to the Mohorovicic diseontinuity. From the Mohorovicic discontinuity up to $70 \mathrm{~km}$ the rate of decrease of $N_{0}$ is larger. Below the depth of about $70 \mathrm{~km}$ and above the depth of about $15 \mathrm{~km}$ the number of aftershocks with $I \geqq t$ is very small: $t_{1}$ varies between a few days up to a few months.

A decrease of the constant $b^{\prime}$ of the cumblative frequency function of the magnitude with depth was observed. This is interpreted as an increase of the homogeneity of the material with depth.

The main shocks were preceded by one or more foreshorks in 16 cases. This means that $40^{\circ}$; of the largi shallow earthquakes are preceded by one or more foreshocks of magnitude $I I \doteq 3 . \breve{s}$. The earthquakes which have foreshocks do not originate from certain regions but their epicenters are distributed all over the area considered. Data for studying the cumulative dist ribution of the magnitudes of the foreshocks were a railable in three (aises only. It was found that in all three cases the constant $b^{\prime}$ of the foreshorks is smaller than that of the aftershocks of the same sequence. The mean value of this difference is approximately 0.2 .

It can be generally concluded that: studies on foreshock and aftershock sequences ean give information about some properties of the material (homogeneity, viscosity, etc.) and the distribution of stress in the aftershock region. Combination of observational, experimental and theoretical work on problems related with foreshock and aftershock sequences could turn out to be one of the powerful methods for studying the anatomy and physiology of the crust and uppermost part of the mantle and may contribute to the problem of earthquake prediction.

\section{ACKNowledGeneNts.}

The research reported in this document has been sponsored by the Air Force Office of Scientific Research under Contract AF 61 (052)303 through the European Office of Aerospace Researeh (OAR) United States Air Force, as part of the Advanced Research Projects Agrency's Projeet VELA-UNIFORM.

The authors would like to express their sincere thanks to Professor Dr. A. G. Galanopoulos and to Professor Dr. T. Utsu for reading critically the manuscript of this paper. 
Table I - THe large siallow earthquakes occurred in the region of GREECE FROM 1926 TILL 1964.

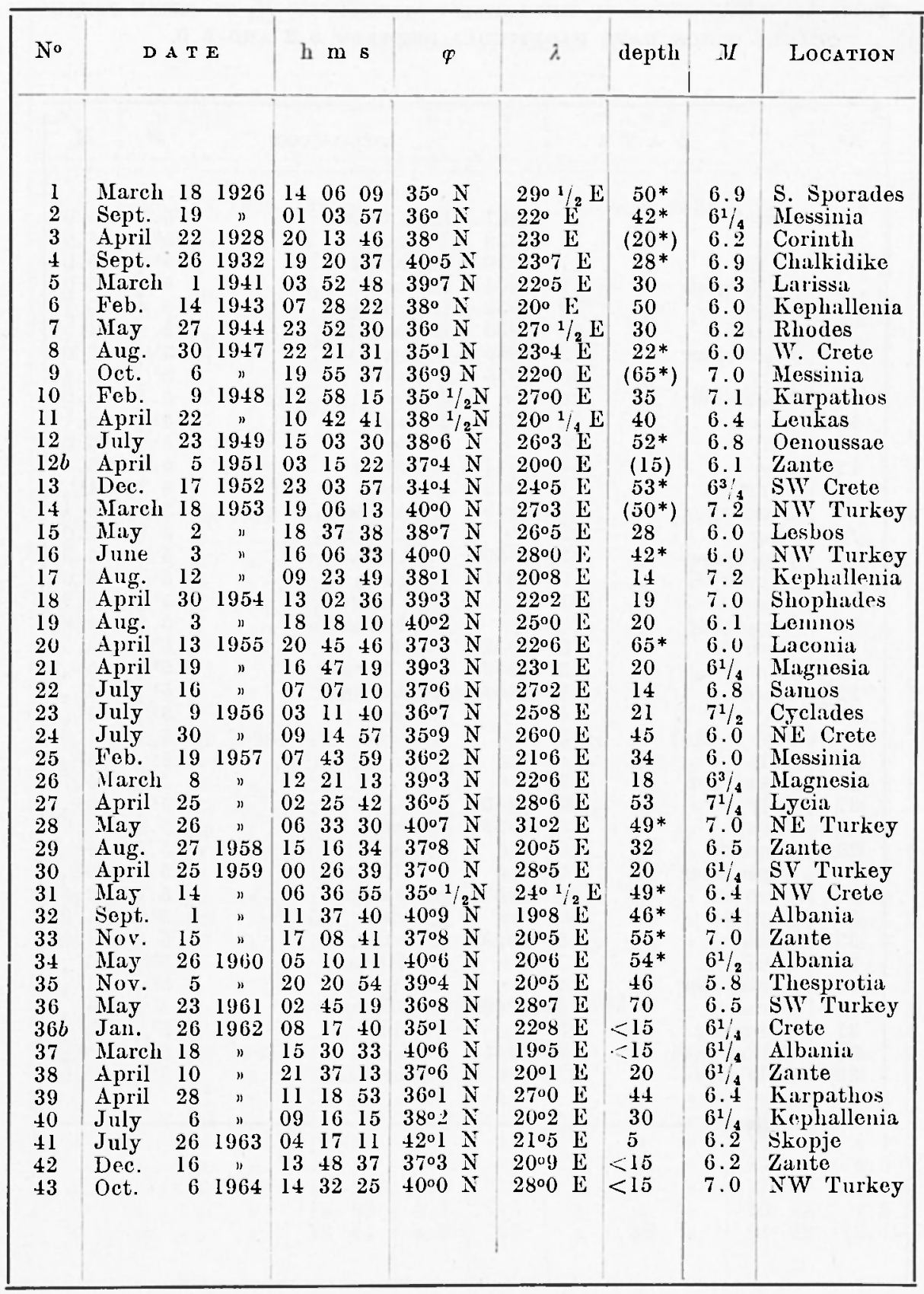




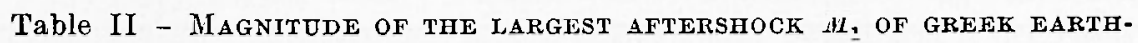
QUAKES WHICH HAVE MAGNITUDES BETWEEN 5.2 AND 6.0.

\begin{tabular}{|c|c|c|c|c|c|c|}
\hline No & \multicolumn{3}{|c|}{$D$ A $T E$} & LOCATION & $M$ & $M I_{1}$ \\
\hline 1 & March & 24 & 1927 & East Crete & 5.5 & 5.0 \\
\hline 2 & March & 3 & 1928 & Astypalaea & $5^{3} / 4$ & 5.0 \\
\hline 3 & April & 17 & 1930 & Corinthia & $53 / 4$ & 5.0 \\
\hline 4 & September & 11 & 1931 & Euboea & $51 / 4$ & 5.0 \\
\hline 5 & June & 29 & 1932 & Karpathos & 5.4 & 5.1 \\
\hline 6 & March & 22 & 1933 & Kephallenia & 5.4 & 4.5 \\
\hline 7 & September & 3 & 1935 & Thesprotia & $5^{1 / 4}$ & 5.0 \\
\hline 8 & July & 20 & 1938 & Attica & $53 / 4$ & 5.4 \\
\hline 9 & December & 26 & $"$ & Zante & 5.4 & 5.0 \\
\hline 10 & May & 31 & 1939 & Achaia & $5^{1 / 4}$ & 5.1 \\
\hline 11 & July & 28 & $"$ & Crete & $51 / 4$ & 5.0 \\
\hline 12 & May & 14 & 1941 & Magnesia & 5.7 & 5.4 \\
\hline 13 & June & 1 & 1942 & Larissa & 5.3 & $4^{3} / 4$ \\
\hline 14 & January & 7 & 1943 & Kephallenia & 5.5 & 5.1 \\
\hline 15 & May & 22 & $"$ & Kephallenia & 5.2 & 5.0 \\
\hline 16 & September & 23 & 1950 & SE Crete & 5.8 & 5.3 \\
\hline 17 & January & 9 & 1951 & Leukas & $5^{1 / 4}$ & 5.0 \\
\hline 18 & August & 31 & $"$ & NW Crete & $5^{3 / 4}$ & 5.6 \\
\hline 19 & December & 20 & $"$ & Kephallenia & 5.2 & 4.8 \\
\hline 20 & October & 5 & 1952 & Zante & $5^{3} / 4$ & 4.5 \\
\hline 21 & June & 3 & 1953 & NW Turkey & $5^{3 / 4}$ & $5^{1 / 4}$ \\
\hline 22 & March & 9 & 1954 & Kephallenia & $5^{1 / 2} / 2$ & $4^{3} / 4$ \\
\hline 23 & May & 1 & $"$ & Samos & $5^{1 / 2}$ & $4^{3} / 4$ \\
\hline 24 & May & 3 & $"$ & Messinia & 5.4 & 4.6 \\
\hline 25 & July & 18 & " & Elis & $5^{1 / 2}$ & $4^{3} / 4$ \\
\hline 26 & December & 23 & $"$ & Elis & 5.9 & 5.7 \\
\hline 27 & July & 9 & 1955 & Pelle & $5^{1 / 2}$ & $5^{3} / 4$ \\
\hline 28 & May & 18 & 1956 & Larissa & 5.8 & 5.0 \\
\hline 29 & August & 16 & $》$ & Messinia & 5.5 & $5^{3 / 4}$ \\
\hline 30 & September & 6 & $"$ & NE Crete & 5.7 & $5^{1} / 4$ \\
\hline 31 & October & 30 & 1957 & Karpathos & 5.7 & 4.8 \\
\hline 32 & October & 30 & $"$ & Rhodes & $5^{3 / 4}$ & 4.9 \\
\hline 33 & January & 2 & 1958 & Laconia & 5.8 & 4.9 \\
\hline 34 & April & 3 & $"$ & W Albania & $5^{3} / 4$ & $5^{1 / 4}$ \\
\hline 35 & September & 4 & $"$ & Astypalaea & $5^{1 / 2}$ & $4^{3} / 4$ \\
\hline 36 & January & 1 & 1960 & Asia Minor & $5^{1} / 4$ & $4^{3} / 4$ \\
\hline 37 & February & 23 & $"$ & Preveza & $5^{1 / 2}$ & $5^{1} / 4$ \\
\hline 38 & January & 19 & 1961 & Phokis & 5.5 & $5^{1 / 4}$ \\
\hline 39 & February & 23 & $"$ & Dodecanisa & $5^{1 / 4}$ & 5.0 \\
\hline
\end{tabular}


Table III - AfTershocks and Foreshochs of the large enRTHQUakes WHICH OCCURRED IN THE REGION OF GREECE FROM 1926 TILL 1964.

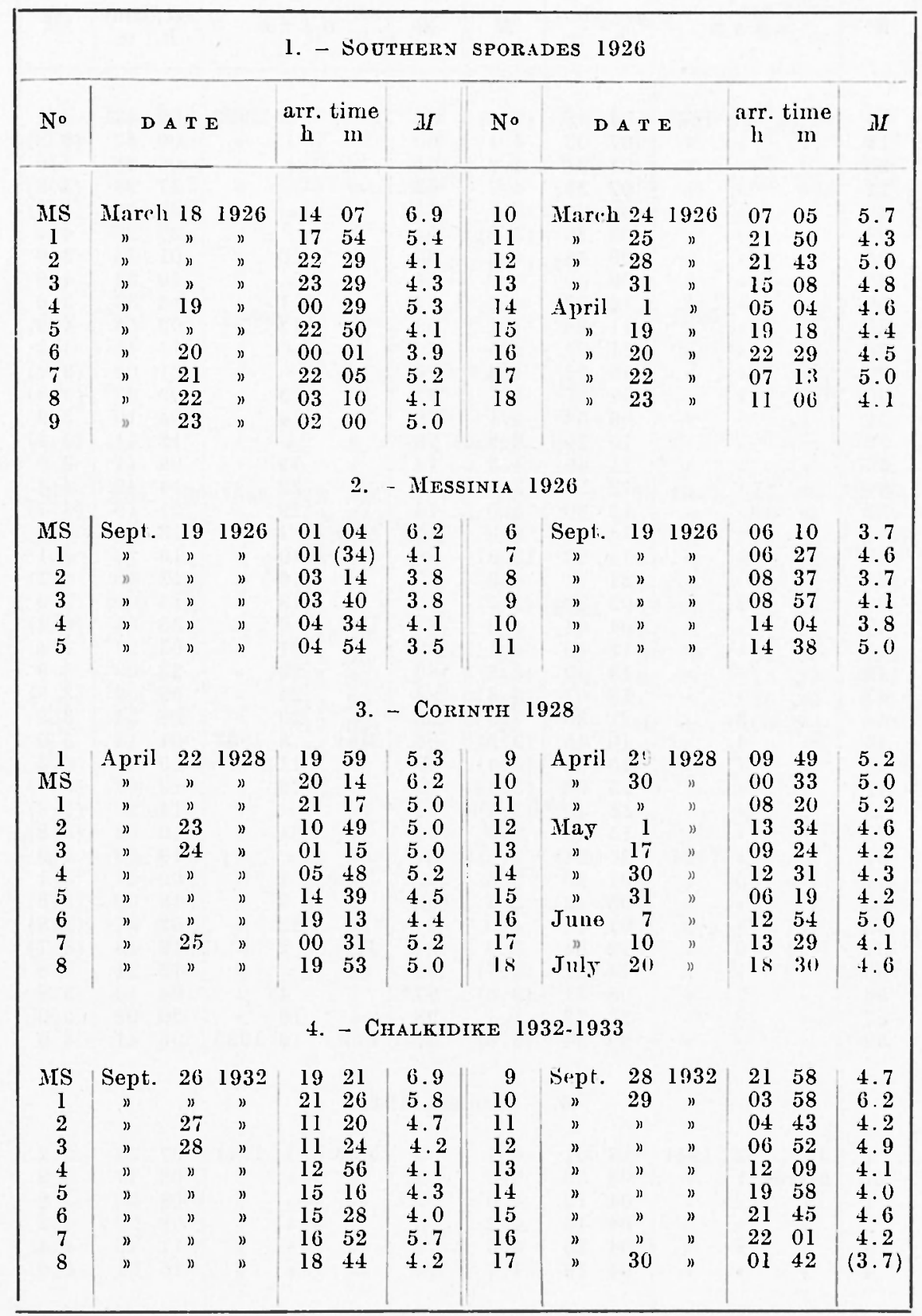


68 B. PAPAZACHOS - N. DELIBASIS S. HAPIS G, MOUMOULJDIS - G. PURCARU

Table III - (continued)

\begin{tabular}{|c|c|c|c|c|c|c|c|c|c|c|c|c|c|}
\hline \multirow{2}{*}{$\begin{array}{l}\text { No } \\
18\end{array}$} & \multicolumn{3}{|c|}{$D A T E$} & \multicolumn{2}{|c|}{$\begin{array}{l}\text { arr. time } \\
\mathrm{h}\end{array}$} &.$I$ & No & \multicolumn{3}{|c|}{$\mathrm{D} A \mathrm{TE}$} & \multicolumn{2}{|c|}{$\underset{\mathrm{h}}{\operatorname{arr}} \mathrm{m}$} & $M$ \\
\hline & Sept. & 30 & 1932 & 03 & 58 & $(3.8)$ & 59 & $0: t$. & 9 & 1932 & 00 & 44 & 4.1 \\
\hline 19 & $"$ & $n$ & $"$ & 07 & 03 & 4.1 & 60 & $"$ & $n$ & ” & 00 & 57 & $(3.8)$ \\
\hline 20 & D & $"$ & $"$ & 07 & 31 & 4.8 & 61 & ” & $n$ & ” & 06 & 25 & 5.0 \\
\hline 21 & $"$ & 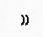 & $"$ & 07 & 39 & 4.7 & 62 & $"$ & $"$ & 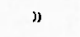 & 11 & 38 & $(3.8)$ \\
\hline 22 & $"$ & ") & $"$ & 08 & 00 & 3.9 & 63 & $"$ & $"$ & p & 22 & 18 & $(3.8)$ \\
\hline 23 & ” & $"$ & " & 08 & 23 & $(3.8)$ & $6 \pm$ & $"$ & $"$ & $"$ & 22 & 29 & 4.4 \\
\hline 24 & ” & $n$ & $"$ & 09 & 48 & 4.2 & 65 & ” & 10 & $"$ & 01 & 34 & 3.9 \\
\hline 25 & $"$ & $n$ & 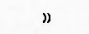 & 09 & 50 & 4.2 & 66 & $"$ & $n$ & 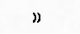 & 10 & 32 & 4.0 \\
\hline 26 & " & $"$ & $"$ & 10 & 52 & 4.0 & 67 & $n$ & 11 & $"$ & 12 & 57 & 3.8 \\
\hline 27 & " & ") & $"$ & 11 & 38 & 4.1 & 68 & 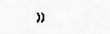 & 12 & $"$ & 02 & 59 & 4.9 \\
\hline 28 & D & $n$ & $n$ & 11 & 59 & 4.5 & 69 & 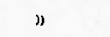 & $n$ & $"$ & 11 & 45 & 4.3 \\
\hline 29 & $"$ & $"$ & $"$ & 19 & 32 & 4.4 & 70 & 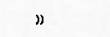 & $n$ & $"$ & 21 & 09 & $(3.7)$ \\
\hline 30 & Oct. & I & $n$ & 07 & 41 & 4.1 & 71 & 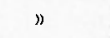 & 13 & " & 00 & 22 & $(3.8)$ \\
\hline 31 & $"$ & $"$ & $"$ & 08 & 08 & 5.1 & 72 & $"$ & 14 & $"$ & 04 & 10 & 3.9 \\
\hline 32 & " & 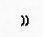 & $"$ & 10 & 29 & 3.9 & 73 & $"$ & $n$ & $"$ & 12 & 41 & $(3.4)$ \\
\hline 33 & » & $"$ & $"$ & 11 & 49 & 4.3 & 74 & D & 19 & $"$ & 09 & 41 & 3.9 \\
\hline 34 & " & $n$ & $"$ & 12 & 53 & $(3.7)$ & 75 & $"$ & 22 & $"$ & 14 & 49 & 4.4 \\
\hline 35 & 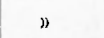 & $"$ & $n$ & 13 & 36 & 5.0 & 76 & ” & 29 & $”$ & 21 & 19 & $(3.7)$ \\
\hline 36 & " & $n$ & ” & 14 & 09 & 3.9 & 77 & Nov. & 1 & $"$ & 16 & 20 & 5.6 \\
\hline 37 & 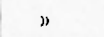 & $"$ & $n$ & 14 & 22 & $(3.8)$ & 78 & $"$ & 10 & $"$ & 19 & 22 & 4.1 \\
\hline 38 & $n$ & $"$ & $"$ & 21 & 11 & 4.3 & 79 & $"$ & 16 & $"$ & 13 & 45 & 4.1 \\
\hline 39 & " & 2 & " & 03 & 29 & $(3.7)$ & 80 & $"$ & 19 & $"$ & 14 & $(00)$ & 3.9 \\
\hline 40 & D & $"$ & ” & 04 & $0 t$ & 4.2 & 81 & Dec. & 9 & $"$ & 30 & 34 & $(3.4)$ \\
\hline 41 & ” & $n$ & D & 12 & 40 & 4.1 & 82 & $"$ & 21 & $"$ & 03 & 27 & 4.4 \\
\hline 42 & $n$ & $n$ & ” & 13 & 49 & $(3.8)$ & 83 & $"$ & 23 & $"$ & 23 & 03 & 3.9 \\
\hline 43 & $"$ & $"$ & $"$ & 18 & 07 & $(3.8)$ & 84 & $"$ & 24 & $"$ & 09 & 09 & $(3.8)$ \\
\hline 44 & $"$ & 3 & $"$ & 21 & 30 & 3.9 & 85 & $"$ & 29 & $"$ & 08 & 54 & 3.9 \\
\hline 45 & ” & 4 & $"$ & 10 & 45 & $(3.5)$ & 86 & May & 8 & 1933 & 01 & 14 & 5.0 \\
\hline 46 & ") & $"$ & $"$ & 15 & 00 & $(3.4)$ & 87 & נ) & 11 & $n$ & 19 & 10 & 6.3 \\
\hline 47 & $n$ & $"$ & " & 15 & 03 & $(3.4)$ & 88 & $"$ & 12 & $"$ & 12 & 54 & $(3.8)$ \\
\hline 48 & n & $"$ & 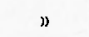 & 15 & 40 & $(3.4)$ & 89 & $n$ & $"$ & $"$ & 14 & 20 & $(3.8)$ \\
\hline 49 & $n$ & $"$ & » & 15 & 46 & 3.9 & 90 & $"$ & 31 & $"$ & 19 & 53 & $(3.8)$ \\
\hline 50 & $n$ & $"$ & $n$ & 20 & 24 & $(3.5)$ & 91 & ” & $n$ & $"$ & 19 & 56 & 4.9 \\
\hline 51 & " & 5 & $\nu$ & 01 & 10 & 3.6 & 92 & June & 1 & " & 02 & 41 & 5.1 \\
\hline 15 & " & $"$ & $"$ & 05 & 42 & 3.8 & 93 & $"$ & 3 & $"$ & 18 & 00 & $(3.6)$ \\
\hline 53 & $"$ & " & 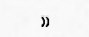 & 07 & 11 & 4.0 & 94 & $"$ & 22 & $"$ & 02 & 57 & $(3.8)$ \\
\hline 54 & $"$ & 6 & 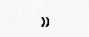 & 12 & 54 & 3.9 & 95 & July & 2 & " & 12 & 18 & $(3.7)$ \\
\hline 55 & " & $"$ & $"$ & 14 & 31 & $(3.7)$ & 96 & ") & $"$ & $"$ & 12 & 21 & 4.8 \\
\hline 56 & $"$ & 7 & $"$ & 08 & 51 & $(3.6)$ & 97 & $"$ & 4 & $"$ & 04 & 19 & 3.9 \\
\hline 57 & D & 8 & $n$ & 23 & 33 & 4.1 & 98 & ") & 19 & " & 20 & 09 & 5.0 \\
\hline 58 & $"$ & $"$ & $"$ & 23 & 34 & $(3.8)$ & 99 & Feb. & 18 & 1935 & 06 & 41 & 4.8 \\
\hline & & & & & & $-L$ & A & & & & & & \\
\hline 1 & Jan. & 2 & 1941 & 18 & 01 & 4.1 & 5 & Mar: h & 1 & 1941 & 07 & 53 & 5.2 \\
\hline MS & March & I & $"$ & 03 & 53 & 6.3 & 6 & $"$ & $n$ & $"$ & 08 & 17 & 3.9 \\
\hline 1 & " & $"$ & $n$ & 04 & 12 & 4.0 & 7 & " & $"$ & $"$ & 08 & 30 & 3.9 \\
\hline 2 & " & $"$ & נ & 04 & 16 & 4.2 & 8 & $”$ & $n$ & $"$ & 09 & 29 & 4.2 \\
\hline 3 & " & 》) & $"$ & 04 & 13 & 4.5 & 9 & ” & $"$ & $"$ & 11 & 46 & 4.4 \\
\hline 4 & $"$ & » & " & 04 & 19 & 4.7 & 10 & $"$ & $"$ & " & 15 & 01 & 5.0 \\
\hline
\end{tabular}


Table III - (continued)

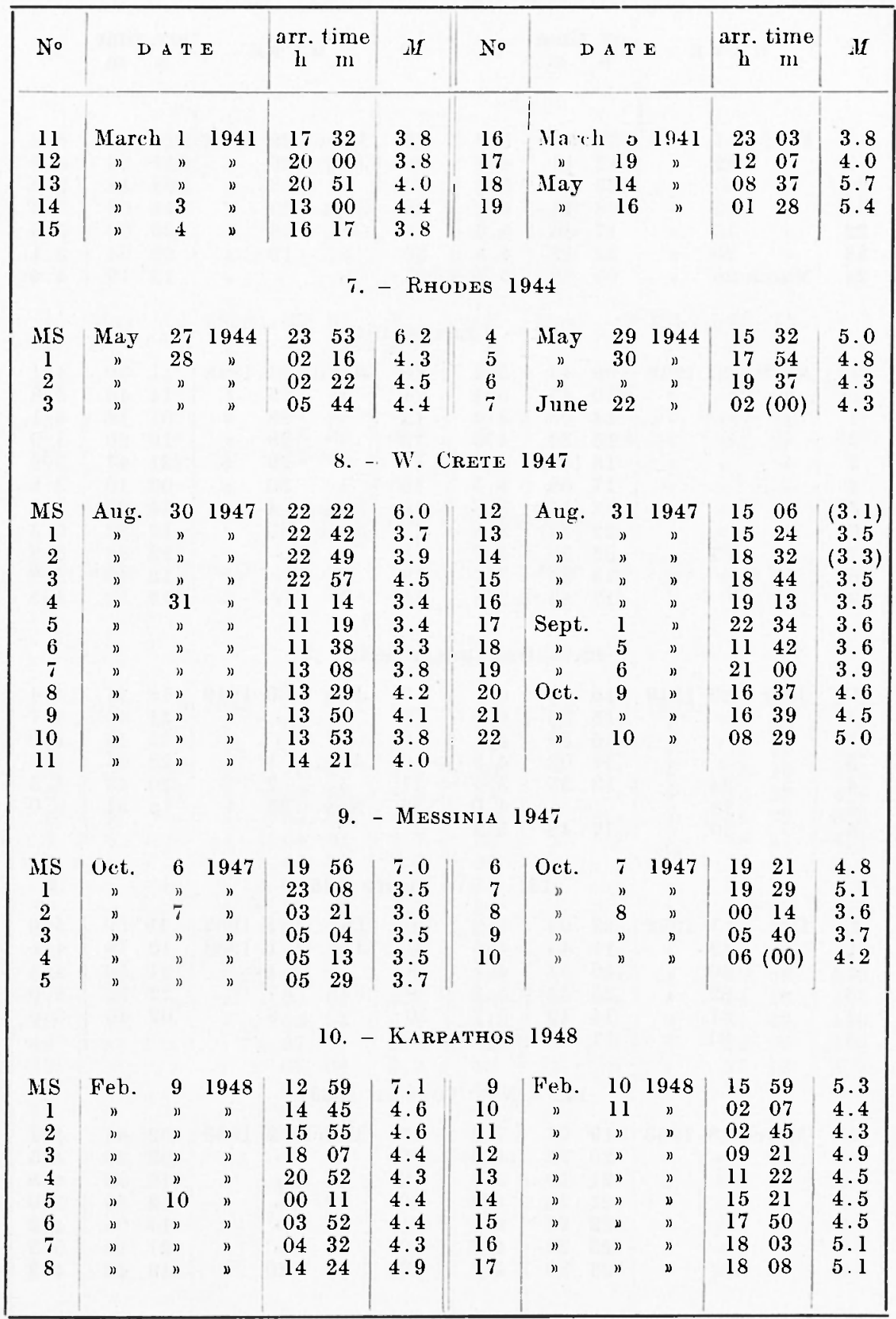


Table III - (continued)

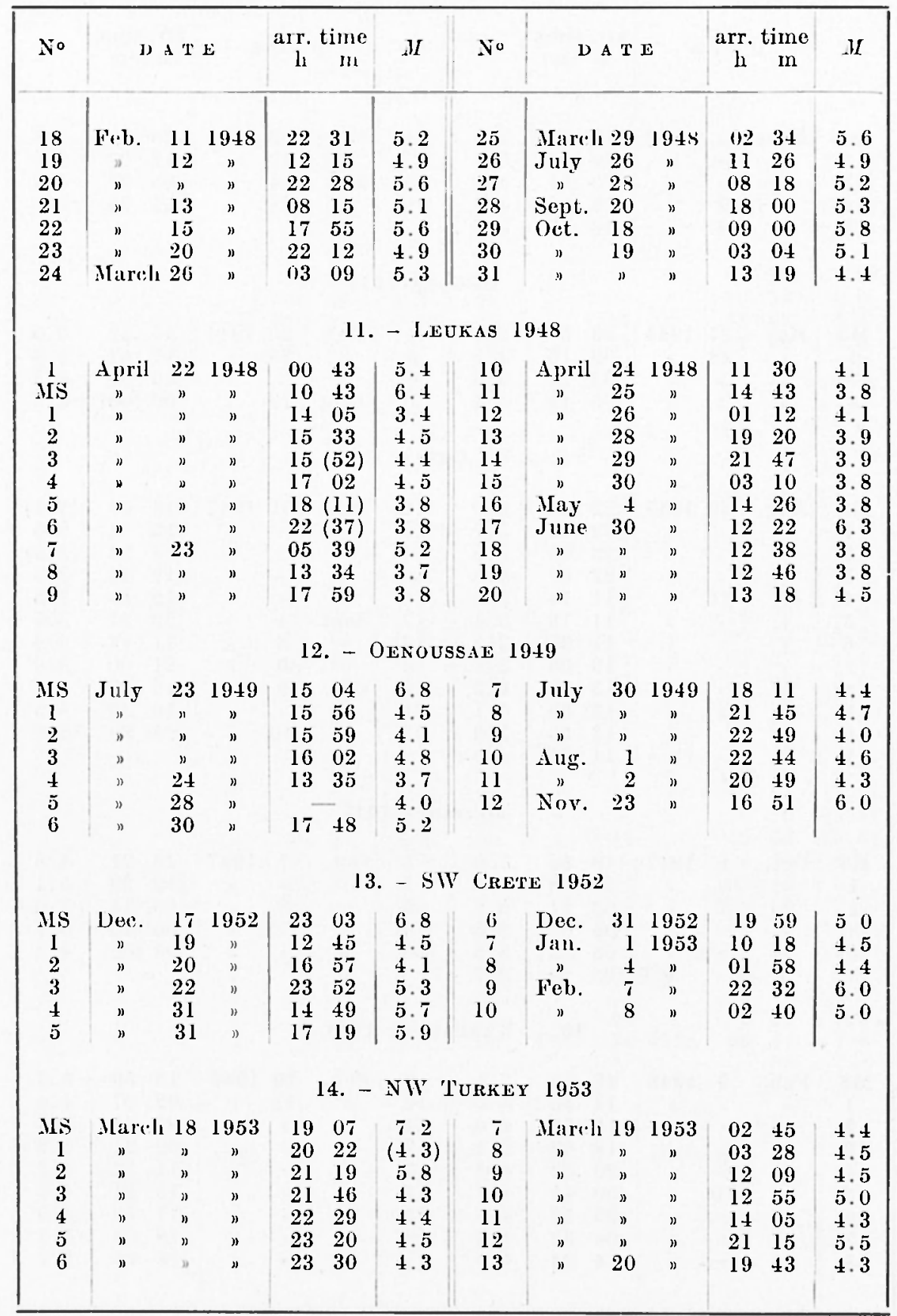


Table III - (continued)

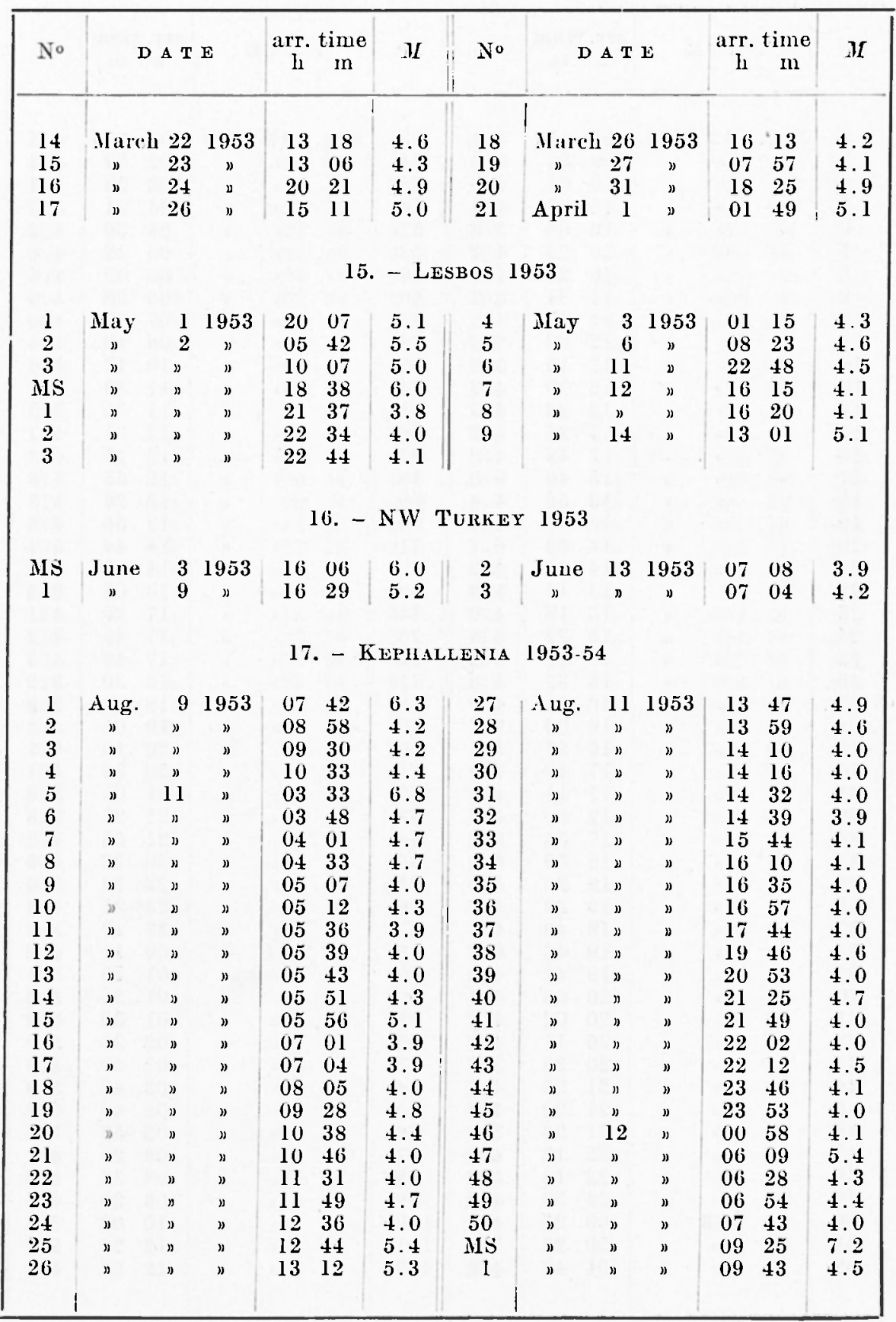




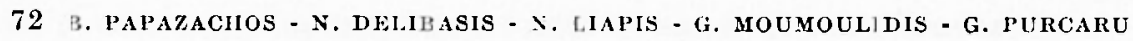

Table III - (continued)

\begin{tabular}{|c|c|c|c|c|c|c|c|c|c|c|c|c|c|}
\hline $\mathrm{No}^{\circ}$ & \multicolumn{3}{|c|}{ D A T E } & \multicolumn{2}{|c|}{$\begin{array}{l}\text { arr. time } \\
\mathrm{h} \mathrm{m}\end{array}$} & $M$ & No & \multicolumn{3}{|c|}{$D \Delta T E$} & \multicolumn{2}{|c|}{$\begin{array}{c}\operatorname{arr} \text { time } \\
\text { a }\end{array}$} & $M$ \\
\hline 2 & Aug. & 12 & 1953 & 09 & 51 & 4.4 & 53 & Aug. & 13 & 1953 & 02 & 15 & 4.3 \\
\hline 3 & $n$ & $n$ & $\eta$ & 09 & 56 & 4.3 & 54 & " & " & נ) & 02 & 58 & 4.3 \\
\hline 4 & $D$ & $"$ & נ & 10 & 05 & 4.0 & 55 & $n$ & $n$ & 》 & 03 & 23 & 5.7 \\
\hline 5 & $n$ & $"$ & נ & 10 & 07 & 4.5 & 56 & " & $"$ & " & 04 & 21 & 4.3 \\
\hline 6 & y & $n$ & $n$ & 10 & 08 & 5.6 & 57 & נ) & $"$ & $n$ & 04 & 50 & 4.2 \\
\hline 7 & $n$ & $"$ & $\pi$ & 10 & 23 & 4. 4 & 58 & $"$ & $"$ & $n$ & 05 & 13 & 4.6 \\
\hline 8 & $n$ & $"$ & $n$ & 10 & 25 & 4. 7 & 59 & $n$ & $"$ & ” & 06 & 02 & 4.4 \\
\hline 9 & $"$ & $"$ & ) & 11 & 34 & 5.7 & 60 & ") & $"$ & $"$ & 06 & 29 & 4.0 \\
\hline 10 & $"$ & $"$ & $n$ & 11 & 47 & 4. 6 & 61 & $"$ & $"$ & $"$ & 07 & 03 & 4.0 \\
\hline 11 & $n$ & $n$ & $"$ & 12 & 06 & 6.5 & 62 & 》) & $"$ & " & 08 & 16 & 4.4 \\
\hline 12 & $"$ & $"$ & 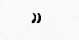 & 12 & 15 & 5.0 & 63 & " & $"$ & $"$ & 10 & 17 & 5.6 \\
\hline 13 & " & $"$ & $"$ & 12 & 19 & 4.9 & 64 & " & $"$ & 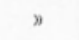 & 11 & 33 & 4.1 \\
\hline 14 & ") & $n$ & $n$ & 12 & 25 & 4. 3 & 65 & ” & $"$ & ” & 11 & 59 & 3.9 \\
\hline 15 & $n$ & $"$ & $n$ & 12 & 26 & 4.3 & 66 & $"$ & $"$ & " & 12 & 01 & 4.7 \\
\hline 16 & $n$ & $"$ & $n$ & 12 & 49 & 4.6 & 67 & ” & $"$ & ” & 12 & 17 & 4.2 \\
\hline 17 & $n$ & " & $n$ & 13 & 40 & 6.0 & 18 & $"$ & $"$ & ” & 12 & 57 & 4.6 \\
\hline 18 & $n$ & $"$ & $n$ & 13 & 52 & 4. 4 & 69 & ") & $"$ & נ & 13 & 26 & 4.5 \\
\hline 19 & $n$ & $"$ & $n$ & 13 & 56 & 4. 3 & 70 & ") & $"$ & b & 13 & 50 & 4.6 \\
\hline 20 & $n$ & $"$ & 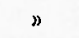 & 14 & 09 & 6.1 & 71 & ” & $"$ & $"$ & 14 & 44 & 5.4 \\
\hline 21 & $n$ & $"$ & $n$ & 14 & 37 & 4.2 & 72 & $n$ & $"$ & ” & 14 & 52 & 4.0 \\
\hline 22 & $n$ & $"$ & $n$ & 15 & 11 & 4.8 & 73 & ”) & ” & 》 & 16 & 05 & 3.9 \\
\hline 23 & $n$ & $"$ & ") & 15 & 18 & 4. 0 & 74 & נ) & $n$ & נ) & 17 & 20 & 4.1 \\
\hline 24 & $n$ & " & 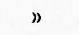 & 15 & 22 & 4. 8 & 75 & ) & $n$ & " & 17 & 48 & 4.2 \\
\hline 25 & $n$ & $n$ & $n$ & 15 & 28 & 4. 0 & 76 & ” & " & $"$ & 17 & 48 & 4.3 \\
\hline 26 & ) & $"$ & $"$ & 15 & 37 & 4.0 & 77 & ) & " & $"$ & 18 & 20 & 3.9 \\
\hline 27 & $n$ & » & " & 16 & 02 & 4.0 & 78 & $n$ & $"$ & " & 18 & 40 & 3.9 \\
\hline 28 & " & " & " & 16 & 09 & 5.7 & 79 & $n$ & $"$ & ” & 19 & 05 & 4.3 \\
\hline 29 & $"$ & נ & $n$ & 16 & 27 & 4. 6 & 80 & $n$ & $"$ & $"$ & 20 & 10 & 4.7 \\
\hline 30 & $n$ & נ & $n$ & 17 & 10 & 4.8 & 81 & $n$ & $"$ & $"$ & 20 & 28 & 4.1 \\
\hline 31 & $n$ & נ" & $n$ & 17 & 11 & 4.1 & 82 & $"$ & ” & ” & 21 & 03 & 3.8 \\
\hline 32 & $"$ & $"$ & $"$ & 17 & 50 & 4.2 & 83 & \#) & $n$ & $n$ & 21 & 27 & 3.8 \\
\hline 33 & $n$ & $"$ & $"$ & 17 & 54 & 5. 1 & 84 & $n$ & " & 》 & 21 & 56 & 4.2 \\
\hline 34 & $n$ & " & $n$ & 18 & 59 & 4.4 & 85 & $n$ & » & 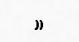 & 22 & 32 & 4.0 \\
\hline 35 & $"$ & n & $"$ & 19 & 20 & 4.3 & $85 \mathrm{~b}$ & ") & $"$ & ” & 22 & 32 & 4.0 \\
\hline 36 & $"$ & ” & $n$ & 19 & 29 & 4.6 & 86 & $n$ & » & ” & 23 & 21 & 4.2 \\
\hline 37 & $"$ & $"$ & $"$ & 19 & 43 & 4.3 & 87 & ") & ” & " & 23 & 47 & 3.8 \\
\hline 38 & $"$ & $\pi$ & $n$ & 19 & 46 & 5.2 & 88 & $"$ & 14 & $"$ & 00 & 17 & 4.0 \\
\hline 39 & $"$ & $n$ & $"$ & 19 & 48 & 4.8 & 89 & $n$ & $"$ & $"$ & 01 & 10 & 4.1 \\
\hline 40 & $"$ & $n$ & $"$ & 20 & 05 & 4.3 & 90 & $"$ & $"$ & $"$ & 01 & 24 & 5.2 \\
\hline 41 & " & $n$ & $"$ & 20 & 06 & 4.0 & 91 & " & $"$ & ” & 01 & 30 & 4.9 \\
\hline 42 & $n$ & n & $"$ & 20 & 11 & 4.0 & 92 & n & $"$ & $n$ & 02 & 35 & 3.9 \\
\hline 43 & ” & " & $"$ & 20 & 38 & 3.9 & 93 & " & " & $"$ & 03 & 43 & 3.9 \\
\hline 44 & $"$ & $n$ & $"$ & 21 & 05 & 4.0 & 94 & n & ” & $n$ & 03 & 43 & 3.8 \\
\hline 45 & $"$ & $n$ & $"$ & 21 & 22 & 4.3 & 95 & $n$ & $"$ & נ) & 05 & 43 & 3.8 \\
\hline 46 & " & $"$ & $"$ & 21 & 36 & 3.9 & 96 & $n$ & ” & " & 05 & 52 & 3.8 \\
\hline 47 & " & $n$ & $"$ & 22 & 13 & 4.0 & 97 & $n$ & » & $n$ & 08 & 26 & 4.1 \\
\hline 48 & $"$ & $"$ & " & 22 & 18 & 5. 3 & 98 & $n$ & " & $"$ & 08 & $\mathbf{3 3}$ & 4.3 \\
\hline 49 & ” & $n$ & " & 22 & 39 & 4.0 & 99 & $n$ & $n$ & $n$ & 09 & 20 & 4.4 \\
\hline 50 & " & 13 & $n$ & 00 & 23 & 4.0 & 100 & $"$ & » & $"$ & 10 & 03 & 3.8 \\
\hline 51 & ” & $n$ & $n$ & 00 & 29 & 3.9 & 101 & " & $"$ & $"$ & 12 & 20 & 3.9 \\
\hline 52 & D & $n$ & $"$ & 01 & 49 & 4.9 & 102 & " & נ) & $"$ & 12 & 23 & 4.0 \\
\hline
\end{tabular}


Table III - (continued)

\begin{tabular}{|c|c|c|c|c|c|c|c|c|c|c|c|c|c|}
\hline $\mathrm{N}^{\circ}$ & D & $A \mathrm{~T}$ & & $\underset{\mathrm{h}}{\operatorname{air} .}$ & ine & $M$ & No & & $\mathrm{A} T$ & & $\underset{\mathrm{h}}{\operatorname{arr} .}$ & $\operatorname{tin}_{\text {III }}$ & $M$ \\
\hline 103 & Aug. & 14 & 1953 & 12 & 28 & 4.0 & 154 & Aug. & 17 & 1953 & 11 & +47 & 3.6 \\
\hline 104 & $n$ & $"$ & $"$ & 16 & 20 & 4.0 & 155 & $"$ & $"$ & ") & 12 & 13 & 3.6 \\
\hline 105 & ” & ") & $"$ & 16 & 47 & 3.8 & 156 & $n$ & $"$ & " & 12 & 38 & 3.9 \\
\hline 106 & ” & $n$ & $"$ & 21 & 37 & 4.4 & 157 & $"$ & נ & 》 & 14 & 52 & 4.2 \\
\hline 107 & ” & $n$ & 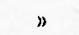 & 22 & 32 & 4.6 & 158 & $"$ & $"$ & $"$ & 15 & 02 & 4.4 \\
\hline 108 & D & 11 & ” & 22 & 42 & 4.4 & 159 & $n$ & $"$ & ” & 20 & 32 & 3.9 \\
\hline 109 & $"$ & 15 & $"$ & 02 & 10 & 3.9 & 160 & " & " & $"$ & 21 & 49 & 3.9 \\
\hline 110 & $"$ & n & $"$ & 02 & 38 & 3.8 & 161 & " & " & $"$ & 23 & 14 & 3.9 \\
\hline 111 & $"$ & 1 & $"$ & 02 & 49 & 4.0 & 162 & " & 18 & $"$ & 04 & 56 & 4.5 \\
\hline 112 & $"$ & " & $"$ & 03 & 50 & 4.5 & 163 & $n$ & $"$ & " & 09 & 40 & 3.8 \\
\hline 113 & נ) & $"$ & ” & 04 & 28 & 4.3 & 164 & $n$ & $"$ & $n$ & 11 & 51 & 4.1 \\
\hline 114 & נ) & $"$ & $"$ & 04 & 42 & 4.0 & 165 & $n$ & $n$ & $"$ & 12 & 09 & 3.9 \\
\hline 115 & " & " & ” & 07 & 05 & 4.0 & 166 & $n$ & $n$ & $"$ & 12 & 38 & 3.8 \\
\hline 116 & ") & " & $"$ & 07 & 28 & 3.8 & 167 & $n$ & " & ” & 12 & 45 & 3.9 \\
\hline 117 & 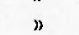 & ") & 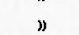 & 08 & 20 & 4.0 & 168 & $"$ & $"$ & " & 14 & 39 & +.0 \\
\hline 118 & n & " & $"$ & 09 & 41 & 4.6 & 169 & " & " & ” & 20 & 29 & 4.3 \\
\hline 119 & $"$ & $n$ & " & 09 & 51 & 3.9 & 170 & " & $"$ & $"$ & 20 & 31 & 3.8 \\
\hline 120 & $"$ & $"$ & $"$ & 11 & 47 & 4.0 & 171 & $"$ & $"$ & $"$ & 21 & 13 & 3.8 \\
\hline 121 & $"$ & $"$ & 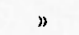 & 12 & 15 & 4.0 & 172 & $"$ & $"$ & $"$ & 22 & 44 & 5.0 \\
\hline 122 & ") & $m$ & " & 14 & 20 & 3.6 & 173 & ") & 19 & " & 00 & 55 & 4.9 \\
\hline 123 & " & $"$ & " & 14 & 37 & 4.0 & 174 & $"$ & " & ” & 01 & 13 & 4.2 \\
\hline 124 & ” & " & $"$ & 15 & 49 & 4.0 & 175 & ") & $n$ & $"$ & 01 & 41 & 3.6 \\
\hline 125 & " & " & $"$ & 22 & 16 & 3.9 & 176 & $"$ & נ & $"$ & 02 & 16 & 4.3 \\
\hline 126 & $"$ & $n$ & $n$ & 23 & 02 & 4.5 & 177 & $"$ & " & $"$ & 02 & 17 & 4.3 \\
\hline 127 & n & $"$ & $n$ & 23 & 31 & 3.8 & 178 & $"$ & ") & $"$ & 03 & 18 & 5.0 \\
\hline 128 & $n$ & " & נ) & 23 & 33 & 4.9 & 179 & $"$ & ") & $"$ & 03 & 48 & 3.6 \\
\hline 129 & $"$ & 16 & $"$ & 02 & 50 & 3.8 & 180 & $"$ & ” & \# & 04 & 05 & 4.3 \\
\hline 130 & $\eta$ & $"$ & ” & 03 & 18 & 3.8 & 181 & $"$ & נ) & $"$ & 08 & 01 & 4.5 \\
\hline 131 & ") & $"$ & $\eta$ & 03 & 31 & 5.0 & 182 & $"$ & " & $"$ & 08 & 31 & 3.9 \\
\hline 132 & 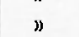 & $"$ & נ) & 09 & 13 & 4.1 & 183 & $"$ & $"$ & $"$ & 09 & 25 & 3.9 \\
\hline 133 & $"$ & $"$ & " & 18 & 40 & 4.0 & 184 & $"$ & $"$ & " & 11 & 02 & 4.0 \\
\hline 134 & $"$ & $"$ & $"$ & 19 & 16 & 3.9 & 185 & $"$ & $"$ & ") & 11 & 04 & 4.4 \\
\hline 135 & $"$ & $"$ & $"$ & 21 & 23 & 3.8 & 186 & $"$ & ") & נ & 11 & 37 & 4.0 \\
\hline 136 & $"$ & $"$ & $"$ & 21 & 45 & 4.1 & 187 & $"$ & ) & נ & 11 & 49 & 4.1 \\
\hline 137 & $"$ & $"$ & $"$ & 21 & 47 & 4.6 & 188 & " & " & נ" & 13 & 19 & 4.3 \\
\hline 138 & $"$ & " & $"$ & 22 & 16 & 4.2 & 189 & $n$ & " & $"$ & 14 & 21 & 3.9 \\
\hline 139 & ") & נ) & $"$ & 22 & 20 & 4.6 & 190 & $n$ & ») & " & 16 & 17 & 4.2 \\
\hline 140 & $"$ & 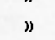 & " & 23 & 37 & 4.3 & 191 & ") & נ) & $\Rightarrow$ & 16 & 30 & 3.9 \\
\hline 141 & $"$ & $"$ & $"$ & 23 & 42 & 4.3 & 192 & $"$ & ") & " & 16 & 59 & 3.8 \\
\hline 142 & $"$ & 17 & $"$ & 00 & 03 & 4.1 & 193 & $"$ & " & $"$ & 19 & 36 & 4.6 \\
\hline 143 & $"$ & $"$ & $"$ & 00 & 13 & 3.9 & 194 & $"$ & נ) & $"$ & 19 & 38 & 4.6 \\
\hline 144 & $n$ & " & $"$ & 00 & 25 & 4.9 & 195 & " & ) & ") & 21 & 21 & 3.6 \\
\hline 145 & $"$ & $"$ & $"$ & 02 & 13 & 5.3 & 196 & $"$ & נ) & $"$ & 23 & 11 & 4.6 \\
\hline 146 & $"$ & ” & $"$ & 02 & 45 & 4.6 & 197 & $"$ & " & $"$ & 00 & 54 & 3.6 \\
\hline 147 & $"$ & $"$ & $"$ & 03 & 36 & 4.0 & 198 & ") & ” & $n$ & 01 & 29 & 3.6 \\
\hline 148 & $"$ & $"$ & " & 04 & 15 & 3.8 & 199 & " & 20 & $"$ & 04 & 40 & 3.7 \\
\hline 149 & $"$ & " & " & 09 & 07 & 4.0 & 200 & $"$ & $"$ & $n$ & 04 & 56 & 4.4 \\
\hline 150 & $"$ & " & נ) & 10 & 21 & 5.0 & 201 & $"$ & $"$ & " & 05 & 07 & 3.8 \\
\hline 151 & $"$ & נ & ") & 10 & 43 & 4.0 & 202 & $n$ & " & " & 08 & 06 & 4.4 \\
\hline 152 & $"$ & $"$ & ") & 10 & 57 & 3.9 & 203 & $"$ & " & $"$ & 09 & 09 & 4.0 \\
\hline 153 & $"$ & $"$ & 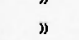 & 11 & 41 & 4.0 & 204 & $"$ & $"$ & $"$ & 11 & 14 & 3.8 \\
\hline
\end{tabular}


74 B. PAPAZACHOS - S. 1)ELIBASIS - S. LIAPIS - G. MOUMUULIDIS - G. PURCARt

Table III - (continued)

\begin{tabular}{|c|c|c|c|c|c|c|c|c|c|c|c|c|c|}
\hline No & & $\mathbf{A} \mathbf{T}$ & & $\underset{\mathrm{h}}{\operatorname{arr}}$ & $\operatorname{tim}_{\mathbf{m}}$ & II & No & & $A^{2}$ & & $\underset{\mathrm{h}}{\operatorname{arr} .}$ & time & II \\
\hline 205 & Iug. & 20 & 1953 & 15 & 29 & 4.3 & 256 & Sept. & 3 & 1953 & 12 & 05 & 4.2 \\
\hline 206 & $"$ & $"$ & " & 19 & 15 & 4.5 & 257 & " & " & ") & 12 & 28 & 4.7 \\
\hline 207 & " & $"$ & $"$ & 19 & 28 & 5.3 & 258 & " & 4 & " & 21 & 42 & 4.6 \\
\hline 208 & $"$ & $"$ & $"$ & 19 & 35 & 4.6 & 259 & 1) & ” & $"$ & 22 & 32 & 4.5 \\
\hline 209 & $n$ & 21 & $"$ & 06 & 42 & 4.1 & 260 & $"$ & 5 & n & 08 & 42 & 4.9 \\
\hline 210 & $"$ & $"$ & " & 18 & 35 & 4.2 & 261 & $n$ & $"$ & " & 21 & 20 & 4.8 \\
\hline 211 & " & 22 & $"$ & 01 & 21 & 5.1 & 262 & $"$ & 6 & " & 05 & 15 & 4.2 \\
\hline 212 & $n$ & $"$ & $"$ & 03 & 11 & 4.6 & 263 & $n$ & $"$ & $n$ & 20 & 59 & 4.1 \\
\hline 213 & 》 & $n$ & "n & 05 & 48 & 4.1 & 264 & $"$ & 7 & "1 & 01 & 00 & 4.3 \\
\hline 214 & n & $"$ & $"$ & 12 & 03 & 4.3 & 265 & " & $"$ & " & 07 & 33 & 5.0 \\
\hline 215 & ” & » & $n$ & 14 & 15 & 4.4 & 266 & $"$ & ” & $"$ & 18 & 02 & 4.2 \\
\hline 216 & ” & $"$ & $n$ & 18 & 38 & 4.0 & 267 & " & $"$ & $n$ & 22 & 21 & 4.2 \\
\hline 217 & $"$ & 23 & $"$ & 02 & 29 & 4.5 & 268 & $"$ & 8 & " & 08 & 33 & 4.1 \\
\hline 218 & " & $"$ & $"$ & 02 & 35 & 3.6 & 269 & $n$ & $"$ & $"$ & 09 & 02 & 4.1 \\
\hline 219 & " & ” & $"$ & 03 & 25 & 4.8 & 270 & » & $"$ & $"$ & 11 & 53 & 5.2 \\
\hline 220 & $"$ & $"$ & $"$ & 08 & 42 & 4.0 & 271 & ” & ” & $"$ & 14 & 27 & 4.4 \\
\hline 221 & ” & $"$ & $"$ & 08 & 59 & 4.3 & 272 & " & 9 & $"$ & 01 & 51 & 3.6 \\
\hline 222 & $"$ & $"$ & $"$ & 09 & 59 & 4.1 & 273 & ” & $"$ & » & 04 & 18 & 4.3 \\
\hline 223 & » & $"$ & " & 10 & 39 & 4.0 & 274 & $"$ & $n$ & " & 10 & 20 & 3.8 \\
\hline 224 & a & $"$ & $n$ & 10 & 40 & 4.0 & 275 & $"$ & 10 & $"$ & 01 & 32 & 3.8 \\
\hline 225 & ” & $"$ & $"$ & 11 & 27 & 3.8 & 276 & $n$ & $"$ & ” & 03 & 54 & 4.0 \\
\hline 226 & $"$ & $n$ & $"$ & 11 & 59 & 3.9 & 277 & $"$ & $"$ & " & 12 & 41 & 3.6 \\
\hline 227 & $"$ & $"$ & $"$ & 12 & 00 & 4.0 & 278 & $"$ & $"$ & " & 13 & 14 & 3.9 \\
\hline 228 & $"$ & 1) & $"$ & 14 & 02 & 4.5 & 279 & $"$ & 12 & ") & 01 & 21 & 3.8 \\
\hline 229 & " & 24 & $n$ & 02 & 22 & 5.2 & 280 & $"$ & $n$ & D & 03 & 06 & 4.4 \\
\hline 230 & " & $"$ & $"$ & 08 & 26 & 4.5 & 281 & $"$ & " & ” & 08 & 35 & 4.3 \\
\hline 231 & $"$ & " & $"$ & 12 & 34 & 4.3 & 282 & D & 13 & $n$ & 06 & 09 & 4.3 \\
\hline 232 & ॥ & 25 & $"$ & 00 & 30 & 4.1 & 283 & $"$ & $n$ & $"$ & 15 & 39 & 4.2 \\
\hline 233 & " & " & $"$ & 05 & 20 & 3.8 & 284 & נ & 14 & » & 02 & 36 & 3.6 \\
\hline 234 & " & $"$ & $"$ & 06 & 44 & 4.7 & 285 & $"$ & $"$ & ” & 03 & 21 & 3.9 \\
\hline 235 & " & $n$ & $"$ & 09 & 58 & 4.3 & 286 & $"$ & " & $"$ & 11 & 24 & 4.0 \\
\hline 236 & $"$ & $"$ & $"$ & 12 & 04 & 3.7 & 287 & $"$ & $"$ & » & 14 & 57 & 5.9 \\
\hline 237 & ״ & $"$ & $"$ & 17 & 03 & 3.9 & 288 & ” & " & » & 16 & 15 & 5.0 \\
\hline 238 & D & $"$ & ” & 18 & 55 & 4.0 & 289 & $"$ & $"$ & ) & 17 & 02 & 4.3 \\
\hline 239 & \# & " & ” & 19 & 15 & 4.0 & 290 & $"$ & $"$ & ” & 17 & 18 & 4.6 \\
\hline 240 & $"$ & 26 & $"$ & 11 & 41 & 3.6 & 291 & " & " & " & 19 & 12 & 4.1 \\
\hline 241 & » & 27 & $"$ & 19 & 35 & 5.4 & 292 & ") & 15 & ") & 09 & 20 & 3.7 \\
\hline 242 & " & 28 & " & 04 & 14 & 4.5 & 293 & $"$ & $"$ & ” & 09 & 24 & 4.5 \\
\hline 243 & נ) & $"$ & $"$ & 12 & 03 & 3.6 & 294 & $"$ & $"$ & $"$ & 11 & 35 & 5.0 \\
\hline 244 & ") & $"$ & » & 12 & 36 & 3.7 & 295 & 》 & 》 & 》 & 11 & 39 & 5.6 \\
\hline 245 & נ" & $"$ & $"$ & 20 & 40 & 5.2 & 296 & $"$ & $"$ & $"$ & 13 & 03 & 3.8 \\
\hline 246 & $"$ & $"$ & $"$ & 23 & 43 & 4.5 & 297 & " & $"$ & " & 13 & 10 & 3.8 \\
\hline 247 & $"$ & 29 & " & 03 & 48 & 4.0 & 298 & $"$ & $n$ & $"$ & 15 & 41 & 4.4 \\
\hline 248 & $"$ & $"$ & $"$ & 10 & 00 & 4.0 & 299 & " & 16 & " & 12 & 05 & 5.3 \\
\hline 249 & " & 30 & $"$ & 07 & 20 & 4.0 & 300 & " & $"$ & " & 12 & 08 & 4.9 \\
\hline 250 & ״ & $"$ & ” & 10 & 23 & 3.8 & 301 & " & 17 & $n$ & 18 & 30 & 4.5 \\
\hline 251 & Sept. & 1 & ") & 11 & 27 & 3.9 & 302 & $"$ & 18 & $"$ & 05 & 49 & 4.0 \\
\hline 252 & 11 & $"$ & $"$ & 20 & 11 & 5.3 & 303 & $"$ & 20 & $"$ & 22 & 11 & 4.5 \\
\hline 253 & $"$ & 2 & $"$ & 19 & 11 & 4.3 & 304 & $n$ & 21 & " & 04 & 40 & 4.2 \\
\hline 254 & נ) & $"$ & 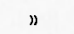 & 19 & 19 & 4.2 & 305 & $"$ & $"$ & ” & 15 & 39 & 3.9 \\
\hline 255 & " & $"$ & » & 21 & 23 & 4.6 & 306 & ” & $"$ & $n$ & 18 & 54 & 4.0 \\
\hline
\end{tabular}


Table III - (continued)

\begin{tabular}{|c|c|c|c|c|c|c|c|c|c|c|c|c|c|}
\hline \multirow{2}{*}{$\begin{array}{l}\text { No } \\
307\end{array}$} & \multicolumn{3}{|c|}{$D A T E$} & \multicolumn{2}{|c|}{$\begin{array}{l}\text { arr. time } \\
h\end{array}$} & $M$ & $\mathrm{No}^{\circ}$ & \multicolumn{3}{|c|}{$\mathrm{DATE}$} & \multicolumn{2}{|c|}{$\begin{array}{l}\operatorname{arr} \text { time } \\
\mathrm{m}\end{array}$} & II \\
\hline & Sept. & 22 & 1953 & 02 & 15 & 4.0 & 358 & Oct. & 21 & 1953 & I I & 32 & 5.6 \\
\hline 308 & $n$ & $"$ & $n$ & 19 & 07 & 3.6 & 359 & " & $"$ & $n$ & 12 & 26 & 4.5 \\
\hline 309 & $"$ & $"$ & $"$ & 20 & 46 & 3.8 & 360 & $n$ & $"$ & " & 12 & 46 & 5.0 \\
\hline 310 & $"$ & 23 & " & 00 & 08 & 3.9 & 361 & i) & $"$ & $"$ & 16 & 31 & 4.8 \\
\hline 311 & " & $n$ & $n$ & 20 & 30 & 4.1 & 362 & " & " & "D & 18 & 41 & 6.5 \\
\hline 312 & $"$ & 24 & $"$ & 07 & 07 & 4.1 & 363 & $"$ & » & ") & 22 & 13 & 4.0 \\
\hline 313 & $"$ & $n$ & $"$ & 16 & 04 & 3.8 & 364 & " & $"$ & 2) & 22 & 16 & 4.5 \\
\hline 314 & " & 25 & $"$ & 05 & 12 & 3.8 & 365 & " & $"$ & $"$ & 22 & 50 & 4.2 \\
\hline 315 & $"$ & $"$ & $"$ & 17 & 21 & 5.1 & 366 & $"$ & " & $"$ & 22 & 54 & 4.0 \\
\hline 316 & $"$ & $n$ & $"$ & 17 & 49 & 4.2 & 367 & $"$ & $"$ & $" 1$ & 23 & 26 & 4.1 \\
\hline 317 & $n$ & 27 & $"$ & 09 & 30 & 4.7 & 368 & $"$ & $"$ & $"$ & 23 & 45 & 5.3 \\
\hline 318 & $n$ & 28 & $n$ & 08 & 50 & 4.0 & 369 & $"$ & 22 & $"$ & 01 & 50 & 4.3 \\
\hline 319 & $n$ & 30 & $"$ & 07 & 07 & 3.9 & 370 & $n$ & $"$ & " & 06 & 48 & 3.9 \\
\hline 320 & Oct. & 1 & $\eta$ & 05 & 54 & 4.4 & $37 \mathrm{l}$ & " & $"$ & $"$ & 07 & 03 & 4.8 \\
\hline 321 & D" & 2 & $"$ & 06 & 33 & 4.3 & 372 & " & 24 & $"$ & 14 & 22 & 4. I \\
\hline 322 & $"$ & $"$ & $"$ & 09 & 58 & 4.0 & 373 & " & 25 & $"$ & 16 & 55 & 4.4 \\
\hline 323 & $"$ & 3 & $"$ & 19 & 18 & 4.0 & 374 & $"$ & 26 & $"$ & 00 & 11 & 3.8 \\
\hline 324 & 1) & 5 & $"$ & 12 & 18 & 4.4 & 375 & $"$ & $"$ & » & 08 & 21 & 3.6 \\
\hline 325 & $"$ & " & $"$ & 23 & 14 & 3.8 & 376 & $"$ & $"$ & $"$ & 11 & 56 & 4.0 \\
\hline 326 & " & 6 & $n$ & 02 & 41 & 4.2 & 377 & $"$ & $"$ & "1 & 16 & 06 & 4.6 \\
\hline 327 & 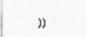 & $"$ & $"$ & 04 & 01 & 3.6 & 378 & $"$ & $"$ & 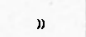 & 16 & 41 & 4.8 \\
\hline 328 & " & " & $"$ & 11 & 15 & 4.0 & 379 & ") & 27 & $"$ & 01 & 05 & 3.7 \\
\hline 329 & ” & $"$ & $"$ & 17 & 05 & 4.8 & 380 & $n$ & $"$ & " & 03 & 18 & 3.6 \\
\hline 330 & $"$ & 7 & $n$ & 07 & 18 & 4.0 & 381 & $"$ & $"$ & ") & 03 & 30 & 4.1 \\
\hline 331 & $"$ & $"$ & $"$ & 10 & 54 & 4.0 & 382 & $"$ & $"$ & $"$ & 11 & 51 & 4.0 \\
\hline 332 & " & 8 & $n$ & 21 & 25 & 4.4 & 383 & $"$ & 28 & $"$ & 05 & 12 & 4.0 \\
\hline 333 & ") & 9 & 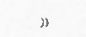 & 02 & 31 & 4.1 & 384 & " & 30 & $n$ & 06 & 54 & 4.2 \\
\hline 334 & $"$ & $"$ & $"$ & 17 & 32 & 5.0 & 385 & " & 31 & " & 10 & 01 & 3.9 \\
\hline 335 & " & 10 & " & I I & 19 & 3.9 & 386 & Nov. & 1 & $"$ & 12 & 33 & 4.0 \\
\hline 336 & $"$ & $"$ & $"$ & 21 & 30 & 5.8 & 387 & $"$ & 2 & $"$ & 14 & 02 & 4.5 \\
\hline 337 & $"$ & ") & " & 21 & 45 & 4.2 & 388 & " & 3 & $"$ & 11 & 39 & 4.0 \\
\hline 338 & $"$ & $"$ & D & 21 & 48 & 3.9 & 389 & " & » & $\eta$ & 22 & 30 & 5.5 \\
\hline 339 & \% & $"$ & " & 22 & 23 & 4.0 & 390 & $n$ & 4 & $"$ & 21 & 43 & 4.5 \\
\hline 340 & $"$ & II & $"$ & 00 & 15 & 5.3 & 391 & $"$ & 5 & $"$ & 19 & 46 & 4.2 \\
\hline 341 & ") & $"$ & ” & 01 & 04 & 4.1 & 392 & n & 7 & " & 09 & 19 & 4.8 \\
\hline 342 & $"$ & 12 & $"$ & 11 & 33 & 4.5 & 393 & " & 8 & $"$ & 01 & 13 & 5.0 \\
\hline 343 & " & 13 & " & 03 & 58 & 4.0 & 394 & $"$ & $"$ & $"$ & 01 & 44 & 3.8 \\
\hline 344 & $"$ & " & $"$ & 13 & 29 & 4.1 & 395 & $"$ & $"$ & $"$ & 02 & 51 & 4. 0 \\
\hline 345 & ") & It & " & 11 & 40 & 3.6 & 396 & " & $"$ & $"$ & 03 & 02 & 4. 0 \\
\hline 346 & $"$ & " & $"$ & 14 & 23 & 3.9 & 397 & $n$ & $"$ & ") & 12 & 28 & 3.9 \\
\hline 347 & " & $1 \tilde{\jmath}$ & $"$ & 13 & 58 & 3.6 & 398 & $n$ & " & " & 13 & 38 & 4.1 \\
\hline 348 & $"$ & " & " & 17 & 59 & 4.1 & 399 & 》 & 10 & $"$ & 03 & 10 & 4.4 \\
\hline 349 & " & $"$ & " & 23 & 40 & 3.6 & 400 & $"$ & $"$ & $"$ & 13 & 07 & 4.5 \\
\hline 350 & " & 16 & $n$ & 12 & 27 & 3.7 & 401 & $n$ & 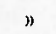 & $"$ & 23 & 07 & 4.6 \\
\hline 351 & $"$ & $"$ & $"$ & 14 & 28 & 4.1 & 402 & $"$ & 15 & $"$ & 04 & 30 & 3.9 \\
\hline 352 & " & $"$ & $"$ & 21 & 45 & 5.2 & 403 & $"$ & 16 & ") & 04 & 51 & 3.9 \\
\hline 353 & $"$ & " & $"$ & 23 & 04 & 4.1 & 404 & $"$ & $"$ & $»$ & 09 & 18 & 4.1 \\
\hline 354 & " & 17 & $"$ & 00 & 55 & 3.7 & 405 & " & $"$ & $"$ & 17 & 26 & 4.3 \\
\hline 355 & $"$ & 19 & $"$ & 18 & $5 \mathrm{I}$ & 4.0 & 406 & $n$ & $"$ & $"$ & 20 & 12 & 4.1 \\
\hline 356 & $"$ & 20 & $"$ & 04 & 41 & 4.8 & 407 & " & 18 & $"$ & 15 & 21 & 4.9 \\
\hline 357 & $"$ & $"$ & . & 12 & 26 & 4.0 & 408 & " & 20 & ” & 19 & 15 & 5.3 \\
\hline
\end{tabular}


76 B. PAPAZACIIOS - N. DELIBASIS - N. LIAPIS - G. MUUMOULIDIS - G. PURGarU

Table III - (continued)

\begin{tabular}{|c|c|c|c|c|c|c|c|c|c|c|c|c|c|}
\hline No & \multicolumn{3}{|c|}{$D A T E$} & \multicolumn{2}{|c|}{$\underset{h}{\operatorname{arr} .} \operatorname{time}$} & $M$ & No & \multicolumn{3}{|c|}{ D A T $\mathbf{E}$} & \multicolumn{2}{|c|}{$\begin{array}{l}\text { arr. time } \\
\mathrm{l}\end{array}$} & $M$ \\
\hline 409 & Nov. & 22 & 1953 & 11 & 41 & 4.7 & 439 & J.ın. & 21 & 1954 & 11 & 42 & 4.9 \\
\hline 410 & $B$ & 28 & $n$ & 20 & 18 & 6.0 & 440 & 11 & 23 & " & 20 & 16 & 4.6 \\
\hline 411 & " & 29 & $"$ & 03 & 31 & 3.9 & 441 & $n$ & 24 & $"$ & 11 & 10 & 4.0 \\
\hline 412 & $n$ & $"$ & $n$ & 03 & 37 & 4.2 & 442 & $n$ & $"$ & " & 11 & 37 & 4.2 \\
\hline 413 & $n$ & $"$ & $n$ & 10 & 46 & 4.1 & 443 & $n$ & $"$ & $"$ & 13 & 34 & 5.4 \\
\hline 414 & $n$ & $n$ & $n$ & 11 & 37 & 3.8 & 444 & $n$ & 25 & $”$ & 17 & 51 & 4.1 \\
\hline 415 & Dec. & 1 & $"$ & 12 & 17 & 4.0 & 445 & $n$ & 30 & \# & 03 & 57 & 5.0 \\
\hline 416 & $n$ & 2 & $"$ & 02 & 38 & 4.7 & 446 & " & $"$ & " & 08 & 40 & 4.7 \\
\hline 417 & $n$ & $"$ & $n$ & 06 & 26 & 4.3 & 447 & 》 & $"$ & ” & 08 & 45 & 4.5 \\
\hline 418 & $n$ & 5 & $"$ & 19 & 35 & 5.2 & 448 & $n$ & $"$ & ” & 12 & 45 & 4.3 \\
\hline 419 & $"$ & 6 & $"$ & 19 & 44 & 4.7 & 449 & $"$ & $"$ & ” & 21 & 59 & 4.3 \\
\hline 420 & ” & 9 & $"$ & 00 & 00 & 4.9 & 450 & Febr. & 9 & " & 13 & 19 & 4.9 \\
\hline 421 & $n$ & $"$ & $n$ & 09 & 09 & 4.0 & 451 & $"$ & 16 & $”$ & 04 & 03 & 4.9 \\
\hline 422 & $"$ & $"$ & $n$ & 11 & 11 & 4.0 & 452 & $"$ & 23 & " & 04 & 27 & 4.0 \\
\hline 423 & $"$ & 16 & " & 14 & 51 & 3.9 & 453 & $"$ & $"$ & 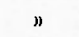 & 19 & 45 & 4.0 \\
\hline 424 & $"$ & 20 & $"$ & 21 & 04 & 4.7 & 454 & & 24 & $"$ & 01 & 23 & 4.1 \\
\hline 425 & ” & 21 & $"$ & 04 & 48 & 4.7 & 455 & March & 3 & " & 03 & 33 & 3.9 \\
\hline 426 & $n$ & $”$ & $"$ & 10 & 25 & 4.2 & 456 & $"$ & $"$ & ” & 19 & 49 & 5.0 \\
\hline 427 & $"$ & $n$ & $n$ & 12 & 01 & 4.0 & 457 & n & 6 & $"$ & 15 & 29 & 3.9 \\
\hline 428 & " & 26 & $"$ & 23 & 27 & 4.0 & 458 & " & 7 & $"$ & 03 & 13 & 4.0 \\
\hline 429 & $n$ & 28 & $"$ & 02 & 39 & 6.0 & 459 & 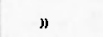 & 8 & $"$ & 08 & 18 & 5.8 \\
\hline 430 & $n$ & $"$ & ” & 04 & 20 & 4.1 & 460 & " & $"$ & " & 08 & 27 & 4.1 \\
\hline 431 & $"$ & $"$ & $"$ & 04 & 41 & 4.6 & 461 & $"$ & $"$ & $"$ & 10 & 50 & 4.0 \\
\hline 432 & $"$ & 29 & $"$ & 19 & 20 & 4.4 & 462 & $n$ & $"$ & $"$ & 16 & 21 & 4.1 \\
\hline 433 & Jan. & 4 & 1954 & 14 & 35 & 4.4 & 463 & $"$ & $n$ & $"$ & 20 & 45 & 4.0 \\
\hline 434 & $"$ & 6 & $"$ & 20 & 15 & 4.2 & 464 & " & 9 & " & 13 & 00 & 4.5 \\
\hline 435 & 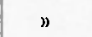 & 7 & $"$ & 12 & 50 & 4.0 & 465 & ” & 10 & ” & 17 & 12 & 3.9 \\
\hline 436 & $n$ & 18 & $n$ & 14 & 17 & 5.8 & 466 & ” & 14 & $"$ & 17 & 01 & 4.6 \\
\hline 437 & $n$ & 19 & $n$ & 14 & 32 & 4.0 & 467 & ” & 15 & $"$ & 06 & 18 & 4.1 \\
\hline 438 & 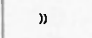 & $"$ & $"$ & 19 & 26 & 4. 7 & 468 & $"$ & w & $"$ & 06 & 51 & 4.3 \\
\hline \multicolumn{14}{|c|}{ 18. - SHOPIIADES 1954} \\
\hline 1 & April & 25 & 1954 & 20 & 04 & 4.7 & 6 & April & 30 & 1954 & 14 & 05 & 4.9 \\
\hline 2 & $" 1$ & $"$ & $"$ & 20 & 16 & 4.4 & 7 & : & $"$ & $n$ & 14 & 24 & 3.6 \\
\hline 3 & $"$ & „ & $n$ & 20 & 22 & 4.3 & 8 & m & $n$ & $"$ & 14 & 25 & 3.6 \\
\hline 4 & $"$ & ” & » & 20 & 28 & 3.6 & 9 & $"$ & $n$ & $n$ & 14 & 26 & 3.6 \\
\hline 5 & " & 26 & $"$ & 18 & 03 & 3.6 & 10 & m & $n$ & $n$ & 14 & 33 & 3.6 \\
\hline 6 & $"$ & ” & $"$ & 18 & 34 & 4.0 & 11 & " & " & $"$ & 14 & 37 & 3.6 \\
\hline 7 & " & 27 & $"$ & 09 & 21 & 3.9 & 12 & ” & $n$ & $"$ & 14 & 38 & 3.9 \\
\hline 8 & " & 28 & $"$ & 13 & 47 & 3.6 & 13 & $"$ & $"$ & $"$ & 14 & 39 & 3.9 \\
\hline 9 & 》 & 29 & " & 06 & 07 & 3.8 & 14 & 》) & " & $"$ & 14 & 40 & 4.4 \\
\hline 10 & " & 30 & $"$ & 12 & 56 & 4.6 & 15 & $"$ & " & $"$ & 14 & 55 & 4.2 \\
\hline $\mathrm{MS}$ & $"$ & $"$ & $"$ & 13 & 03 & 7.0 & 16 & ” & $"$ & " & 14 & 58 & 4.2 \\
\hline 1 & $"$ & $"$ & $"$ & 13 & 51 & 3.9 & 17 & $"$ & $"$ & $"$ & 15 & 11 & 4.2 \\
\hline 2 & $"$ & $"$ & $"$ & 13 & 56 & 4.6 & 18 & " & " & $"$ & 15 & 15 & 3.5 \\
\hline 3 & " & $"$ & » & 14 & 00 & 3.6 & 19 & $”$ & $"$ & $"$ & 15 & 20 & 3.6 \\
\hline 4 & $"$ & $"$ & " & 14 & 01 & 3.6 & 20 & $”$ & $n$ & " & 15 & 23 & 3.6 \\
\hline 5 & $"$ & $"$ & $n$ & 14 & 04 & 4.2 & 21 & $"$ & $n$ & $"$ & 15 & 24 & 3.6 \\
\hline
\end{tabular}


Table III - (continued)

\begin{tabular}{|c|c|c|c|c|c|c|c|c|c|c|c|c|c|}
\hline $\mathrm{N}^{0}$ & & $\mathrm{~A} T$ & & $\underset{\mathrm{l}}{\operatorname{arr}}$ & $\begin{array}{l}\text { time } \\
\mathrm{m}\end{array}$ & M & $\mathrm{N}^{\circ}$ & & $A T$ & & $\underset{h}{\operatorname{arr} .}$ & $\operatorname{time}_{\mathrm{m}}$ & $M$ \\
\hline 22 & April & 30 & 1954 & 15 & 28 & 4.3 & 73 & April & 30 & 1954 & 20 & 50 & 4.6 \\
\hline 23 & 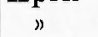 & " & " & 15 & 30 & 3.6 & 74 & $"$ & $"$ & ” & 20 & 56 & 3.4 \\
\hline 24 & 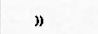 & " & $"$ & 15 & 35 & 3.6 & 75 & » & $"$ & $"$ & 21 & 06 & 3.2 \\
\hline 25 & $"$ & $"$ & $"$ & 15 & 38 & 3.6 & 76 & 》 & $"$ & $"$ & 21 & 14 & 3.4 \\
\hline 26 & $"$ & $n$ & $n$ & 15 & 42 & 3.9 & 77 & $»$ & $"$ & $"$ & 21 & 16 & 4.5 \\
\hline 27 & ” & $"$ & $"$ & 15 & 51 & 3.4 & 78 & " & $"$ & $"$ & 21 & 19 & 3.6 \\
\hline 28 & $n$ & $n$ & $"$ & 15 & 52 & 3.2 & 79 & ” & $"$ & $"$ & 21 & 20 & 3.6 \\
\hline 29 & $"$ & $n$ & $"$ & 16 & 05 & 3.6 & 80 & ” & " & $"$ & 21 & 31 & 3.4 \\
\hline 30 & $"$ & $n$ & $"$ & 16 & 07 & 4.3 & 81 & » & n & $"$ & 21 & 46 & 4.3 \\
\hline 31 & 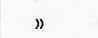 & $"$ & $"$ & 16 & 12 & 3.9 & 82 & $"$ & $"$ & $"$ & 21 & 47 & 4.0 \\
\hline 32 & $»$ & $"$ & $"$ & 16 & 17 & 4.3 & 83 & 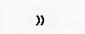 & $”$ & $n$ & 22 & 02 & 3.6 \\
\hline 33 & ” & $"$ & $"$ & 16 & 19 & 4.2 & 84 & $"$ & $"$ & $"$ & 22 & 04 & 4.1 \\
\hline 34 & $"$ & $"$ & $"$ & 16 & 24 & 3.6 & 85 & " & $”$ & $"$ & 22 & 24 & 3.2 \\
\hline 35 & 》 & $"$ & $"$ & 16 & 27 & 3.6 & 86 & $"$ & $"$ & $"$ & 22 & 40 & 4.2 \\
\hline 36 & " & $"$ & $"$ & 16 & 33 & 3.4 & 87 & ” & $"$ & $"$ & 23 & 25 & 4.1 \\
\hline 37 & $"$ & $"$ & $"$ & 16 & 34 & 4.6 & 88 & » & $"$ & $"$ & 23 & 36 & 4.1 \\
\hline 38 & $"$ & $"$ & $"$ & 16 & 38 & 3.5 & 89 & » & $"$ & $"$ & 23 & 54 & 3.6 \\
\hline 39 & ” & $"$ & $"$ & 16 & 43 & 3.4 & 90 & May & l & $"$ & 00 & 11 & 3.6 \\
\hline 40 & $"$ & $"$ & $"$ & 16 & 44 & 3.6 & 91 & " & $"$ & $"$ & 00 & 25 & 3.5 \\
\hline 41 & " & $"$ & $"$ & 16 & 50 & 3.5 & 92 & » & $"$ & $"$ & 00 & 35 & 3.9 \\
\hline 42 & " & $"$ & $n$ & 16 & 51 & 3.6 & 93 & $"$ & $"$ & $"$ & 00 & 37 & 3.6 \\
\hline 43 & ") & " & $"$ & 17 & 04 & 3.6 & 94 & $"$ & $"$ & $"$ & 01 & 09 & 3.6 \\
\hline 44 & $"$ & $"$ & $"$ & 17 & 13 & 3.6 & 95 & ” & $n$ & " & 01 & 18 & 3.2 \\
\hline 45 & $"$ & $"$ & $"$ & 17 & 15 & 3.4 & 96 & $n$ & $"$ & " & 01 & 26 & 4.2 \\
\hline 46 & $"$ & $n$ & ” & 17 & 16 & 4.1 & 97 & " & $n$ & $"$ & 02 & 04 & 4.2 \\
\hline 47 & $" 1$ & " & $"$ & 17 & 21 & 3.5 & 98 & $n$ & $"$ & $"$ & 02 & 42 & 5.0 \\
\hline 48 & $"$ & $"$ & $"$ & 17 & 36 & 3.6 & 99 & 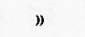 & $»$ & 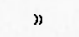 & 03 & 20 & 3.5 \\
\hline 49 & ") & " & $"$ & 17 & 49 & 4.5 & 100 & ") & $n$ & $"$ & 03 & 25 & 3.6 \\
\hline 50 & ") & " & $"$ & 18 & 04 & 3.9 & 101 & ") & $"$ & $"$ & 03 & 29 & 3.6 \\
\hline 51 & $"$ & $"$ & $"$ & 18 & 06 & 3.4 & 102 & » & $»$ & $"$ & 03 & 46 & 3.6 \\
\hline 52 & 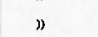 & $"$ & $"$ & 18 & 07 & 3.6 & 103 & ") & 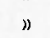 & $"$ & 04 & 18 & 4.0 \\
\hline 53 & ” & " & $"$ & 18 & 27 & 3.9 & 104 & $\eta$ & $"$ & $"$ & 05 & 38 & 3.6 \\
\hline 54 & $"$ & " & $"$ & 18 & 31 & 4.3 & 105 & $"$ & " & $"$ & 08 & 18 & 3.6 \\
\hline 55 & 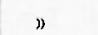 & $"$ & $"$ & 18 & 35 & 3.6 & 106 & $n$ & $»$ & ” & 09 & 59 & 4.2 \\
\hline 56 & $"$ & $"$ & $"$ & 18 & 38 & 3.6 & 107 & $"$ & $"$ & $"$ & 10 & 10 & 3.9 \\
\hline 57 & ") & " & $"$ & 18 & 38 & 3.5 & 108 & 》 & ” & $n$ & 10 & 16 & 3.8 \\
\hline 58 & 1 & $n$ & $"$ & 18 & 40 & 3.4 & 109 & $"$ & $"$ & $"$ & 10 & 59 & 4.2 \\
\hline 59 & $"$ & $"$ & $"$ & 18 & 41 & 3.8 & 110 & $"$ & $"$ & $"$ & 11 & 24 & 3.6 \\
\hline 60 & $\eta$ & $"$ & $"$ & 18 & 44 & 4.0 & 111 & 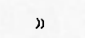 & $"$ & $"$ & 19 & 25 & 3.6 \\
\hline 61 & $"$ & $"$ & $"$ & 18 & 54 & 3.4 & 112 & ") & $"$ & $"$ & 19 & 29 & 3.6 \\
\hline 62 & $"$ & $"$ & $"$ & 18 & 55 & 3.9 & 113 & $"$ & $"$ & $"$ & 19 & 45 & 3.6 \\
\hline 63 & ") & " & $"$ & 19 & 05 & 3.4 & 114 & ") & $"$ & $"$ & 21 & 21 & 3.9 \\
\hline 64 & " & $"$ & " & 19 & 15 & 3.5 & 115 & $\eta$ & $n$ & » & 21 & 26 & 3.6 \\
\hline 65 & \# & $"$ & $"$ & 19 & 31 & 3.9 & 116 & » & " & $"$ & 21 & 28 & 3.6 \\
\hline 66 & & $"$ & & 19 & 34 & 4.9 & 117 & » & $"$ & $"$ & 21 & 45 & 4.1 \\
\hline 67 & " & " & $"$ & 19 & 54 & 3.6 & 118 & $»$ & " & $"$ & 21 & 56 & 3.6 \\
\hline 68 & & $"$ & ” & 20 & 20 & 4.5 & 119 & $"$ & " & $"$ & 22 & 30 & 3.8 \\
\hline 69 & ” & "1) & $"$ & 20 & 26 & 4.0 & 120 & $"$ & 2 & ") & 00 & 17 & 3.6 \\
\hline 70 & $"$ & " & " & 20 & 28 & 3.9 & 121 & $"$ & $"$ & $"$ & 00 & 51 & 3.6 \\
\hline 71 & ") & $"$ & $"$ & 20 & 32 & 3.9 & 122 & $"$ & " & $"$ & 00 & 53 & 3.6 \\
\hline 72 & " & , & $"$ & 20 & 48 & 3.4 & 123 & " & $"$ & $"$ & 02 & 41 & 3.4 \\
\hline
\end{tabular}


78 B. PAPAZACIIOS - S. DELIBASIS - N. LIAPIS - G. MOUMOULIDIS - G. PLRCAJU

Table III (continued)

\begin{tabular}{|c|c|c|c|c|c|c|c|c|c|c|c|c|c|}
\hline No & \multicolumn{3}{|c|}{$D A T E$} & \multicolumn{2}{|c|}{$\underset{\mathbf{h}}{\operatorname{arr} . \operatorname{mime}}$} & $I I$ & No & \multicolumn{3}{|c|}{ D A T E } & \multicolumn{2}{|c|}{$\begin{array}{l}\text { arr. time } \\
l_{1} \mathrm{~m}\end{array}$} & $I I$ \\
\hline 124 & H:y & 2 & 1954 & 06 & 52 & $4 . \overline{5}$ & 175 & Vay & 7 & 1954 & 08 & 34 & 4.4 \\
\hline 125 & $"$ & $"$ & $"$ & 07 & 58 & 3.6 & 176 & $"$ & $\eta$ & $p$ & 11 & 44 & 3.6 \\
\hline 126 & $"$ & " & $n$ & 08 & 10 & 3.6 & 177 & " & $n$ & $"$ & 13 & 19 & 4.1 \\
\hline 127 & $"$ & " & $"$ & 08 & 24 & 3.6 & 178 & " & $n$ & 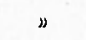 & 20 & 03 & 4.0 \\
\hline 128 & » & ” & $n$ & 10 & 08 & 3.6 & 179 & $"$ & $"$ & $"$ & 22 & 14 & $\begin{array}{l}4.2 \\
\end{array}$ \\
\hline 129 & ") & $"$ & $n$ & 10 & 11 & 3.6 & 180 & " & 8 & $"$ & 01 & 01 & 4.4 \\
\hline 130 & $"$ & " & " & 15 & 23 & 3.4 & 181 & $"$ & $"$ & $"$ & 12 & 51 & 4.3 \\
\hline 131 & $"$ & ” & " & 17 & 13 & 3.6 & 182 & $"$ & $"$ & 》 & 13 & 09 & 3.9 \\
\hline 132 & n & $"$ & $n$ & 22 & 07 & 3.6 & 183 & " & $"$ & " & 13 & 49 & 4.4 \\
\hline 133 & " & 3 & $"$ & 03 & 53 & 3.8 & 184 & $"$ & $"$ & $n$ & 14 & 06 & 3.7 \\
\hline 134 & $"$ & ") & $"$ & 03 & $5 \overline{5}$ & 3.9 & 185 & $n$ & » & $n$ & 14 & 29 & 3.4 \\
\hline 135 & $"$ & $"$ & $"$ & 03 & 58 & 3.6 & 186 & " & $"$ & $"$ & 15 & 21 & 3.6 \\
\hline 136 & $"$ & $"$ & $"$ & 06 & 58 & 3.9 & 187 & " & " & " & 15 & 51 & 3.4 \\
\hline 137 & ") & $"$ & $"$ & 08 & 17 & 4.6 & 188 & $"$ & נ) & $"$ & 17 & 56 & 3.9 \\
\hline 138 & $n$ & » & $"$ & 09 & 24 & 3.9 & 189 & $n$ & " & $"$ & 19 & 45 & 3.2 \\
\hline 139 & $"$ & $"$ & $"$ & 17 & 47 & 5.0 & 190 & $n$ & " & $"$ & 21 & 14 & 3.6 \\
\hline 140 & $n$ & $n$ & $"$ & 22 & 24 & 3.9 & 191 & $n$ & $"$ & $"$ & 23 & 03 & 3.5 \\
\hline 141 & ") & $n$ & $"$ & 23 & 26 & 3.6 & 192 & " & 9 & $"$ & 03 & 58 & 3.4 \\
\hline 142 & $n$ & $t$ & $"$ & 00 & 24 & 3.7 & 193 & $n$ & " & $"$ & 08 & 18 & 3.4 \\
\hline 143 & $n$ & $n$ & $"$ & 00 & 44 & 3.6 & 194 & $n$ & $»$ & $"$ & 13 & 42 & 3.9 \\
\hline 144 & $"$ & $"$ & $n$ & 05 & 16 & 3.6 & $19 \overline{5}$ & " & » & $"$ & 16 & 14 & 4.9 \\
\hline 145 & $"$ & $"$ & $n$ & 05 & 39 & 3.5 & 196 & $n$ & » & $"$ & 16 & 40 & 3.6 \\
\hline 146 & $n$ & $"$ & $n$ & 14 & 07 & 3.6 & 197 & $"$ & ” & $"$ & 16 & 51 & 4.0 \\
\hline 147 & $n$ & ״ & $"$ & 15 & 08 & 4.0 & 198 & $n$ & $»$ & D & 16 & 54 & 3.6 \\
\hline 148 & $"$ & $"$ & $"$ & 16 & 15 & 3.9 & 199 & $"$ & " & $"$ & 20 & 14 & 4.7 \\
\hline 149 & $"$ & ” & $"$ & 16 & 44 & 5.8 & 200 & "1) & $"$ & $"$ & 23 & 22 & 3.4 \\
\hline 150 & $"$ & $"$ & $"$ & 16 & 46 & 5.9 & 201 & $"$ & 10 & $"$ & 00 & 11 & 3.5 \\
\hline 151 & 1 & $"$ & $"$ & 17 & 02 & 3.6 & 202 & " & " & $"$ & 14 & 03 & 3.4 \\
\hline 152 & $"$ & $"$ & " & 17 & $0 \overline{5}$ & 3.6 & 203 & $"$ & $"$ & $"$ & 21 & 02 & $\begin{array}{l}4 . \\
4.1\end{array}$ \\
\hline 153 & " & $"$ & " & 17 & 52 & 3.6 & 204 & $"$ & $"$ & $"$ & 22 & 47 & 3.5 \\
\hline 154 & $"$ & $n$ & $"$ & 18 & 35 & 3.6 & 205 & $n$ & $»$ & ” & 23 & 03 & 3.6 \\
\hline 155 & $n$ & $"$ & " & 19 & 45 & 3.4 & 206 & $"$ & 11 & $"$ & 16 & 11 & 3.5 \\
\hline 156 & $"$ & $"$ & " & 20 & $4 \mathrm{I}$ & 3.4 & 207 & $n$ & " & $"$ & 22 & 47 & $\begin{array}{l}4.0 \\
\end{array}$ \\
\hline 157 & $"$ & " & " & 21 & 24 & 4.0 & 208 & $"$ & 12 & $"$ & 11 & 21 & 3.5 \\
\hline 158 & $"$ & $n$ & $"$ & 23 & 45 & 5.2 & 209 & " & $"$ & $"$ & 13 & 36 & 3.8 \\
\hline 159 & $"$ & 5 & $"$ & 00 & 59 & 4.8 & 210 & $"$ & $"$ & $n$ & 16 & 48 & 3.8 \\
\hline 160 & $"$ & " & $"$ & 06 & 34 & 3.6 & 211 & " & $"$ & ") & 17 & 18 & 3.3 \\
\hline 161 & $"$ & $"$ & $"$ & 10 & 54 & 4.4 & 212 & $"$ & $"$ & ") & 21 & 02 & 4.0 \\
\hline 162 & $"$ & $"$ & $"$ & 13 & 56 & 3.8 & 213 & $"$ & $\eta$ & 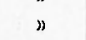 & 23 & 39 & 3.7 \\
\hline 163 & » & 6 & $n$ & 09 & 25 & 3.4 & 214 & $"$ & 13 & $"$ & 00 & 18 & 3.6 \\
\hline 164 & $"$ & $n$ & $"$ & 09 & 37 & 3.5 & 215 & " & " & ״ & 01 & 50 & 3.6 \\
\hline 165 & $"$ & n & " & 10 & 53 & 3.6 & 216 & $"$ & $"$ & $"$ & 03 & 12 & $\begin{array}{l}3.2 \\
3.2\end{array}$ \\
\hline 166 & $"$ & $"$ & $"$ & 11 & 42 & 3.6 & 217 & $"$ & 14 & 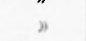 & 04 & 49 & 3.2 \\
\hline 167 & $"$ & 1) & $"$ & 11 & 49 & 4.0 & 218 & $"$ & " & $"$ & 09 & 14 & 4.4 \\
\hline 168 & $"$ & " & $"$ & 18 & 50 & 3.6 & 219 & $"$ & $"$ & $"$ & 11 & 42 & 3.4 \\
\hline 169 & $"$ & ") & $"$ & 19 & 08 & 3.6 & 220 & " & 15 & $"$ & 12 & 03 & 3.6 \\
\hline 170 & $"$ & " & $"$ & 21 & 49 & 3.4 & 221 & $"$ & 1 & $"$ & 13 & 54 & 3.5 \\
\hline 171 & $n$ & 7 & " & 03 & 55 & 4.0 & 222 & $"$ & 16 & $"$ & 15 & $\begin{array}{l}5 x \\
59\end{array}$ & $\begin{array}{l}4.4 \\
\end{array}$ \\
\hline 172 & $"$ & ") & $"$ & 03 & 57 & 3.9 & 223 & " & 17 & $"$ & 03 & 01 & 3.2 \\
\hline 173 & $"$ & " & $"$ & 03 & 59 & 4.5 & 224 & $n$ & $"$ & $"$ & 05 & 37 & 3.6 \\
\hline 174 & $"$ & " & $"$ & 07 & 09 & 3.6 & 225 & $"$ & $"$ & " & 11 & 18 & 4.7 \\
\hline
\end{tabular}


Table III - (continued)

\begin{tabular}{|c|c|c|c|c|c|c|c|c|c|c|c|c|c|}
\hline No & \multicolumn{3}{|c|}{ D A T E } & \multicolumn{2}{|c|}{$\begin{array}{c}\text { arr. ime } \\
\mathrm{h}\end{array}$} & $M$ & No & \multicolumn{3}{|c|}{$\mathbf{D} \boldsymbol{\Lambda} \mathbf{T}$} & \multicolumn{2}{|c|}{$\begin{array}{l}\text { arr. time } \\
\mathrm{h} \text { m }\end{array}$} & $M$ \\
\hline 226 & May & 20 & 1954 & 09 & 04 & 3.6 & 263 & June & 6 & 1954 & 03 & 35 & 3.9 \\
\hline 227 & $"$ & ) & $"$ & 12 & 42 & 3.5 & 264 & " & " & ") & 16 & 08 & 3.4 \\
\hline 228 & $n$ & " & $"$ & 12 & 53 & 3.5 & 265 & $"$ & 7 & $"$ & 00 & 20 & 3.6 \\
\hline 229 & $n$ & $n$ & $n$ & 15 & 01 & 4.1 & 266 & $n$ & $"$ & D & 11 & 47 & 3.4 \\
\hline 230 & $n$ & $"$ & $n$ & 17 & 29 & 3.6 & 267 & D) & 11 & $n$ & 13 & 15 & 4.0 \\
\hline 231 & $n$ & 24 & $"$ & 14 & 12 & 4.1 & 268 & $n$ & » & $n$ & 17 & 22 & 3.2 \\
\hline 232 & $n$ & " & $n$ & 14 & 26 & 3.2 & 269 & $"$ & 12 & " & 09 & $\overline{\mathbf{5} 0}$ & 3.9 \\
\hline 233 & 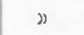 & 25 & $"$ & 21 & 06 & 4.4 & 270 & $"$ & ” & " & 15 & 43 & 4.4 \\
\hline 234 & $n$ & " & $n$ & 22 & 04 & 5.8 & 271 & 1 & $»$ & ") & 16 & 52 & 3.6 \\
\hline 235 & " & $"$ & $n$ & 22 & 19 & 3.6 & 272 & $"$ & 14 & a & 12 & 18 & 4.2 \\
\hline 236 & $n$ & 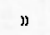 & $n$ & 22 & 20 & 3.7 & 273 & ) & 15 & $"$ & 00 & 16 & 3.7 \\
\hline 237 & $"$ & 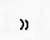 & $n$ & 23 & 14 & 4.0 & 274 & " & 16 & $"$ & 22 & 09 & 4.9 \\
\hline 238 & ” & 26 & " & 00 & 05 & 3.6 & 275 & " & 19 & D & 12 & 05 & 3.9 \\
\hline 239 & " & $n$ & $"$ & 00 & 15 & 3.6 & 276 & $"$ & $"$ & ” & 14 & 03 & 3.6 \\
\hline 240 & " & $"$ & $"$ & 00 & 32 & 3.4 & 277 & b & 22 & $"$ & 06 & 21 & 3.6 \\
\hline 241 & $"$ & $"$ & $"$ & 00 & 40 & 3.6 & 278 & " & 24 & $"$ & 13 & 02 & 3.9 \\
\hline 242 & $"$ & $n$ & $"$ & 00 & 45 & 3.9 & 279 & $"$ & 25 & $"$ & 04 & 29 & 3.6 \\
\hline 243 & " & $n$ & $"$ & 01 & 27 & 3.9 & 280 & $n$ & $"$ & 》" & 06 & 30 & 4.2 \\
\hline 244 & ") & $"$ & $"$ & 08 & 14 & 4.0 & 281 & $"$ & " & ” & 12 & 12 & 4.2 \\
\hline 245 & $"$ & " & $"$ & 08 & 52 & 3.6 & 282 & $n$ & " & " & 15 & 26 & 4.2 \\
\hline 246 & ") & " & $"$ & 09 & 44 & 3.4 & 283 & $n$ & 26 & $n$ & 12 & 10 & 3.9 \\
\hline 247 & $"$ & $n$ & $"$ & 10 & 21 & 3.6 & 284 & $"$ & 27 & $"$ & 03 & 30 & 3.2 \\
\hline 248 & $"$ & 27 & ") & 17 & 20 & 3.9 & 285 & $n$ & ” & " & 08 & 34 & 3.4 \\
\hline 249 & $"$ & $n$ & $"$ & 17 & 42 & 3.9 & 286 & $"$ & $n$ & " & 12 & 29 & 3.6 \\
\hline 250 & $"$ & 28 & $n$ & 01 & 58 & 4.5 & 287 & $n$ & $"$ & $"$ & 12 & 42 & 3.4 \\
\hline 251 & $"$ & $n$ & $n$ & 07 & 44 & 5.0 & 288 & $n$ & $n$ & " & 13 & 55 & 3.6 \\
\hline 252 & " & $n$ & $"$ & 07 & 50 & 3.7 & 289 & $"$ & " & " & 23 & 32 & 3.4 \\
\hline 253 & $"$ & $"$ & $"$ & 17 & 27 & 3.9 & 290 & ” & 28 & $n$ & 03 & 48 & 3.9 \\
\hline 254 & $n$ & $n$ & $"$ & 22 & 44 & 3.4 & 291 & $"$ & » & " & 22 & 31 & 3.6 \\
\hline 255 & " & 29 & " & 02 & 10 & 3.2 & 292 & July & 1 & $"$ & 04 & 49 & 3.6 \\
\hline 256 & " & $"$ & " & 16 & 52 & 3.2 & 293 & נ) & 2 & " & 23 & 21 & 4.3 \\
\hline 257 & June & I & $n$ & 23 & 00 & 3.8 & 294 & $"$ & 3 & $"$ & 13 & 10 & 4.2 \\
\hline 258 & נ & 3 & נ & 08 & 43 & 3.7 & 295 & " & 4 & $n$ & 05 & 47 & 4.4 \\
\hline 259 & ") & $"$ & $n$ & 22 & 23 & 4.2 & 296 & $n$ & 6 & $"$ & 13 & 51 & 3.6 \\
\hline 260 & ") & 4 & $\eta$ & 01 & 53 & 4.4 & 297 & $n$ & $»$ & $n$ & 16 & 57 & 4.0 \\
\hline 261 & $n$ & $n$ & $"$ & 15 & 10 & 3.6 & 298 & ) & 9 & $"$ & 23 & 18 & 4.6 \\
\hline 262 & $"$ & $\overline{5}$ & $"$ & 14 & 06 & 5.0 & 299 & Aug. & 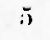 & $"$ & 03 & 49 & 4.8 \\
\hline & & & & & 19 & $-\mathrm{L}$ & & 54 & & & & & \\
\hline MS & Aug. & 3 & 1954 & 18 & 18 & 6.1 & 11 & Aug. & 7 & 1954 & 00 & 17 & 4.1 \\
\hline 1 & $"$ & $n$ & $»$ & 18 & 44 & 4.4 & 12 & $"$ & " & $"$ & 01 & 11 & 4.1 \\
\hline 2 & $"$ & $"$ & ” & 23 & 18 & 4.9 & 13 & $"$ & נ & " & 13 & 02 & 4.1 \\
\hline 3 & $n$ & 4 & " & 01 & 13 & 4.6 & 14 & $"$ & " & $n$ & 14 & 46 & 4.0 \\
\hline 4 & $n$ & $\tilde{5}$ & $"$ & 04 & 13 & $\tilde{\mathbf{5}} . \tilde{\mathbf{5}}$ & 15 & $"$ & $n$ & ” & 14 & 50 & 4.0 \\
\hline 5 & $"$ & $"$ & $"$ & 04 & 38 & 5.3 & 16 & $"$ & 8 & $"$ & 10 & 14 & 4.1 \\
\hline 6 & " & $n$ & " & 04 & 45 & 4.1 & 17 & $"$ & $"$ & $n$ & 10 & 47 & 3.8 \\
\hline 7 & " & " & ” & 04 & 48 & 4.2 & 18 & $"$ & $"$ & $n$ & 17 & 18 & 4.2 \\
\hline 8 & " & $n$ & " & 07 & 32 & 4.3 & 19 & Sept. & 20 & " & 02 & 52 & +.8 \\
\hline 9 & $"$ & $"$ & $"$ & 17 & 25 & 4.5 & 20 & Oct. & 12 & $"$ & 19 & 29 & 4.1 \\
\hline 10 & $\mu$ & 6 & $"$ & 16 & 02 & 5.2 & 21 & Nov. & 4 & $"$ & 20 & 38 & 4.9 \\
\hline
\end{tabular}


Table III - (continued)

\begin{tabular}{|c|c|c|c|c|c|c|c|c|c|c|c|c|c|}
\hline \multicolumn{14}{|c|}{ 21. - Tinessalia 1955} \\
\hline No & \multicolumn{3}{|c|}{$\mathrm{D} A \mathrm{~T} \mathrm{ID}$} & \multicolumn{2}{|c|}{$\underset{\mathrm{h} \mathrm{m}}{\operatorname{arr} \text { time }}$} & II & No & \multicolumn{3}{|c|}{$\mathrm{DA} T \mathrm{~T}$} & \multicolumn{2}{|c|}{$\underset{\mathrm{h}}{\operatorname{arr} \mathrm{m}}$} & $M$ \\
\hline 1 & Febr. & 21 & $195 \overline{5}$ & 19 & 47 & 5.0 & 20 & April & 23 & 1955 & 05 & 43 & 3.5 \\
\hline 2 & 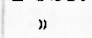 & $"$ & $"$ & 23 & 17 & 3.9 & 21 & $"$ & " & $"$ & 15 & 44 & 3.7 \\
\hline 3 & $\mu$ & 22 & n & 09 & 44 & 4.8 & 22 & $"$ & $"$ & $"$ & 18 & 40 & 3.3 \\
\hline 4 & $n$ & $"$ & $"$ & 09 & 53 & 3.6 & 23 & $"$ & $"$ & $"$ & 19 & 09 & 3.3 \\
\hline 5 & $"$ & $n$ & $"$ & 09 & 56 & 4.3 & 24 & $"$ & 25 & " & 03 & 28 & 3.5 \\
\hline 6 & $"$ & $"$ & $"$ & 13 & 11 & 3.6 & 25 & $"$ & $"$ & $"$ & 14 & 43 & 4.4 \\
\hline 7 & April & 17 & » & 11 & 29 & 3.6 & 26 & $"$ & 28 & » & 17 & 22 & 4.3 \\
\hline MS & " & 19 & 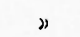 & 16 & 48 & 6.3 & 27 & $"$ & $"$ & $"$ & 22 & 18 & 4.4 \\
\hline 1 & " & $"$ & $"$ & 19 & 07 & 3.6 & 28 & $"$ & 29 & ” & 12 & 37 & 3.3 \\
\hline 2 & $"$ & $"$ & $"$ & 19 & 08 & 4.0 & 29 & May & 2 & 1955 & 12 & 22 & 3.5 \\
\hline 3 & $"$ & $"$ & $"$ & 19 & 24 & 3.3 & 30 & $"$ & $n$ & $"$ & 21 & 41 & 4.3 \\
\hline 4 & 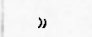 & $"$ & $"$ & 21 & 32 & $3 . !$ & 31 & $"$ & 3 & 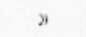 & 12 & 56 & 3.3 \\
\hline 5 & $"$ & $"$ & $"$ & 21 & 34 & 3.5 & 32 & $"$ & $"$ & $n$ & 12 & 56 & 3.8 \\
\hline 6 & $n$ & $" 1$ & $"$ & 23 & 06 & 3.5 & 33 & $"$ & $"$ & $n$ & 14 & 42 & 3.5 \\
\hline 7 & $"$ & 20 & " & 00 & 51 & 3.6 & 34 & $"$ & $"$ & $"$ & 18 & 44 & 3.5 \\
\hline 8 & $"$ & $"$ & $"$ & 03 & 27 & 4.4 & 35 & " & 10 & $"$ & 17 & 11 & 3.3 \\
\hline 9 & $"$ & $"$ & $"$ & 10 & 18 & 3.9 & 36 & » & 13 & " & 19 & 48 & 3.3 \\
\hline 10 & $"$ & $n$ & $n$ & 11 & 14 & 3.5 & 37 & $"$ & $n$ & $n$ & 19 & 55 & 4.9 \\
\hline 11 & $\Rightarrow$ & 21 & $n$ & 00 & 34 & 4.0 & 38 & " & 14 & $"$ & 08 & 45 & 3.4 \\
\hline 12 & $n$ & $"$ & $n$ & 03 & 50 & 3.9 & 39 & $"$ & $"$ & $n$ & 09 & 01 & 3.3 \\
\hline 13 & $"$ & $"$ & $"$ & 07 & 19 & 5.9 & 40 & » & 17 & \# & 02 & 31 & 3.7 \\
\hline 14 & $"$ & $"$ & $n$ & 09 & 00 & 5.0 & 41 & $"$ & 24 & " & 14 & 40 & 3.3 \\
\hline 15 & $"$ & $"$ & $"$ & 09 & 01 & 3.5 & 42 & June & 4 & $"$ & 11 & 56 & 3.9 \\
\hline 16 & $"$ & $n$ & $"$ & 09 & 49 & 3.3 & 43 & Jan. & 21 & 1956 & 09 & 51 & 5.2 \\
\hline 17 & $"$ & " & $n$ & 11 & 40 & 3.4 & 44 & March & 26 & $"$ & 22 & 52 & 5.2 \\
\hline 18 & $"$ & $"$ & $"$ & 11 & 51 & 3.5 & 45 & 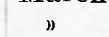 & 28 & $"$ & 11 & 40 & 5.2 \\
\hline 19 & ” & 22 & n & 23 & 25 & 3.5 & & & & & & & \\
\hline \multicolumn{14}{|c|}{ 22. - SAMOS 1955} \\
\hline 1 & July & 10 & 1955 & 22 & 56 & 4.4 & 14 & July & 20 & 1955 & 16 & 07 & 4.4 \\
\hline MS & $" 1$ & 16 & $»$ & 07 & 08 & 6.8 & 15 & $"$ & $"$ & ” & 22 & 56 & 4.2 \\
\hline 1 & $n$ & $"$ & $"$ & 07 & 19 & 4.7 & 16 & $"$ & 21 & ” & 13 & 16 & 4.4 \\
\hline 2 & $"$ & $"$ & $"$ & 16 & 57 & 4.5 & 17 & " & 31 & $"$ & 15 & 23 & 4.2 \\
\hline 3 & $"$ & $"$ & $"$ & 17 & 07 & 4.0 & 18 & Aug. & 1 & $"$ & 10 & 01 & 4.2 \\
\hline 4 & "1 & 17 & $"$ & 00 & 52 & 4.2 & 19 & $"$ & 5 & $"$ & 12 & 58 & 4.3 \\
\hline$\check{5}$ & $"$ & $"$ & $"$ & 08 & 24 & 4.7 & 20 & $"$ & 28 & $"$ & 13 & 40 & 5.2 \\
\hline 6 & $"$ & " & $n$ & 10 & 30 & 4.0 & 21 & Sept. & 12 & " & 03 & 56 & 3.9 \\
\hline 7 & " & 18 & $"$ & 03 & 07 & 4.6 & 22 & Nov. & 10 & $n$ & 08 & 43 & 4.9 \\
\hline 8 & $"$ & " & $"$ & 04 & 29 & 4.5 & 23 & " & $"$ & $"$ & 09 & 08 & 4.4 \\
\hline 9 & $"$ & 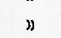 & $"$ & 07 & 32 & 4.3 & 24 & $"$ & " & $"$ & 13 & 01 & 4.4 \\
\hline 10 & $"$ & $"$ & $n$ & 11 & 04 & 4.3 & 25 & $"$ & $"$ & $"$ & 22 & 07 & 4.4 \\
\hline 11 & $"$ & $"$ & $"$ & 16 & 19 & 4.5 & 26 & ” & 11 & $"$ & 18 & 28 & 4.8 \\
\hline 12 & $n$ & 20 & ” & 15 & 19 & 4.2 & 27 & $n$ & $"$ & $"$ & 20 & 05 & 4.6 \\
\hline 13 & $"$ & " & $"$ & 16 & 05 & +0 & & & & & & & \\
\hline
\end{tabular}


Table III - (continued)

\begin{tabular}{|c|c|c|c|c|c|c|c|c|c|c|c|c|c|}
\hline \multicolumn{14}{|c|}{ 23. - AMORGOS 1956} \\
\hline No & \multicolumn{3}{|c|}{ U A T E } & \multicolumn{2}{|c|}{$\begin{array}{c}\text { arr. time } \\
\mathrm{h}_{1} \mathrm{III}\end{array}$} & \multirow{2}{*}{$\begin{array}{c}. I \\
5.0\end{array}$} & \multirow{2}{*}{$\begin{array}{l}N^{\circ} \\
47\end{array}$} & \multicolumn{3}{|c|}{ 1) I T E } & \multicolumn{2}{|c|}{$\begin{array}{l}\text { arr.time } \\
\text { hl } \mathrm{m}\end{array}$} & \multirow{2}{*}{$\begin{array}{r}.1 \\
+.1\end{array}$} \\
\hline 1 & July & 8 & 1956 & 13 & 06 & & & July & 9 & 1956 & 05 & 14 & \\
\hline MS & " & 9 & " & 03 & 12 & 7.5 & 48 & $"$ & $"$ & $"$ & 05 & 15 & 5.1 \\
\hline 1 & $n$ & " & $"$ & 03 & 24 & 6.8 & 49 & $"$ & $"$ & " & 05 & 17 & 3.9 \\
\hline 2 & " & $"$ & " & 03 & 46 & 4.2 & 50 & ") & $"$ & $"$ & 05 & 20 & 3. \\
\hline 3 & $"$ & $"$ & $"$ & 03 & 47 & 4.0 & 51 & ") & $"$ & $"$ & 05 & 26 & 3. \\
\hline 4 & " & ” & " & 03 & 48 & 4.5 & 52 & $"$ & $"$ & $"$ & 05 & 26 & 4.1 \\
\hline$\tilde{5}$ & " & $"$ & " & 03 & 48 & 4.8 & 53 & $"$ & $"$ & " & 05 & 30 & 3.4 \\
\hline 6 & " & " & $"$ & 03 & 49 & 4.3 & 54 & , & $"$ & $"$ & 05 & 31 & 4.0 \\
\hline 7 & " & " & $"$ & 03 & 52 & $\begin{array}{l}1.0\end{array}$ & $\tilde{5} 5$ & $"$ & $"$ & $"$ & 05 & 31 & 4.1 \\
\hline 8 & $n$ & " & " & 03 & 54 & 4.0 & 56 & \# & $"$ & $"$ & $0 \tilde{5}$ & 32 & 3. \\
\hline 9 & D & $n$ & $n$ & 03 & 56 & 4.9 & 57 & " & " & " & 05 & 34 & 3.1 \\
\hline 10 & " & " & $n$ & 03 & 57 & 4.6 & 58 & " & $"$ & $"$ & 05 & 37 & 3.6 \\
\hline 11 & " & $"$ & " & 03 & 59 & 4.2 & 59 & " & $"$ & $"$ & $0 \tilde{5}$ & 38 & 3.1 \\
\hline 12 & ") & $n$ & " & 04 & 01 & 4.0 & 60 & " & " & $"$ & 05 & 42 & 3. \\
\hline 13 & $n$ & $"$ & $"$ & 04 & 02 & 4.7 & 61 & $"$ & $n$ & $"$ & 05 & 48 & 3.5 \\
\hline 14 & $n$ & $"$ & " & 04 & 05 & 4.2 & 62 & $n$ & " & $n$ & 05 & 49 & 4.2 \\
\hline 15 & $"$ & $"$ & » & 04 & 08 & 4.2 & 63 & $"$ & $n$ & $"$ & 05 & 56 & 4.0 \\
\hline 16 & " & $"$ & $"$ & 04 & 10 & 4.0 & 64 & " & $"$ & $"$ & 05 & 58 & 1.0 \\
\hline 17 & " & " & " & 04 & 11 & 4.0 & 65 & $"$ & $"$ & $"$ & 06 & 01 & 3.0 \\
\hline 18 & n & $"$ & $n$ & 04 & 12 & 4.0 & 66 & $"$ & $"$ & $"$ & 06 & 07 & 4.8 \\
\hline 19 & $"$ & $"$ & $" 1$ & 04 & 14 & 4.2 & 67 & $"$ & $"$ & $"$ & 06 & 11 & 3.9 \\
\hline 20 & $"$ & $"$ & " & 04 & 16 & 5.0 & 68 & $"$ & " & " & 06 & 13 & 3.6 \\
\hline 21 & " & " & " & $0 \pm$ & 18 & 4.2 & 69 & $"$ & $"$ & " & 06 & 18 & 3.9 \\
\hline 22 & " & " & " & 04 & 20 & 4.0 & 70 & $"$ & B & " & 06 & 20 & 5.7 \\
\hline 23 & n & $n$ & $"$ & 04 & 22 & 3.6 & 71 & " & " & " & 06 & 23 & 5.0 \\
\hline 24 & n & $"$ & " & 04 & 22 & 4.1 & 72 & $"$ & " & $n$ & 06 & 46 & 4.4 \\
\hline 25 & w & " & $"$ & 04 & 26 & 3.6 & 73 & $"$ & $n$ & " & 06 & 48 & 4.1 \\
\hline 26 & $"$ & " & $"$ & 04 & 27 & 3.6 & 74 & $"$ & n & " & 06 & $\tilde{5} \tilde{5}$ & 3.9 \\
\hline 27 & ") & $"$ & $"$ & 04 & 29 & 3.6 & 75 & " & $"$ & " & 06 & 57 & 4.0 \\
\hline 28 & $"$ & " & $"$ & 04 & 34 & 5.1 & 76 & " & ") & $"$ & 07 & 00 & 4.2 \\
\hline 29 & $"$ & $"$ & " & 04 & 37 & 4.8 & 77 & $"$ & $"$ & $"$ & 07 & 06 & 3.9 \\
\hline 30 & 0 & $"$ & ") & 04 & 39 & 4.0 & 78 & $"$ & $"$ & $"$ & 07 & 10 & 3.6 \\
\hline 31 & $"$ & $"$ & " & 04 & 41 & 3.6 & 79 & " & $"$ & " & 07 & 13 & 3.6 \\
\hline 32 & $"$ & " & " & 04 & 42 & 3.6 & 80 & " & $"$ & $"$ & 07 & 14 & 3.6 \\
\hline 33 & " & " & $"$ & 04 & 44 & 5.0 & 81 & " & $n$ & " & 07 & 19 & 3.5 \\
\hline 34 & $"$ & $"$ & $"$ & $0 \pm$ & 46 & 4.7 & 82 & $"$ & ") & $"$ & 07 & 21 & 4.2 \\
\hline 35 & $"$ & $"$ & " & 04 & 48 & 4.4 & 83 & $"$ & $"$ & $n$ & 07 & 24 & 3.8 \\
\hline 36 & 1 & " & $"$ & 04 & 49 & 4.0 & 84 & $"$ & " & " & 07 & 29 & 3.6 \\
\hline 37 & , & " & $"$ & 04 & 50 & +.0 & 85 & $"$ & $"$ & " & 07 & 36 & 3.6 \\
\hline 38 & $"$ & " & $"$ & 04 & 51 & 4.3 & 86 & " & " & $"$ & 07 & 37 & 5.4 \\
\hline 39 & " & " & $"$ & 04 & 52 & 4.0 & 87 & $"$ & $"$ & $"$ & 07 & 44 & 3.8 \\
\hline 40 & " & $n$ & " & 04 & 52 & +.2 & 88 & " & ") & $"$ & 07 & 45 & 3.9 \\
\hline 41 & $"$ & " & " & 04 & 54 & 4.2 & 89 & " & $"$ & $"$ & 07 & 50 & 3.0 \\
\hline 42 & $"$ & $"$ & " & 04 & 55 & 4.7 & 90 & $"$ & ") & $"$ & 07 & 52 & 3.9 \\
\hline 43 & $"$ & " & $"$ & 04 & 59 & 4.2 & 91 & $"$ & $"$ & $"$ & 07 & 53 & 3.8 \\
\hline 44 & $"$ & " & " & 05 & 05 & 3.5 & 92 & $"$ & $"$ & $"$ & 07 & 59 & 3.9 \\
\hline 45 & $"$ & " & $"$ & 05 & 07 & 3.5 & 93 & " & D & $"$ & 08 & 03 & 3.8 \\
\hline 46 & " & " & 0 & 05 & 12 & 4.6 & 94 & $"$ & " & $"$ & 08 & 05 & 4.0 \\
\hline
\end{tabular}


Jable III - (continued)

\begin{tabular}{|c|c|c|c|c|c|c|c|c|c|c|c|c|c|}
\hline \multirow{2}{*}{$\begin{array}{l}\text { No } \\
9 \pi\end{array}$} & \multicolumn{3}{|c|}{ " $\triangle \mathrm{THE}$} & \multicolumn{2}{|c|}{$\begin{array}{l}\text { arr time } \\
\mathrm{h} \mathrm{m}\end{array}$} & \multirow{2}{*}{$\begin{array}{c}.1 \\
3.5\end{array}$} & \multirow{2}{*}{$\begin{array}{l}\text { No } \\
146\end{array}$} & \multicolumn{3}{|c|}{$D A C E$} & \multicolumn{2}{|c|}{$\begin{array}{l}\text { arr. time } \\
h\end{array}$} & \multirow{2}{*}{$\begin{array}{l}U \\
3 . \overline{5}\end{array}$} \\
\hline & July & 9 & 1956 & 08 & 13 & & & July & 9 & 1956 & 13 & 55 & \\
\hline 96 & " & " & $"$ & 08 & 15 & 4.2 & 147 & $"$ & n & $"$ & 13 & 57 & 3.9 \\
\hline 97 & $"$ & " & $"$ & 08 & 17 & 4.0 & 148 & $"$ & " & $"$ & 14 & 188 & 3.9 \\
\hline 98 & $"$ & " & $"$ & 08 & 19 & 3.6 & 149 & $n$ & n & $n$ & 14 & 32 & 3.6 \\
\hline 99 & $"$ & " & $"$ & 08 & 28 & 3.5 & 150 & $"$ & n & $"$ & 14 & $3 \overline{5}$ & 3.5 \\
\hline 100 & $"$ & " & $"$ & 08 & 32 & 3.6 & 151 & $"$ & " & 1 & 14 & 39 & 4.0 \\
\hline 101 & " & " & $"$ & 08 & 37 & 4.3 & 152 & , & " & " & 14 & 48 & 3.5 \\
\hline 102 & " & $n$ & $n$ & 08 & 38 & 4.2 & 153 & " & " & " & 14 & 49 & 3.6 \\
\hline 103 & . & " & $"$ & 08 & 40 & 3.9 & 1.54 & $"$ & " & $"$ & 14 & 50 & 3.5 \\
\hline 104 & $n$ & " & $n$ & 08 & 46 & 3.5 & 155 & " & " & $"$ & 14 & 52 & 3.6 \\
\hline 105 & $"$ & " & $n$ & 08 & 55 & 3.6 & 156 & $"$ & " & $n$ & 14 & 54 & 3.9 \\
\hline 106 & $n$ & $n$ & $"$ & 09 & 02 & 3.6 & 157 & $"$ & " & $n$ & 14 & 58 & 3.5 \\
\hline 107 & $"$ & n & $"$ & 09 & 06 & 3.5 & 158 & $n$ & " & $"$ & 15 & 03 & 3.9 \\
\hline 108 & " & " & $"$ & 09 & 07 & 4.4 & 159 & $"$ & " & $"$ & 15 & 59 & 3.8 \\
\hline 109 & " & " & $n$ & 09 & 13 & 3.6 & 160 & $"$ & " & $"$ & 16 & 09 & 3.5 \\
\hline 110 & $"$ & " & $"$ & 09 & 17 & 3.6 & 161 & $n$ & " & $"$ & 16 & 10 & 3.0 \\
\hline 111 & " & " & ” & 09 & 18 & 4.5 & 162 & " & " & $"$ & 16 & 24 & 3.9 \\
\hline 112 & $"$ & " & $"$ & 09 & 21 & 3.8 & 163 & 1 & " & $"$ & 16 & 25 & 3.9 \\
\hline 113 & D & $"$ & $"$ & 09 & 31 & 4.0 & 164 & $n$ & " & $"$ & 16 & 29 & 3.5 \\
\hline 114 & $"$ & $"$ & $"$ & 09 & 35 & 3.6 & 165 & $n$ & " & $"$ & 16 & 44 & 3.5 \\
\hline 115 & " & $"$ & $"$ & 09 & 36 & 4.1 & 166 & $"$ & " & $"$ & 16 & 52 & 3.5 \\
\hline 116 & $"$ & " & $"$ & 09 & 44 & 3.9 & 167 & $"$ & " & $"$ & 16 & 56 & 3.9 \\
\hline 117 & $"$ & " & " & 09 & 46 & 5.0 & 168 & " & $n$ & $"$ & 17 & 08 & 3.9 \\
\hline 118 & $"$ & " & $"$ & 10 & 20 & 4.9 & 169 & $"$ & " & $n$ & 17 & 28 & 3.5 \\
\hline 119 & " & n & $"$ & 10 & 27 & 3.8 & 170 & $"$ & " & $"$ & 17 & 41 & 4.1 \\
\hline 120 & " & " & $"$ & 10 & 33 & 3.5 & 171 & $"$ & " & $"$ & 17 & 51 & 3.5 \\
\hline 121 & $"$ & " & $"$ & 10 & 37 & 4.0 & 172 & $"$ & " & 2 & 17 & 54 & 3.9 \\
\hline 122 & $"$ & " & $"$ & 10 & 42 & 4.6 & 173 & " & " & " & 17 & 58 & 3.8 \\
\hline 123 & " & " & $"$ & 10 & 56 & 3.9 & 174 & $"$ & " & $"$ & is & 06 & 3.9 \\
\hline 124 & $"$ & " & $n$ & 11 & 05 & 3.8 & 175 & $"$ & " & "1) & 18 & 13 & 3.8 \\
\hline 125 & " & $"$ & $"$ & 11 & 15 & 3.9 & 176 & $"$ & " & " & 18 & 1.5 & 3.9 \\
\hline 126 & " & $"$ & " & 11 & 21 & 4.1 & 177 & $n$ & " & $n$ & 18 & 24 & 3.5 \\
\hline 127 & $"$ & " & ” & 11 & 29 & 3.9 & 178 & $"$ & " & $"$ & 18 & 33 & 3.0 \\
\hline 128 & $n$ & " & $"$ & 11 & 31 & 5.3 & 179 & $n$ & " & 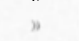 & is & 35) & 3.8 \\
\hline 129 & $"$ & " & $"$ & 11 & 35 & 4.0 & 180 & $"$ & " & ” & 18 & 36 & 3.9 \\
\hline 130 & " & " & " & 11 & 38 & 3.6 & 181 & $"$ & " & " & 18 & 38 & 3.5 \\
\hline 131 & $n$ & $"$ & $n$ & 11 & 40 & 4.6 & 182 & " & " & $"$ & is & 39 & 3.8 \\
\hline 132 & ") & " & $"$ & 11 & 47 & 4.1 & 183 & $"$ & " & $"$ & is & 58 & 4.0 \\
\hline 133 & " & " & $"$ & 12 & 06 & 4.5 & 184 & $n$ & " & $”$ & 19 & (1) 2 & 3.0 \\
\hline 134 & $"$ & " & $"$ & 12 & 18 & 3.9 & 185 & $n$ & " & $"$ & 19 & 05 & 3.6 \\
\hline 135 & $"$ & $"$ & $"$ & 12 & 13 & 3.9 & 186 & $n$ & " & " & 19 & 11 & 3.8 \\
\hline 136 & $n$ & $"$ & $"$ & 12 & 31 & 3.6 & 187 & $"$ & , & $"$ & 19 & 14 & 3.6 \\
\hline 137 & " & " & ” & 12 & 36 & 3.9 & 188 & $"$ & " & $"$ & 19 & 24 & 3.5 \\
\hline 138 & $"$ & " & $"$ & 12 & 44 & 3.6 & 189 & $"$ & " & $"$ & 19 & 33 & 3.5 \\
\hline 139 & $n$ & $"$ & $"$ & 12 & 50 & 3.6 & 190 & " & " & " & 19 & 36 & $3.6 \mathrm{i}$ \\
\hline 140 & " & " & $"$ & 12 & 57 & 4.2 & 191 & $"$ & " & $"$ & 19 & 37 & 3.5 \\
\hline$I+I$ & $"$ & " & $"$ & 12 & 58 & 4.2 & 192 & $n$ & " & " & 19 & 48 & 3.5 \\
\hline $1+2$ & ") & " & ") & 13 & 04 & 3.5 & 193 & " & " & $"$ & 19 & 57 & 3.5 \\
\hline $1+3$ & $"$ & " & $"$ & 13 & 09 & $3 . \overline{5}$ & 194 & $"$ & " & " & 20 & 66 & 3.5 \\
\hline 144 & $"$ & n & $n$ & 13 & 11 & 4.0 & 195 & $"$ & " & , & 20 & 11 & 5.1 \\
\hline 145 & $n$ & $"$ & $"$ & 13 & 45 & 3.5 & 196 & $"$ & " & $"$ & 20 & 14 & 5.6 \\
\hline
\end{tabular}


Table III - (contiuned)

\begin{tabular}{|c|c|c|c|c|c|c|c|c|c|c|c|c|c|}
\hline $\mathrm{N}^{\circ}$ & \multicolumn{3}{|c|}{$\mathrm{D} \triangle \mathrm{TE}$} & \multicolumn{2}{|c|}{$\begin{array}{l}\text { arr. } \\
\text { he } \mathrm{me}\end{array}$} & \multirow{2}{*}{$\begin{array}{r}. K \\
\\
4.5\end{array}$} & \multirow{2}{*}{$\begin{array}{l}\text { No } \\
2+8\end{array}$} & \multicolumn{3}{|c|}{$\mathrm{DAC}$} & \multicolumn{2}{|c|}{$\begin{array}{l}\text { arr. time } \\
\mathrm{h} n\end{array}$} & u \\
\hline 197 & July & 9 & 1956 & 20 & 24 & & & July & 10 & 1956 & 03 & 36 & 3.6 \\
\hline 198 & $"$ & " & $"$ & 20 & 34 & 3.8 & 249 & $"$ & " & $"$ & 03 & 31 & 3.5 \\
\hline 199 & $"$ & $n$ & $"$ & 20 & 36 & 4.8 & 250 & $"$ & $"$ & " & 03 & 48 & 3.5 \\
\hline 200 & $"$ & $n$ & $"$ & 20 & 38 & 3.6 & 251 & $"$ & " & $"$ & 04 & $0_{\bar{T}}$ & $3 . \overline{5}$ \\
\hline 201 & $"$ & $n$ & $"$ & 20 & 41 & 3.9 & 252 & $"$ & ,1) & $"$ & 04 & 09 & t.0 \\
\hline 202 & $"$ & " & $"$ & 20 & 45 & 3.5 & 253 & $"$ & $n$ & n & 04 & 36 & 3.9 \\
\hline 203 & " & " & $n$ & 20 & 49 & 5.3 & 254 & $"$ & " & $"$ & 04 & 48 & 3.6 \\
\hline 204 & $"$ & $"$ & $n$ & 20 & 57 & 3.5 & 255 & $n$ & $"$ & $"$ & 05 & 02 & +.2 \\
\hline 205 & $"$ & $"$ & $n$ & 21 & 17 & 3.5 & 256 & , & $"$ & $"$ & 05 & 17 & 3.9 \\
\hline 206 & $"$ & $"$ & $n$ & 21 & 24 & 3.6 & 257 & $"$ & $n$ & $"$ & $0 \tilde{3}$ & 36 & 3.5 \\
\hline 207 & $"$ & $"$ & $n$ & 21 & 29 & 5.8 & 258 & $"$ & $n$ & $"$ & $0 \tilde{5}$ & 38 & 3.8 \\
\hline 208 & $"$ & $"$ & $"$ & 21 & 37 & 3.9 & 259 & $"$ & $"$ & $"$ & 06 & 02 & 3.9 \\
\hline 209 & $n$ & $n$ & $"$ & 21 & 43 & 3.9 & 260 & $"$ & $"$ & $"$ & 07 & 13 & 3.9 \\
\hline 210 & $"$ & $"$ & $"$ & 21 & 49 & 4.4 & 261 & $n$ & " & $"$ & 07 & 24 & 3.5 \\
\hline 211 & $"$ & $"$ & $"$ & 21 & 52 & 4.7 & 262 & $"$ & " & $"$ & 07 & 30 & 3.6 \\
\hline 212 & " & $"$ & $"$ & 22 & 04 & 3.9 & 263 & " & $"$ & $"$ & 07 & $3 \overline{5}$ & 4.2 \\
\hline 213 & $D$ & $"$ & $"$ & 22 & 26 & 3.5 & 264 & $"$ & $"$ & $"$ & 08 & 09 & 3.5 \\
\hline 214 & ") & 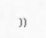 & $D$ & 22 & 35 & 3.6 & 265 & $"$ & " & $"$ & 08 & 12 & 3.5 \\
\hline 215 & $"$ & $"$ & $"$ & 22 & 49 & 3.6 & 266 & $"$ & $"$ & $"$ & 08 & 32 & 3.5 \\
\hline 216 & $n$ & $"$ & $"$ & 23 & 43 & 3.6 & 267 & $"$ & $"$ & $"$ & 08 & $3 \overline{5}$ & 3.8 \\
\hline 217 & $n$ & $"$ & ") & 23 & 44 & 3.6 & 268 & $"$ & $n$ & " & 08 & 48 & 3.9 \\
\hline 218 & ") & $"$ & $"$ & 23 & 50 & 4.0 & 269 & " & $n$ & $"$ & 09 & 09 & 3.9 \\
\hline 219 & $n$ & $"$ & $"$ & 23 & $5 \overline{5}$ & 3.9 & 270 & $"$ & $n$ & $"$ & 10 & 00 & 3.5 \\
\hline 220 & $"$ & $"$ & $n$ & 23 & 57 & 3.6 & 271 & $"$ & $"$ & $n$ & 10 & 37 & $3 . \tilde{5}$ \\
\hline 221 & $n$ & $"$ & $"$ & 23 & 59 & 3.6 & 272 & $"$ & $"$ & $"$ & 10 & 39 & 3.6 \\
\hline 222 & $n$ & $"$ & $"$ & 00 & 03 & 3.5 & 273 & $"$ & $n$ & " & 10 & 52 & 3.9 \\
\hline 223 & $"$ & 10 & $"$ & 60 & 27 & 3.8 & 274 & $"$ & $"$ & $"$ & 11 & 03 & 3.5 \\
\hline 224 & $n$ & $"$ & $"$ & 00 & 29 & 4.6 & 275 & ") & $"$ & $n$ & 11 & 21 & 3.5 \\
\hline 225 & $n$ & $"$ & $"$ & 00 & 36 & 3.5 & 276 & D & $"$ & $"$ & 11 & 48 & 3.6 \\
\hline 226 & $"$ & $n$ & $"$ & 00 & 38 & 3.9 & 277 & 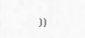 & 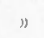 & $"$ & 11 & 58 & 4.2 \\
\hline 227 & $"$ & $"$ & 1 & 00 & 51 & 3.5 & 278 & ” & $"$ & $"$ & 12 & 12 & 3.5 \\
\hline 228 & " & $"$ & $"$ & 00 & 54 & 4.4 & 279 & $"$ & $"$ & $"$ & 12 & 17 & $3 . \tilde{5}$ \\
\hline 229 & " & $n$ & ") & 01 & 19 & 3.5 & 280 & " & $"$ & $"$ & 12 & 18 & 3.6 \\
\hline 230 & " & " & " & 01 & 20 & 3.9 & 281 & $"$ & $n$ & $"$ & 12 & 38 & 4.6 \\
\hline 231 & $n$ & $"$ & $"$ & 01 & 31 & 3.6 & 282 & $"$ & $"$ & $"$ & 12 & 53 & 3.9 \\
\hline 232 & " & " & $"$ & (0) & 35 & 3.5 & 283 & " & $"$ & " & 13 & 51 & 3.5 \\
\hline 233 & $n$ & " & $"$ & 01 & $3 \vec{\imath}$ & 3.9 & 284 & 1 & $"$ & " & 14 & 15 & 3.6 \\
\hline 234 & $n$ & $"$ & $"$ & 02 & 00 & 5.2 & 285 & $"$ & $"$ & $"$ & 14 & 26 & 4.5 \\
\hline 235 & " & ” & $"$ & 02 & 13 & 3.6 & 286 & $"$ & $"$ & $"$ & 14 & 38 & 3.9 \\
\hline 236 & $n$ & $n$ & " & 02 & 24 & 3.5 & 287 & $"$ & $"$ & $n$ & 15 & 02 & 3.6 \\
\hline 237 & " & ” & $"$ & 02 & 34 & 3.6 & 288 & $"$ & $"$ & $n$ & 15 & 16 & 3.6 \\
\hline 238 & $n$ & , & $n$ & 02 & 40 & 3.6 & 289 & $"$ & $n$ & $"$ & $1 \tilde{5}$ & +1 & 3.5 \\
\hline 239 & $n$ & " & $n$ & 02 & 46 & 3.5 & 290 & " & $n$ & $"$ & 15 & 53 & 3.5 \\
\hline $2+0$ & " & $n$ & $"$ & 02 & 47 & 3.8 & 291 & $"$ & $n$ & " & 16 & 29 & 3.9 \\
\hline $2+1$ & in & ” & " & 02 & 54 & 3.9 & 292 & $"$ & " & " & 16 & 30 & 4.4 \\
\hline 242 & " & $\eta$ & $"$ & 03 & 02 & 5.6 & 293 & $"$ & $n$ & $"$ & 16 & 54 & 3.5 \\
\hline $2+3$ & ") & $"$ & $"$ & 03 & 14 & 3.5 & 294 & $"$ & $"$ & $n$ & 16 & $5 \bar{i}$ & 3.6 \\
\hline 244 & 1) & $"$ & $"$ & 03 & 16 & 3.9 & 295 & " & $"$ & " & 17 & 08 & 4.4 \\
\hline 245 & " & $"$ & $n$ & 03 & 25 & 3.9 & 290 & $"$ & n & "1) & 17 & 15 & 4.8 \\
\hline $2+6$ & " & 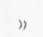 & ” & 03 & 29 & 4.0 & 297 & $"$ & $n$ & " & 18 & 37 & 3.5 \\
\hline 247 & " & $"$ & $"$ & 03 & 33 & 3.6 & 298 & $"$ & " & $n$ & 19 & 01 & 4.0 \\
\hline
\end{tabular}


Table III - (continued)

\begin{tabular}{|c|c|c|c|c|c|c|c|c|c|c|c|c|c|}
\hline \multirow{2}{*}{$\begin{array}{l}\mathrm{No} \\
299\end{array}$} & \multicolumn{3}{|c|}{ D ホは } & \multicolumn{2}{|c|}{$\begin{array}{l}\text { arr. time } \\
\mathrm{h} \text { III }\end{array}$} & \multirow{2}{*}{$\begin{array}{c}. H \\
3.8\end{array}$} & \multirow{2}{*}{$\begin{array}{l}\text { No } \\
350\end{array}$} & \multicolumn{3}{|c|}{$\mathrm{D} A \mathrm{TE}$} & \multicolumn{2}{|c|}{$\begin{array}{l}\text { arr. time } \\
\mathrm{h} \mathrm{m}\end{array}$} & \multirow{2}{*}{$\begin{array}{r}M \\
+.2\end{array}$} \\
\hline & July & 10 & 1956 & 19 & 20 & & & July & 11 & 1956 & 23 & 51 & \\
\hline 300 & ") & $n$ & $"$ & 19 & 39 & 3.5 & 351 & $"$ & 12 & $"$ & 0)1 & 20 & 3.8 \\
\hline 301 & " & $n$ & $"$ & 20 & $0 \overline{5}$ & $3 . \overline{5}$ & 352 & $"$ & $"$ & $"$ & 06 & 18 & 4.9 \\
\hline 302 & $n$ & $"$ & ” & 20 & 22 & 3.6 & 353 & » & $"$ & $"$ & 08 & 04 & 3.9 \\
\hline 303 & $"$ & $"$ & $"$ & 21 & 28 & 3.5 & 354 & $"$ & " & $"$ & os & 11 & 4.7 \\
\hline 304 & $"$ & " & $"$ & 21 & 46 & 3.5 & $35 \%$ & " & " & " & 08 & 56 & 3.9 \\
\hline 305 & $"$ & $"$ & $"$ & 22 & 10) & 4.5 & 356 & $"$ & $"$ & " & 09 & 00 & 3.6 \\
\hline 306 & $"$ & $"$ & $"$ & 22 & 18 & 4.0 & 357 & $"$ & $"$ & $"$ & 09 & 20 & 3.5 \\
\hline 307 & $"$ & $n$ & $"$ & 22 & 39 & 3.6 & 358 & $"$ & $"$ & $"$ & 10) & 08 & 3.5 \\
\hline 308 & " & $"$ & $"$ & 22 & 46 & 4.2 & 359 & $n$ & $"$ & $n$ & 11 & 23 & 3.6 \\
\hline 309 & $"$ & $n$ & » & 23 & 29 & 3.9 & 360 & $n$ & $"$ & $"$ & 16 & 11 & 4.1 \\
\hline 310 & » & $"$ & $n$ & 23 & 42 & 4.2 & 361 & " & $"$ & $n$ & 21 & 22 & 4.2 \\
\hline 311 & » & " & " & 23 & 54 & 3.6 & 362 & " & $"$ & $n$ & 23 & 59 & 4.0 \\
\hline 312 & $n$ & 11 & $"$ & 00 & 00 & 3.5 & 363 & $"$ & 13 & $"$ & 00 & $2 \tilde{5}$ & 3.6 \\
\hline 313 & $"$ & " & $"$ & 00 & 01 & 3.9 & 364 & " & $"$ & $"$ & 02 & +1 & 4.0 \\
\hline 314 & n & $"$ & $"$ & 00 & 32 & 3.5 & 365 & $n$ & $"$ & $"$ & 03 & 16 & 3.6 \\
\hline 315 & $»$ & $n$ & $n$ & 01 & $0 \overline{5}$ & 4.1 & 366 & $n$ & $"$ & " & 04 & 10 & 3.6 \\
\hline 316 & $"$ & " & $n$ & 01 & 44 & 3.6 & 367 & $"$ & $"$ & $n$ & 08 & 29 & 4.0 \\
\hline 317 & $"$ & $n$ & " & (1) & 47 & 3.5 & 368 & $n$ & $n$ & $n$ & 10 & 42 & 4.2 \\
\hline 318 & " & $"$ & $n$ & 02 & 03 & 4.0 & 369 & $n$ & ” & $"$ & 11 & 16 & 3.9 \\
\hline 319 & 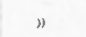 & $"$ & $n$ & 02 & 13 & 3.5 & 370 & $n$ & $"$ & $n$ & 11 & 20 & 4.1 \\
\hline 320 & ” & $n$ & $"$ & 02 & 15 & 3.6 & 371 & $n$ & $"$ & » & 14 & 42 & 4.0 \\
\hline 321 & $n$ & $"$ & " & 02 & 17 & 3.6 & 372 & $"$ & ” & » & 16 & 53 & 4.7 \\
\hline 322 & $"$ & $n$ & $n$ & 02 & 48 & 4.9 & 373 & " & " & $"$ & 19 & 00 & 3.5 \\
\hline 323 & $"$ & $"$ & $"$ & 03 & 08 & 3.5 & 374 & $n$ & $n$ & $"$ & 21 & 22 & 3.5 \\
\hline 324 & " & " & $n$ & 03 & 15 & 3.6 & 375 & $n$ & $"$ & $"$ & 21 & 52 & 3.9 \\
\hline 325 & ") & " & $"$ & 03 & 24 & 3.5 & 376 & " & 14 & $n$ & 01 & 30 & 3.9 \\
\hline 326 & " & " & " & 04 & 22 & 3.6 & 377 & $n$ & $"$ & $n$ & 03 & 24 & 3.6 \\
\hline 327 & 1 & " & $"$ & 04 & 23 & 4.0 & 378 & $"$ & $n$ & ” & $0 \overline{5}$ & 42 & 4.1 \\
\hline 328 & $"$ & $n$ & $"$ & 04 & 35 & 3.9 & 379 & " & $"$ & » & 06 & 06 & 4.2 \\
\hline 329 & $"$ & " & $"$ & 04 & 42 & 3.5 & 380 & " & $"$ & $"$ & 17 & 55 & 3.9 \\
\hline 330 & $"$ & $"$ & $"$ & 04 & 53 & 3.9 & 381 & $n$ & $"$ & " & 23 & 47 & 4.0 \\
\hline 331 & $"$ & " & " & $0 \overline{5}$ & 11 & 3.9 & 382 & $n$ & 15 & $"$ & 10 & 22 & 4.1 \\
\hline 332 & ") & $n$ & $"$ & $0 \tilde{5}$ & 13 & 3.5 & 383 & $n$ & 16 & $"$ & 02 & 22 & 3.8 \\
\hline 333 & $n$ & 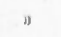 & " & $0 \tilde{5}$ & 42 & 3.9 & 384 & $"$ & $"$ & $"$ & 05 & 06 & 3.9 \\
\hline 334 & $"$ & $n$ & $n$ & 06 & 13 & 3.9 & 385 & n & $"$ & $n$ & 05 & 35 & 4.2 \\
\hline 335 & $"$ & $n$ & $n$ & 06 & 48 & 3.9 & 386 & $n$ & $"$ & $"$ & 05 & $3 \bar{t}$ & 3.9 \\
\hline 336 & $"$ & $"$ & " & 08 & 12 & 4.2 & 387 & " & $"$ & " & 06 & 20) & 3.9 \\
\hline 337 & " & " & " & 09 & 04 & 3.6 & 388 & $"$ & $"$ & $"$ & 17 & 31 & 3.9 \\
\hline 338 & $"$ & " & $"$ & 09 & 39 & 3.6 & 389 & " & $"$ & $»$ & 21 & 10 & 3.9 \\
\hline 339 & $"$ & $"$ & $"$ & 10 & 35 & 4.3 & 390 & $n$ & $"$ & $"$ & 21 & 20 & 3.9 \\
\hline 340 & $"$ & " & $"$ & 10) & 58 & 3.5 & 391 & " & $"$ & $»$ & 21 & 46 & 4.0 \\
\hline $3+1$ & $"$ & " & $"$ & 11 & 13 & 3.5 & 392 & " & " & " & 22 & 39 & 3.6 \\
\hline 342 & $"$ & $"$ & $"$ & 12 & 32 & 3.6 & 393 & $"$ & 17 & $n$ & 08 & 20 & 3.9 \\
\hline 343 & " & $n$ & $n$ & 12 & 36 & 3.5 & 394 & $"$ & 18 & $\eta$ & 02 & 56 & 3.8 \\
\hline 344 & " & $n$ & $n$ & 13 & 32 & 3.5 & 395 & & & & 06 & 01 & 4.0 \\
\hline 345 & $"$ & $n$ & $n$ & 14 & 25 & 3.5 & 396 & $"$ & $n$ & $n$ & 07 & 11 & 3.9 \\
\hline 346 & " & " & $n$ & 15 & 32 & 3.9 & 397 & $"$ & 22 & $n$ & 03 & 29 & 5.1 \\
\hline 347 & 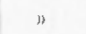 & $"$ & $"$ & 15 & 58 & 3.5 & 398 & $n$ & $"$ & $n$ & 12 & 12 & 3.9 \\
\hline 348 & $"$ & $n$ & $"$ & 21 & 57 & 4.4 & 399 & $n$ & $"$ & $"$ & 20 & 57 & 4.0 \\
\hline 349 & " & $"$ & $"$ & 22 & 01 & 3.5 & 400 & $n$ & 26 & $n$ & 22 & 00 & 3.5 \\
\hline
\end{tabular}


Table 111 -. (continued)

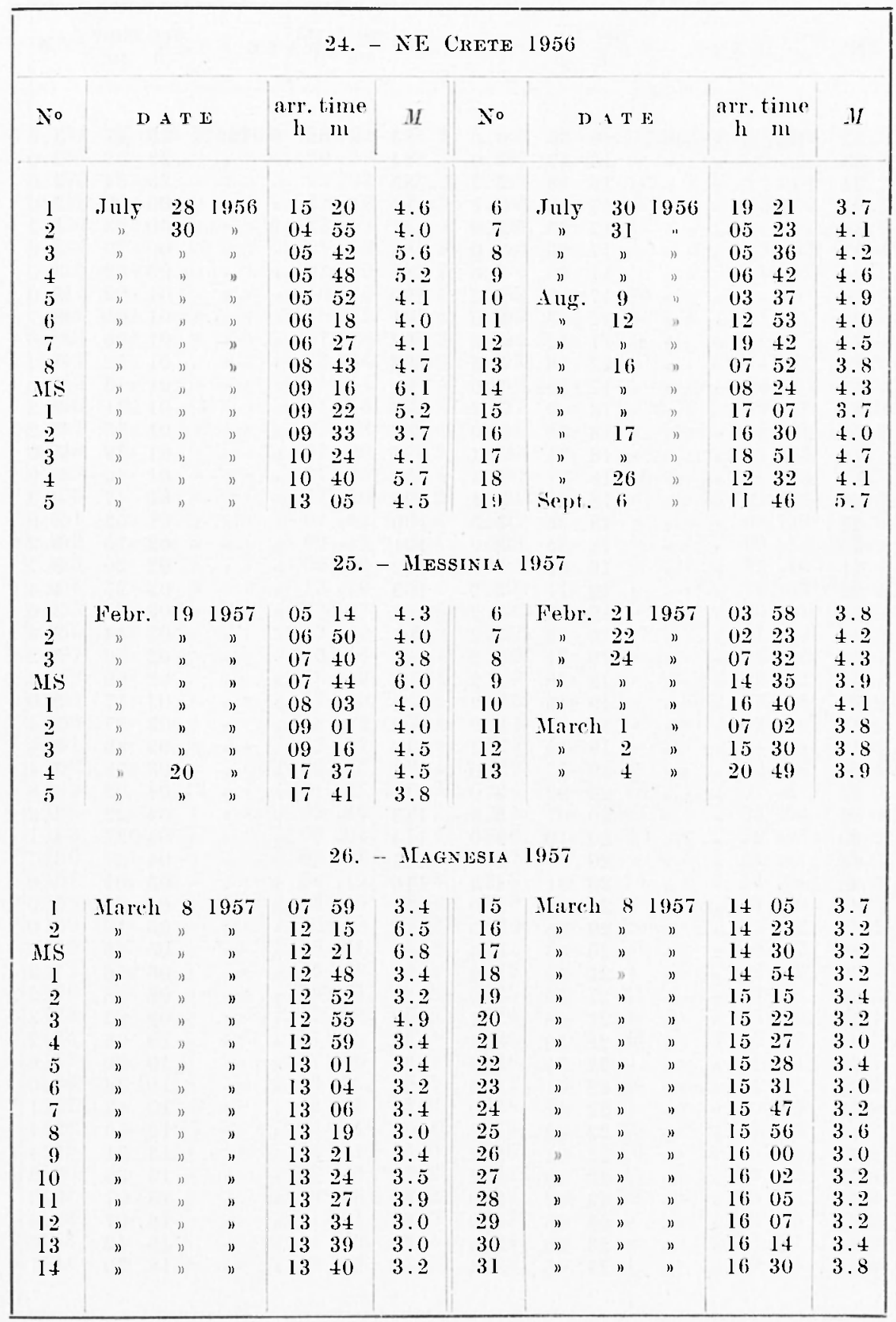




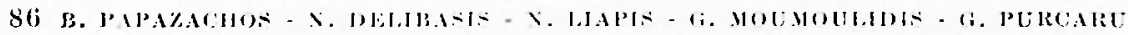

Table III - (continued)

\begin{tabular}{|c|c|c|c|c|c|c|c|c|c|c|c|c|c|}
\hline$\therefore$ & $D A$ & 1 & & $\underset{\mathrm{h}}{\mathrm{arr} .}$ & $\begin{array}{l}\text { time } \\
\text { III }\end{array}$ &.$I$ & $N^{0}$ & D: $A$ & 11 & & $\begin{array}{c}\operatorname{arr} . \\
\mathrm{h}_{\mathrm{l}}\end{array}$ & time & .11 \\
\hline 32 & Hareh & 8 & 1957 & 16 & $3 \overline{5}$ & 3.2 & 83 & Hareh & 8 & 1957 & 23 & 47 & 3.0 \\
\hline 33 & $"$ & " & $"$ & 16 & 47 & 3.0 & 84 & n & " & $n$ & 23 & 52 & 3.0 \\
\hline 34 & n & s & D & 16 & 48 & 3.3 & 85 & n & $"$ & $"$ & 23 & 54 & 3.0 \\
\hline 35 & $n$ & $n$ & D & 17 & 03 & 3.3 & 86 & " & " & " & 00 & 07 & 3.0 \\
\hline 36 & $"$ & , & $"$ & 17 & 20 & 3.0 & 87 & $"$ & 9 & " & 00 & 23 & 3.2 \\
\hline 37 & $n$ & $"$ & i) & 17 & 25 & 3.0 & 88 & $"$ & " & ") & 00 & 29 & 3.0 \\
\hline 38 & $"$ & " & $"$ & 17 & 35 & 3.0 & 89 & " & $n$ & 川 & 00 & 52 & 3.0 \\
\hline 39 & " & " & $"$ & 17 & 39 & 3.2 & 90 & $"$ & $"$ & " & 01 & 02 & 3.0 \\
\hline 40 & " & $"$ & ") & 17 & 43 & 3.0 & 91 & " & " & $"$ & 01 & 05 & 3.7 \\
\hline 41 & th & " & D & 17 & 52 & 3.2 & 92 & " & " & " & 01 & 06 & 3.6 \\
\hline 42 & $"$ & $"$ & $"$ & 17 & 58 & 3.5 & 93 & " & " & $"$ & 01 & 12 & 3.2 \\
\hline 43 & " & $"$ & ” & 17 & 59 & 3.0 & 94 & $"$ & " & $"$ & 01 & 25 & 3.0 \\
\hline 44 & 》) & " & $"$ & 18 & 09 & 3.2 & $9 \tilde{5}$ & $"$ & $n$ & " & 01 & 31 & 3.2 \\
\hline $4 \tilde{5}$ & $n$ & $"$ & נ) & 18 & 15 & 3.0 & 96 & " & " & $"$ & $0 \mathrm{I}$ & 33 & 3.2 \\
\hline 46 & ") & $"$ & $n$ & 18 & 24 & 3.4 & 97 & $"$ & " & $"$ & 01 & 39 & 3.0 \\
\hline 47 & $n$ & $"$ & $"$ & 18 & 31 & 3.4 & 98 & " & " & $"$ & 01 & 40 & 3.0 \\
\hline 48 & $"$ & n & $"$ & 18 & 34 & 3.4 & 99 & $"$ & " & $"$ & 01 & 47 & 3.3 \\
\hline 49 & $\pi$ & $"$ & $"$ & 18 & 36 & 3.3 & 100 & " & " & $"$ & 01 & 52 & 3.0 \\
\hline 50 & $n$ & $"$ & $"$ & 18 & 55 & 3.0 & 101 & $"$ & " & $"$ & 0.2 & 15 & 3.2 \\
\hline 51 & $n$ & " & $"$ & 19 & 09 & 3.0 & 102 & $"$ & " & " & 02 & 20 & 3.7 \\
\hline 52 & $n$ & " & $"$ & 19 & 11 & 3.2 & 103 & $n$ & n & $"$ & 02 & 27 & 4.4 \\
\hline 53 & $n$ & " & $"$ & 19 & 19 & 3.2 & 104 & $"$ & " & " & 02 & 31 & 3.6 \\
\hline 54 & $"$ & $"$ & $"$ & 19 & 23 & 3.2 & 105 & " & " & $n$ & 02 & 44 & 3.3 \\
\hline 55 & $n$ & " & ") & 19 & 31 & 3.2 & 106 & " & " & " & 02 & 56 & 3.2 \\
\hline 56 & " & " & 》 & 19 & 38 & 3.2 & 107 & " & " & " & (1)2 & 59 & 4.3 \\
\hline 57 & $n$ & " & $"$ & 19 & 46 & 3.2 & Ios & $n$ & " & $"$ & 03 & 17 & 3.0 \\
\hline 58 & $"$ & " & 》 & 19 & $\tilde{50}$ & 3.2 & 109 & $n$ & $"$ & " & 03 & 37 & 3.4 \\
\hline 59 & $n$ & $"$ & $"$ & 19 & $5+$ & 3.2 & 110 & $"$ & $n$ & " & 03 & 40 & 3.8 \\
\hline 60 & $"$ & " & $"$ & 19 & 57 & 3.0 & 111 & $"$ & $"$ & ") & 0.3 & 58 & 3.4 \\
\hline 61 & $n$ & " & $"$ & 20 & 02 & 3.0 & 112 & $"$ & " & $"$ & 04 & 02. & 4.8 \\
\hline 62 & n & " & $"$ & 20 & 07 & 3.0 & 113 & " & " & n & 04 & $2 \cdot 2$ & 3.2 \\
\hline 63 & $n$ & $"$ & $"$ & 20 & 10 & 3.0 & 114 & " & $"$ & " & 04 & 27 & 4.1 \\
\hline 64 & $n$ & $"$ & $"$ & 20 & 18 & 3.0 & 115 & " & " & " & 04 & 37 & 3.7 \\
\hline 65 & $n$ & $"$ & ” & 20 & 31 & 4.5 & 116 & ") & " & " & 05 & 01 & 3.0 \\
\hline 66 & A & $"$ & " & 20 & 38 & 3.0 & 117 & " & " & " & $0 \tilde{3}$ & 03 & 3.0 \\
\hline 67 & " & " & $n$ & 20 & 38 & 5.5 & 118 & " & $"$ & " & $0 \overline{3}$ & 10 & 3.0 \\
\hline 68 & n & $"$ & $"$ & 20 & 45 & 4.4 & 119 & " & $n$ & $"$ & $0 \bar{s}$ & 45 & 3.6 \\
\hline 69 & $"$ & " & " & 21 & 30 & 3.2 & 120 & " & " & " & 106 & 56 & 3.2 \\
\hline 70 & ") & ” & $"$ & 21 & 39 & 3.0 & 121 & " & " & $n$ & 06 & 58 & 4.2 \\
\hline 71 & $"$ & " & " & 21 & 48 & 3.7 & 122 & $n$ & $"$ & " & 69 & 22 & 3.8 \\
\hline 72 & $n$ & $"$ & $"$ & 21 & 50 & 3.4 & 123 & " & " & 》) & 10 & 08 & 3.2 \\
\hline 73 & $"$ & $"$ & $"$ & 22. & 31 & 3.4 & 124 & $n$ & $"$ & " & 10 & 30 & 4.6 \\
\hline 74 & $"$ & " & " & 2.2 & 41 & 3.2 & 125 & D & $n$ & $"$ & 10 & 36 & 3.0 \\
\hline 75 & " & " & $"$ & 22 & +1 & 4.0 & 126 & $"$ & " & " & 10 & 43 & 4.1 \\
\hline 76 & $"$ & " & $"$ & $2 \cdot 2$ & 42 & 4.0 & 127 & $"$ & " & $"$ & 12 & 10 & 3.4 \\
\hline 77 & " & " & $n$ & 22 & 51 & 3.2 & 128 & ఎ) & " & $\Rightarrow$ & 13 & 31 & 3.4 \\
\hline 78 & " & " & " & 2.2 & 53 & 3.2 & 129 & $"$ & " & " & 13 & $3 \overline{5}$ & 3.2 \\
\hline 79 & 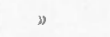 & $"$ & $"$ & 23 & 02 & 3.0 & 130 & " & " & $"$ & $1 \overline{5}$ & 07 & 3.2 \\
\hline 80 & D & " & $"$ & 23 & 06 & 3.0 & 131 & $"$ & " & " & 16 & 67 & 3.4 \\
\hline 81 & x & " & $"$ & 23 & 36 & 5.9 & 132 & " & " & " & 16 & 42 & 4.5 \\
\hline 82 & " & $"$ & $"$ & 23 & 45 & 3.4 & 133 & $x$ & " & $n$ & is & 30 & 4.7 \\
\hline
\end{tabular}


Table III - (continued)

\begin{tabular}{|c|c|c|c|c|c|c|c|c|c|c|c|c|c|}
\hline \multirow{2}{*}{$\begin{array}{l}\text { No } \\
134\end{array}$} & \multicolumn{3}{|c|}{ D I I E } & \multicolumn{2}{|c|}{$\begin{array}{l}\text { arr. time } \\
\mathrm{h} \\
\mathrm{m}\end{array}$} & \multirow{2}{*}{$\begin{array}{l}. \\
4.2\end{array}$} & \multirow{2}{*}{$\begin{array}{l}\mathrm{No}^{\circ} \\
185\end{array}$} & \multicolumn{3}{|c|}{$D A T E$} & \multicolumn{2}{|c|}{$\begin{array}{l}\text { arr. time } \\
\mathrm{h} m\end{array}$} & \multirow{2}{*}{$\begin{array}{c}. U \\
3.2\end{array}$} \\
\hline & March & 9 & 1957 & 20 & 54 & & & Mare & 13 & $195 \overline{7}$ & 18 & 09 & \\
\hline 135 & $"$ & $"$ & $"$ & 20 & 59 & 3.8 & 186 & $"$ & $\nu$ & $"$ & 20 & 23 & 3.2 \\
\hline 136 & $"$ & $"$ & $"$ & 22 & 07 & 3.2 & 187 & $"$ & $n$ & $n$ & 22 & 46 & 3.2 \\
\hline 137 & $"$ & " & $"$ & 22 & 42 & 3.3 & 188 & ” & $n$ & $"$ & 23 & 26 & 3.2 \\
\hline 138 & $"$ & $"$ & $n$ & 23 & 08 & 3.4 & 189 & " & 14 & $"$ & 01 & 04 & 3.2 \\
\hline 139 & " & 10 & $"$ & 01 & 33 & 3.2 & 190 & $"$ & $"$ & $n$ & 03 & 09 & 3.4 \\
\hline 140 & $"$ & $"$ & $"$ & 01 & 59 & 3.2 & 191 & 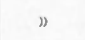 & $"$ & $"$ & 03 & 37 & 3.2 \\
\hline $1+1$ & $"$ & ״ & $n$ & 16 & 25 & 3.4 & 192 & $"$ & 15 & " & 01 & 09 & 3.9 \\
\hline $1+2$ & $"$ & $"$ & $"$ & 16 & 32 & 3.4 & 193 & $n$ & $"$ & $"$ & 01 & 56 & 3.4 \\
\hline $1+3$ & $"$ & $"$ & $n$ & 17 & 18 & 3.3 & 194 & $"$ & $"$ & " & 02 & 03 & 3.4 \\
\hline 144 & " & $"$ & $n$ & 23 & 34 & 4.0 & 195 & $"$ & " & $"$ & 04 & 12 & 3.9 \\
\hline 145 & » & $"$ & " & 01 & 14 & 3.4 & 196 & " & " & $"$ & 04 & 50 & 3.4 \\
\hline 146 & $"$ & 11 & $"$ & 01 & 16 & 3.8 & 197 & $"$ & " & $"$ & 09 & 47 & 3.4 \\
\hline 147 & $n$ & $"$ & $n$ & 03 & 08 & 3.4 & 198 & $"$ & $"$ & $n$ & 11 & 20 & 3.0 \\
\hline $1+8$ & $"$ & $"$ & $"$ & 07 & 20 & 4.9 & 199 & " & $n$ & $"$ & 11 & 33 & 3.7 \\
\hline 149 & $"$ & ע & $n$ & 07 & 25 & 3.4 & 200 & n & 16 & " & 00 & 46 & 3.0 \\
\hline 150 & $n$ & $"$ & ע & 07 & 40 & 3.2 & 201 & $"$ & $n$ & $n$ & () 1 & 26 & 3.0 \\
\hline 151 & $"$ & $"$ & $"$ & 07 & 42 & 3.4 & 202 & " & $"$ & $"$ & 08 & 25 & 3.0 \\
\hline 152 & $n$ & " & $n$ & 09 & 17 & 3.4 & 203 & $"$ & $"$ & $"$ & 09 & 18 & 4.0 \\
\hline 153 & " & " & $n$ & 09 & 32 & 5.5 & 204 & $"$ & " & $"$ & 12 & 48 & 3.4 \\
\hline 154 & " & " & " & 13 & 16 & 3.4 & 205 & " & $"$ & $"$ & 16 & 53 & 3.3 \\
\hline 155 & $"$ & $"$ & $"$ & 13 & 27 & 4.5 & 206 & " & $"$ & $"$ & 20 & 01 & 3.2 \\
\hline 156 & $"$ & $"$ & $"$ & 13 & 40 & 5.4 & 207 & $"$ & 17 & " & 01 & 39 & 3.2 \\
\hline 157 & " & $"$ & " & 15 & 46 & 3.2 & 208 & $"$ & $"$ & $"$ & 02 & 36 & 3.0 \\
\hline 158 & " & $"$ & " & 16 & 19 & 3.4 & 209 & $"$ & " & $"$ & 09 & 12 & 3.4 \\
\hline 159 & " & "1" & " & 17 & 49 & 3.2 & 210 & " & $"$ & " & 10 & 58 & 3.2 \\
\hline 160 & " & " & " & 18 & 42 & 3.4 & 211 & " & " & $"$ & 13 & 19 & 3.4 \\
\hline 161 & $n$ & $"$ & n & 22 & 37 & 3.2 & 212 & ” & $n$ & $"$ & 14 & $0 \overline{5}$ & 3.4 \\
\hline 162 & $"$ & $"$ & " & 22 & 52 & 3.4 & 213 & " & $n$ & $"$ & 20 & 38 & 3.4 \\
\hline 163 & $"$ & 12 & $"$ & 01 & 57 & 3.2 & 214 & $"$ & 18 & $"$ & 01 & 5 & 3.0 \\
\hline 164 & $n$ & $"$ & $"$ & 02 & 46 & 3.7 & 215 & $"$ & $"$ & $"$ & 03 & 02 & 3.0 \\
\hline 165 & $"$ & " & $"$ & 05 & 04 & 3.2 & 216 & " & $"$ & $"$ & 20 & 35 & 3.2 \\
\hline 166 & $n$ & $"$ & $"$ & 05 & 11 & 3.4 & 217 & $"$ & $"$ & " & 21 & 41 & 3.2 \\
\hline 167 & " & $"$ & $"$ & 05 & 49 & 3.2 & 218 & $n$ & 19 & " & 14 & 04 & 3.2 \\
\hline 168 & $"$ & " & " & 12 & 55 & 3.4 & 219 & " & $n$ & $n$ & 23 & 50 & 3.2 \\
\hline 169 & $n$ & $"$ & " & 15 & 50 & 3.2 & 220 & " & 20 & $"$ & $1: 4$ & 56 & 3.2 \\
\hline 170 & " & i" & $"$ & 15 & 51 & 3.2 & 221 & " & $"$ & $n$ & 14 & 47 & 3.4 \\
\hline 171 & " & $n$ & $"$ & 15 & 56 & 3.4 & 222 & $"$ & $n$ & $n$ & 22 & 49 & 3.7 \\
\hline 172 & " & $"$ & $"$ & 16 & 39 & 3.8 & 223 & $"$ & 21 & $"$ & 03 & 31 & 3.2 \\
\hline 173 & $n$ & $"$ & " & 17 & 02 & 3.5 & 224 & $"$ & $"$ & $n$ & 03 & $\tilde{\jmath} 0$ & 3.4 \\
\hline 174 & " & $"$ & $"$ & 17 & 20 & 3.4 & 225 & " & 23 & $"$ & 15 & 16 & 3.4 \\
\hline 175 & n & $"$ & $"$ & 17 & 36 & 3.2 & 22 & $"$ & $"$ & $n$ & 21 & 21 & 3.4 \\
\hline 176 & $"$ & $"$ & " & 19 & 30 & 3.2 & 227 & $"$ & 24 & " & 04 & 11 & 3.2 \\
\hline 177 & $"$ & $"$ & $"$ & 2.2 & 41 & 3.2 & 228 & $"$ & $"$ & $"$ & 06 & 25 & 4.9 \\
\hline 178 & $"$ & 13 & $"$ & 03 & 44 & 3.4 & 229 & " & 25 & n & 13 & 03 & 3.2 \\
\hline 179 & " & $"$ & $"$ & 04 & 14 & 3.0 & 230 & $"$ & 26 & $"$ & 23 & 24 & 4.4 \\
\hline 180 & $"$ & $"$ & " & 07 & 46 & 3.2 & 231 & $"$ & 27 & " & 08 & 12 & 3.4 \\
\hline 181 & $"$ & $n$ & $"$ & 09 & 16 & 3.2 & 232 & " & 28 & $"$ & 09 & 04 & 3.2 \\
\hline 182 & $"$ & $"$ & $"$ & 11 & 21 & 4.0 & 233 & $"$ & $n$ & $"$ & 19 & 15 & 3.0 \\
\hline 183 & $"$ & $n$ & $"$ & 14 & 42 & 3.4 & 234 & $"$ & $"$ & $"$ & 22 & 27 & 5.2 \\
\hline 184 & " & $n$ & $n$ & 16 & 29 & 3.2 & 235 & $"$ & $"$ & $"$ & 23 & 04 & 3.4 \\
\hline
\end{tabular}


Table III - (continued)

\begin{tabular}{|c|c|c|c|c|c|c|c|c|c|c|c|c|c|}
\hline \multirow{2}{*}{$\begin{array}{l}\mathrm{No}^{\circ} \\
236\end{array}$} & \multicolumn{3}{|c|}{ D A ' } & \multicolumn{2}{|c|}{$\underset{h}{a r r . t i m e}$} & \multirow{2}{*}{$\begin{array}{l}\text { H } \\
3.2\end{array}$} & \multirow{2}{*}{$\begin{array}{l}\text { No } \\
276\end{array}$} & \multicolumn{3}{|c|}{ I) $A$ T } & \multicolumn{2}{|c|}{$\begin{array}{l}\text { arr. time } \\
\mathrm{h} m\end{array}$} & \multirow{2}{*}{$\begin{array}{l}u \\
3.2\end{array}$} \\
\hline & Inrch & & 1957 & 20 & 03 & & & Nlay & 22 & 1957 & 02 & 44 & \\
\hline $23 \bar{t}$ & $"$ & 30 & $n$ & 11 & 09 & 3.0 & 277 & $n$ & " & $"$ & 04 & 02 & 3.2 \\
\hline 238 & $"$ & 31 & $"$ & 13 & 15 & 3.0 & 278 & $"$ & 23 & $"$ & 03 & 53 & 3.8 \\
\hline 239 & & $n$ & $"$ & 15 & 50 & 3.0 & 279 & $"$ & 24 & $"$ & 09 & 04 & 3.4 \\
\hline 240 & April & 1 & " & 04 & 45 & 3.0 & 280 & $"$ & $"$ & $"$ & 17 & 45 & 3.4 \\
\hline 241 & $"$ & $"$ & $"$ & 12 & 20 & 3.5 & 281 & $"$ & 26 & $"$ & 15 & 50 & 3.3 \\
\hline 242 & $"$ & $"$ & $"$ & 14 & 02 & 4.5 & 282 & $"$ & 29 & ) & 04 & 38 & 3.8 \\
\hline 243 & $"$ & 2 & $"$ & 12 & 59 & 3.2 & 283 & $"$ & $"$ & $"$ & 21 & 34 & 3.8 \\
\hline 244 & " & 4 & $"$ & 01 & 08 & 3.4 & 284 & $"$ & 30 & $”$ & 04 & 32 & 3.4 \\
\hline 245 & $"$ & 10 & " & 20 & 55 & 3.4 & 285 & $\mathrm{~J}_{\text {une }}$ & 2 & $"$ & 23 & 20 & 3.4 \\
\hline 246 & $"$ & 14 & $"$ & 08 & 10 & 3.2 & 286 & " & $\overline{5}$ & $"$ & 19 & 32 & 3.2 \\
\hline 247 & ” & $"$ & » & 15 & 14 & 3.3 & 287 & $"$ & 6 & $"$ & 10 & 34 & 3.7 \\
\hline 248 & " & 15 & " & 14 & 49 & 3.4 & 288 & $n$ & 10 & $n$ & 19 & 37 & 3.3 \\
\hline 249 & $"$ & 16 & $"$ & 02 & 39 & 3.8 & 289 & $n$ & 13 & ") & 04 & 40 & 3.2 \\
\hline 250 & $"$ & 22 & $n$ & 00 & 17 & 3.2 & 290 & $"$ & 15 & $"$ & 16 & 39 & 3.4 \\
\hline 251 & Iay & 1 & " & 22 & 17 & 3.2 & 291 & " & $"$ & $"$ & 21 & 12 & 3.7 \\
\hline 252 & $"$ & 3 & $"$ & 16 & 59 & 3.5 & 292 & $"$ & 18 & $"$ & 20 & 47 & 3.4 \\
\hline 253 & $"$ & 6 & $"$ & 17 & 16 & 3.4 & 293 & $"$ & 23 & $"$ & 67 & 51 & 3.2 \\
\hline 254 & $n$ & 11 & $"$ & 00 & 39 & 3.8 & 294 & $"$ & 24 & $"$ & 04 & 31 & 4.5 \\
\hline 255 & $"$ & 12 & $"$ & 07 & 53 & 4.9 & 295 & $"$ & 25 & $"$ & 19 & 06 & 3.4 \\
\hline 256 & " & 13 & $"$ & 01 & 33 & 3.2 & 296 & $"$ & 27 & $"$ & 07 & 11 & 4.5 \\
\hline 257 & $"$ & $"$ & $"$ & 06 & 35 & 4.6 & 297 & July & 3 & $"$ & 07 & 42 & 3.2 \\
\hline 258 & $"$ & $n$ & " & 09 & 28 & 3.4 & $29 \mathrm{~s}$ & $n$ & 13 & $n$ & 03 & 32 & 4.5 \\
\hline 259 & $"$ & 19 & $"$ & 00 & 15 & 3.4 & 299 & $"$ & 14 & $n$ & 21 & 21 & 3.0 \\
\hline 260 & $"$ & $"$ & $n$ & 12 & 00 & 3.4 & 300 & " & 19 & $"$ & 09 & 57 & 3.7 \\
\hline 261 & $n$ & ij & $n$ & 15 & 55 & 3.4 & 301 & Sept. & 17 & " & 21 & 11 & 4.0 \\
\hline 262 & $"$ & $"$ & " & 17 & 48 & 3.2 & 302 & $"$ & 20 & $n$ & 02 & 20 & 4.7 \\
\hline 263 & $"$ & 21 & D & 01 & 24 & 3.4 & 303 & $"$ & $"$ & ” & 03 & 14 & 3.2 \\
\hline 264 & $"$ & $"$ & $"$ & 06 & 16 & 3.4 & 304 & $"$ & $"$ & ” & 14 & 51 & 3.2 \\
\hline 265 & $n$ & $n$ & $"$ & 13 & 25 & 5.8 & 305 & $"$ & 21 & $n$ & 16 & 51 & 4.3 \\
\hline 266 & $"$ & $n$ & $n$ & 15 & 06 & 3.2 & 306 & oel. & 2 & $"$ & 21 & 35 & 3.4 \\
\hline 267 & $"$ & $n$ & $"$ & 15 & 43 & 3.5 & 307 & " & 24 & " & 22 & 46 & 4.2 \\
\hline 268 & $"$ & n & " & 17 & 35 & 3.4 & 308 & $"$ & 25 & " & 00 & 24 & 3.4 \\
\hline 269 & $"$ & $"$ & $"$ & 18 & 29 & 3.5 & 309 & " & $"$ & " & 02 & 19 & 5.2 \\
\hline 270 & $"$ & " & $"$ & 18 & 53 & 3.4 & 310 & " & 28 & $"$ & 02 & 39 & 3.2 \\
\hline 271 & $"$ & $n$ & $"$ & 19 & 11 & 3.4 & 311 & $"$ & 30 & $"$ & 03 & 32 & 3.4 \\
\hline 272 & $n$ & $n$ & $"$ & 19 & 48 & 3.4 & 312 & Nor. & 14 & $"$ & 23 & 09 & 3.7 \\
\hline 273 & " & n & $"$ & 21 & 18 & 3.4 & 313 & $"$ & 26 & " & us & 16 & 5.2 \\
\hline 274 & $"$ & $n$ & $"$ & 21 & 2.2 & 3.2 & 314 & $"$ & $"$ & $"$ & 11 & 51 & 5.0 \\
\hline 275 & $n$ & 22 & " & 00 & 17 & 3.3 & 315 & $"$ & 27 & " & 03 & 09 & 5.6 \\
\hline & & & & & & - & IA 1 & & & & & & \\
\hline & April & 20 & 1957 & 15 & 0.2 & 4.6 & & Ilay & 13 & 1957 & 04 & 35 & 5.0 \\
\hline 2 & 1 & 24 & ") & 19 & 11 & 7.0 & $\tilde{5}$ & (3) & 28 & " & 02 & 52 & 4.4 \\
\hline Ms & $"$ & 25 & $"$ & 02 & 26 & 7.3 & 6 & July & 14 & $"$ & 04 & 32 & 4.5 \\
\hline 1 & $"$ & $"$ & $n$ & 07 & 53 & 5.3 & 7 & Aur. & 14 & $"$ & 02 & 46 & 5.1 \\
\hline 2 & " & 26 & " & 06 & 34 & 6.3 & 8 & $"$ & $"$ & ” & 05 & 15 & 4.3 \\
\hline 3 & " & $n$ & $"$ & 16 & 10 & 5.0 & 9 & $n$ & 18 & $n$ & 03 & 23 & 4.4 \\
\hline
\end{tabular}


Table 111 - (continued)

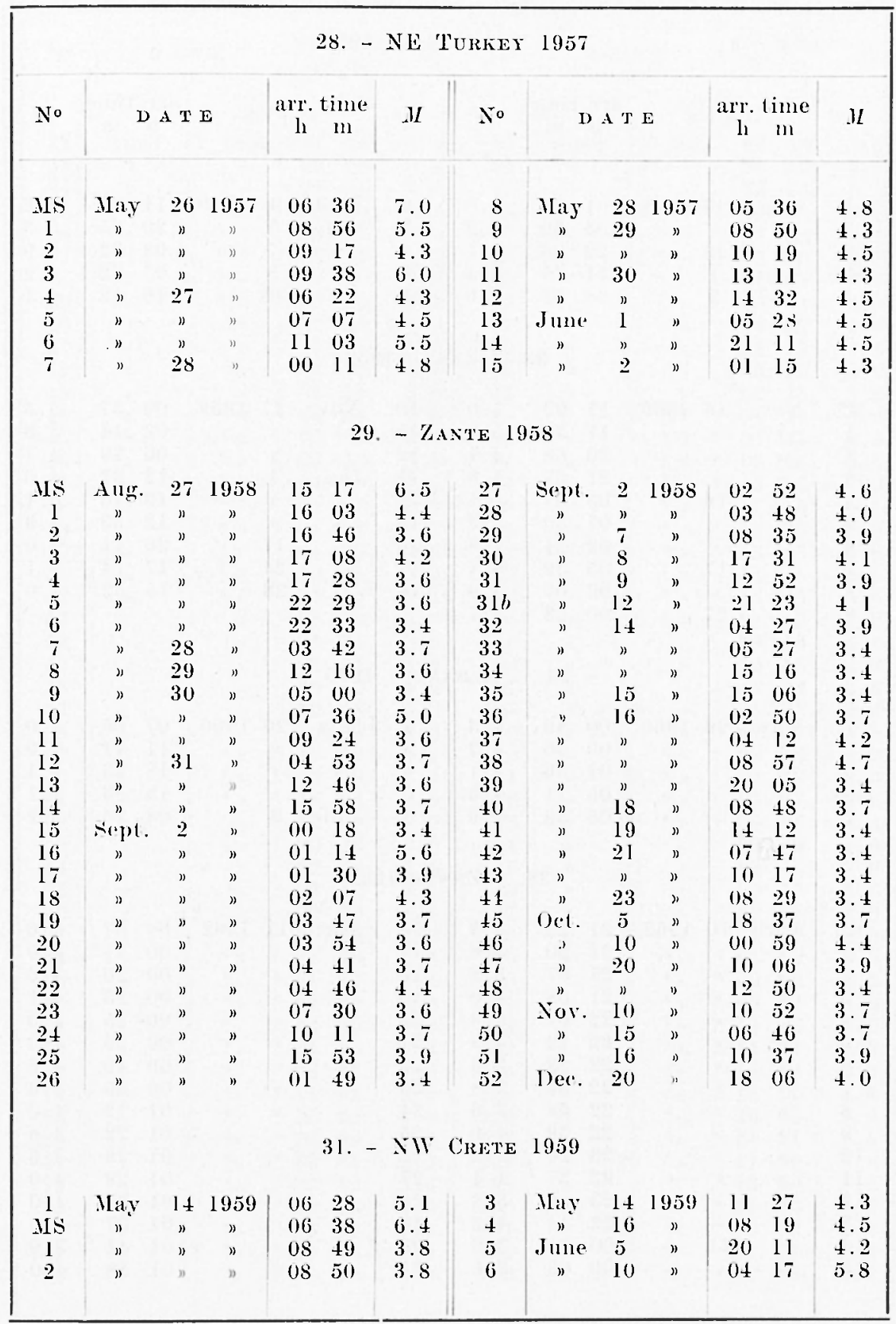


lable III - (continued)

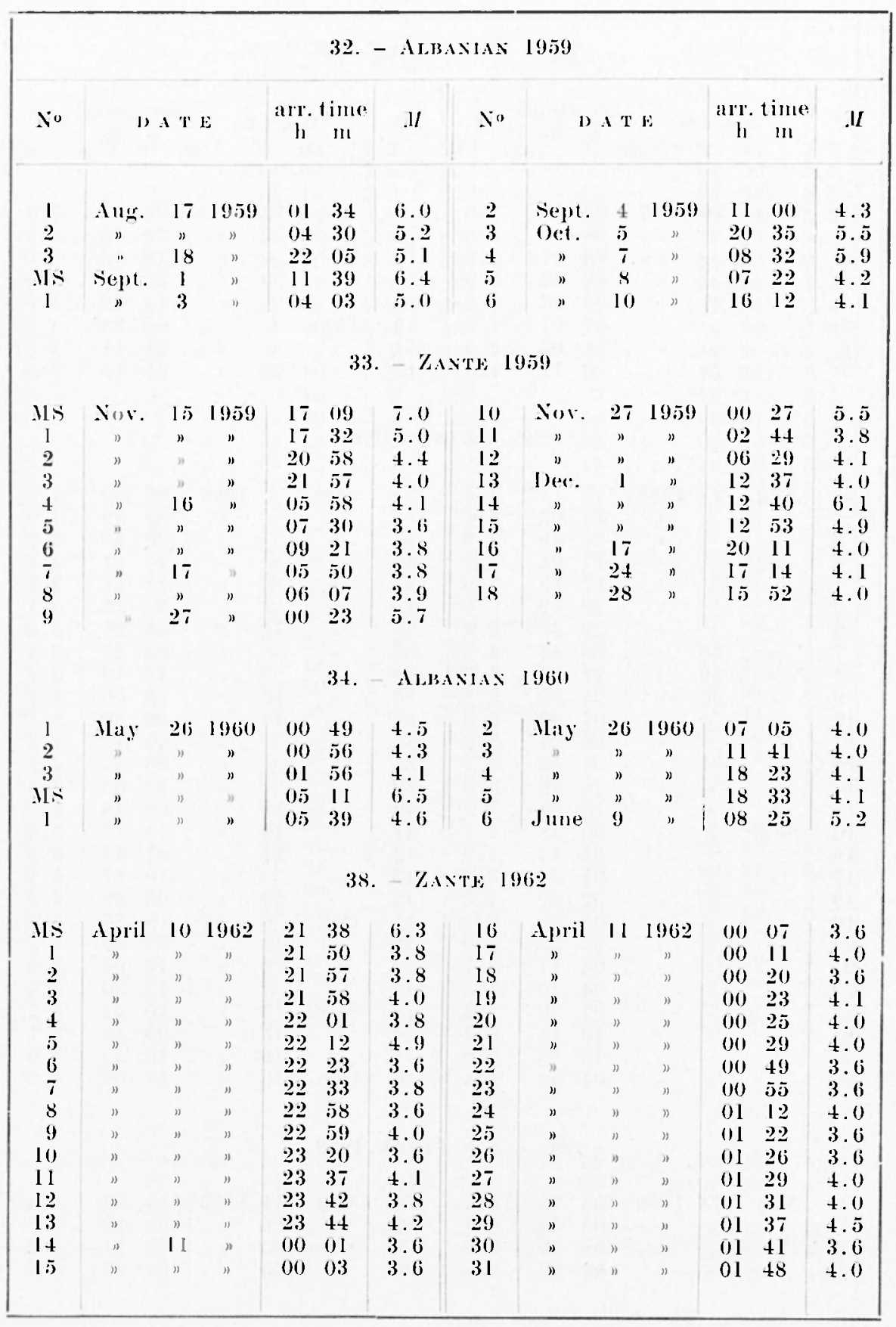


Table III - (continued)

\begin{tabular}{|c|c|c|c|c|c|c|c|c|c|c|c|c|c|}
\hline$N^{\circ}$ & \multicolumn{3}{|c|}{$D A T E$} & \multicolumn{2}{|c|}{$\begin{array}{l}\text { arr. time } \\
\text { hl } \mathrm{II}\end{array}$} & . & So & \multicolumn{3}{|c|}{ D A TE } & \multicolumn{2}{|c|}{$\begin{array}{l}\text { arr. time } \\
\text { all }\end{array}$} &.$M$ \\
\hline 32 & $\Delta p$ ril & I I & 1962 & $0 \mathrm{I}$ & 59 & +.1 & 83 & April & 13 & 1962 & 22 & 09 & 3.9 \\
\hline 33 & " & " & $"$ & 02 & 12 & 3.6 & 84 & " & 14 & $"$ & 08 & 59 & 3.8 \\
\hline 34 & $"$ & $"$ & $"$ & 02 & 27 & 3.6 & 85 & $"$ & " & $"$ & 16 & 58 & 3.6 \\
\hline 35 & " & $"$ & $n$ & 02 & 30 & 3.6 & 36 & $"$ & $"$ & $"$ & 17 & 57 & 3.6 \\
\hline 36 & $"$ & $n$ & $"$ & 02 & 31 & 3.6 & 87 & $"$ & $"$ & $"$ & 21 & 03 & 3.8 \\
\hline 37 & $"$ & $"$ & $"$ & 02 & 39 & 3.6 & 38 & " & $1 \overline{0}$ & $"$ & 03 & 30 & 3.6 \\
\hline $3 \mathrm{~s}$ & $n$ & $n$ & $n$ & 02 & 50 & 3.6 & 89 & $"$ & נر & $"$ & 04 & 09 & 3.6 \\
\hline 39 & $"$ & $"$ & $"$ & 02 & $5 \overline{5}$ & 3.9 & 90 & $"$ & $"$ & $"$ & 09 & $4 t$ & 4.0 \\
\hline 40 & $"$ & " & $"$ & 02 & 56 & +.0 & 91 & $n$ & $"$ & $n$ & 11 & 53 & 3.6 \\
\hline 41 & $"$ & 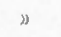 & $"$ & 03 & 07 & 3.6 & 92 & $"$ & $"$ & $n$ & 22 & 11 & 3.6 \\
\hline 42 & $"$ & $"$ & $"$ & 03 & 12 & 4.0 & 93 & $n$ & 16 & $"$ & 00 & 06 & 3.9 \\
\hline 43 & " & $"$ & $"$ & 03 & 19 & 3.6 & 94 & $"$ & " & $n$ & 00 & 16 & 5.2 \\
\hline 44 & $"$ & $"$ & $"$ & 03 & 44 & t. 0 & 95 & $"$ & $"$ & $"$ & 01 & 36 & 3.6 \\
\hline 45 & $"$ & $"$ & $"$ & 03 & 49 & 3.6 & 96 & $"$ & " & $"$ & 01 & 47 & 3.6 \\
\hline 46 & $"$ & $"$ & $"$ & 03 & $\overline{5} 6$ & 3.6 & 97 & $"$ & $»$ & $n$ & 03 & 28 & 3.6 \\
\hline 47 & $"$ & $"$ & $n$ & 04 & 06 & 3.8 & 98 & $"$ & " & " & 13 & 12 & 4.0 \\
\hline 48 & $"$ & " & $"$ & 04 & 07 & 3.6 & 99 & $"$ & 17 & " & 11 & 16 & 4.1 \\
\hline 49 & $"$ & $"$ & $n$ & 04 & 22 & 3.6 & 100 & $"$ & $"$ & $"$ & 11 & 35 & 5.3 \\
\hline 50 & " & $"$ & $"$ & 04 & 26 & 3.6 & 101 & $"$ & $"$ & $n$ & 13 & 25 & 3.8 \\
\hline 51 & $"$ & $"$ & $"$ & 04 & 48 & 3.6 & 102 & $"$ & D & $n$ & 14 & $5 \overline{5}$ & 4.1 \\
\hline 52 & " & $"$ & $"$ & 04 & 54 & 3.6 & 103 & $"$ & $"$ & $"$ & 15 & 46 & 3.6 \\
\hline 53 & $"$ & " & $"$ & 04 & 58 & 3.6 & 104 & $n$ & 18 & $"$ & os & 12 & 3.9 \\
\hline i) 4 & $"$ & $"$ & $"$ & 0.5 & 34 & 3.6 & 105 & $"$ & $"$ & $"$ & 09 & 16 & $\begin{array}{l}4 \\
4.1\end{array}$ \\
\hline $5 \overline{5}$ & $"$ & $"$ & $"$ & os & 15 & 3.6 & 106 & $"$ & $"$ & " & 10 & 45 & +.6 \\
\hline 56 & $"$ & $"$ & $"$ & 09 & 43 & +.0 & 107 & $"$ & $n$ & $n$ & 17 & 33 & 3.8 \\
\hline 57 & ") & $"$ & $"$ & 10 & 48 & 5.3 & 108 & " & 19 & $"$ & 00 & 57 & 3.6 \\
\hline 58 & " & $"$ & $"$ & 10 & 59 & 3.6 & 109 & $"$ & $"$ & " & 02 & 07 & $4 . \overline{0}$ \\
\hline 59 & " & $"$ & $"$ & 13 & 12 & 4.1 & 110 & $"$ & " & $"$ & 03 & 18 & 4.7 \\
\hline 60 & " & $"$ & $"$ & 13 & 19 & 3.6 & 111 & " & 20 & $n$ & 14 & 43 & 3.6 \\
\hline 61 & $"$ & $"$ & $"$ & 16 & 24 & 4.0 & 112 & " & 24 & " & 07 & 47 & 3.6 \\
\hline 62 & " & , & $\Rightarrow$ & 18 & $5 \overline{5}$ & 3.9 & 113 & $"$ & $2 \overline{5}$ & $n$ & 06 & 23 & 4.8 \\
\hline 63 & " & $"$ & " & 20 & 33 & 3.6 & 114 & $"$ & $"$ & $"$ & 09 & 50 & 4.0 \\
\hline $6-1$ & $"$ & $n$ & $"$ & $2 \cdot 2$ & 46 & 3.6 & 115 & $"$ & 27 & $"$ & 00 & 59 & 3.6 \\
\hline 65 & $"$ & $"$ & $"$ & 23 & 15 & 3.6 & 116 & " & 28 & $"$ & 05 & 46 & 3.6 \\
\hline 66 & $"$ & 12 & $"$ & 00 & 03 & 4.1 & 117 & $"$ & $n$ & $"$ & 20 & 57 & 4.0 \\
\hline 67 & $"$ & " & $"$ & 00 & 44 & 4.2 & 118 & i) & 29 & $"$ & 07 & 57 & 4.0 \\
\hline 68 & " & $"$ & $"$ & 01 & 28 & 3.6 & 119 & " & $n$ & $"$ & us & 09 & 3.6 \\
\hline 69 & $"$ & $"$ & " & 01 & 31 & 3.6 & 120 & " & д & $"$ & 09 & 26 & 4.0 \\
\hline 70 & " & $"$ & $"$ & 01 & 38 & 3.6 & 121 & $"$ & $"$ & $"$ & 09 & 44 & 3.6 \\
\hline 71 & " & $n$ & $"$ & 03 & 30 & 3.9 & 122 & $"$ & » & $"$ & 11 & 08 & 3.6 \\
\hline 72 & $"$ & $"$ & " & 05 & $15 \overline{5}$ & 3.8 & 123 & $"$ & $"$ & $n$ & 11 & 11 & 4.0 \\
\hline 73 & $"$ & $"$ & $"$ & 08 & 57 & +.2 & 124 & " & נ) & $"$ & 14 & 04 & 3.6 \\
\hline 74 & $"$ & " & $"$ & 11 & 33 & 4.0 & 125 & » & $n$ & $"$ & 18 & 02 & 4.4 \\
\hline 75 & $"$ & $"$ & $"$ & 15 & 25 & 4.0 & 126 & $"$ & " & $n$ & 20 & 03 & 3.6 \\
\hline 76 & $"$ & $"$ & $"$ & 16 & 19 & 3.6 & 127 & ” & ” & $n$ & 21 & 31 & 3.6 \\
\hline 77 & " & $"$ & $n$ & 10 & 04 & 3.9 & 128 & " & 30 & D & 11 & 51 & 4.0 \\
\hline 78 & ", & " & $"$ & 20 & 12 & 3.6 & 129 & $"$ & $n$ & $"$ & 12 & 00 & 3.6 \\
\hline 79 & " & $"$ & $"$ & 22 & 58 & 3.6 & 130 & Mny & 1 & $"$ & 11 & 55 & 4.2 \\
\hline 80 & $"$ & " & $"$ & 23 & 52 & 3.8 & 131 & $"$ & 4 & " & 00 & 29 & 3.6 \\
\hline 81 & $"$ & 13 & " & 04 & 16 & 3.6 & 132 & " & $\overline{5}$ & $n$ & 21 & 37 & 3.6 \\
\hline 82 & $"$ & 18 & $"$ & 10) & 50 & 4.0 & 133 & ) & $"$ & $"$ & 22 & 29 & 4.0 \\
\hline
\end{tabular}


Table III - (continued)

\begin{tabular}{|c|c|c|c|c|c|c|c|c|c|c|c|c|c|}
\hline So & \multicolumn{3}{|c|}{ I) I TE } & \multicolumn{2}{|c|}{$\underset{\text { I }}{\text { arr. time }}$} & M & So & \multicolumn{3}{|c|}{$D A \mathbf{T} \mathbf{E}$} & \multicolumn{2}{|c|}{$\begin{array}{c}\text { arr. time } \\
\mathrm{h} \mathrm{m}\end{array}$} & 1 \\
\hline 134 & IIay & (j) & 1962 & 04 & 02 & \pm .0 & 137 & May & (i) & 1962 & 22 & 28 & 4.0 \\
\hline 135 & $"$ & $n$ & $n$ & 06 & 43 & +.3 & 138 & " & " & $"$ & 23 & 37 & 4.0 \\
\hline 136 & " & " & $n$ & 21 & +1 & +.3 & 139 & $"$ & $2 !$ & " & 23 & 45 & +.5 \\
\hline \multicolumn{14}{|c|}{ 40. - KEPHALLENiA 1962} \\
\hline MS & July & 6 & 1962 & 09 & 17 & 6.3 & 19 & July & 6 & 1962 & 16 & 42 & 4.1 \\
\hline 1 & $"$ & $"$ & " & 09 & 29 & +.3 & 20 & $"$ & $"$ & $"$ & 16 & 46 & 4.0 \\
\hline 2 & ” & $"$ & $"$ & 09 & 37 & 4.7 & 21 & $"$ & " & " & 16 & $\overline{5} 6$ & 4.0 \\
\hline 3 & 1 & $"$ & " & 10 & 58 & 4.0 & 22 & $"$ & $n$ & $n$ & 17 & 00 & 4.3 \\
\hline \pm & $"$ & $"$ & $"$ & 10 & 59 & +.2 & 23 & " & $n$ & ") & 18 & 58 & 3.8 \\
\hline$\overline{5}$ & ” & $"$ & $"$ & 11 & 10 & 4.2 & 24 & $"$ & " & $"$ & 19 & 04 & 3.8 \\
\hline 6 & $"$ & $"$ & " & 11 & 34 & 4.2 & 25 & $"$ & " & $"$ & 20 & 22 & 4.0 \\
\hline 7 & ") & " & ") & 11 & 37 & t. 1 & 26 & $"$ & 7 & 1 & 04 & 18 & 3.8 \\
\hline 8 & " & $"$ & $"$ & 12 & 36 & 3.8 & $2 \overline{7}$ & $"$ & $"$ & " & 08 & 08 & 4.1 \\
\hline 9 & " & $n$ & $"$ & 12 & 37 & 3.8 & 28 & $n$ & $n$ & $n$ & 08 & 31 & 3.8 \\
\hline 10 & n & $"$ & " & 12 & 43 & 3.8 & 29 & $"$ & " & " & 09 & 09 & 3.8 \\
\hline 11 & $n$ & $n$ & $"$ & 13 & 26 & 4.3 & 30 & $"$ & $n$ & " & 12 & 21 & 4.3 \\
\hline 12 & " & $"$ & $"$ & 13 & 46 & 4.2 & 31 & $n$ & $n$ & " & 12 & 47 & 4.7 \\
\hline 13 & " & $"$ & $"$ & 14 & 20 & 4.5 & 32 & $"$ & " & $n$ & 13 & 11 & 3.8 \\
\hline 14 & $n$ & " & $"$ & & $(21)$ & 4.2 & 33 & $"$ & " & $n$ & 15 & 46 & 4.0 \\
\hline 15 & D & $"$ & " & 15 & 52 & 4.2 & 34 & " & " & " & 23 & 10 & 4.2 \\
\hline 16 & $n$ & " & ” & 15 & $5 \overline{5}$ & 4.2 & 35 & i & 8 & " & 02 & 13 & 3.8 \\
\hline 17 & $n$ & $"$ & ") & $16 j$ & $06 j$ & 4.2 & 36 & $"$ & 28 & $"$ & 12 & 17 & +.5 \\
\hline 18 & $"$ & $"$ & " & 16 & 11 & 4.2 & & & & & & & \\
\hline
\end{tabular}

\section{REFERENCES}

(') BגTI II. and DUDA S. J., Earthquake volume, Faull plane area, seismic energy, shain deformation und related quantities. "Ann. di Geofisicil", 17, 353-368, (1964).

(2) Benioff II., Earthquake and rock creep. Part I: "Bull. Seism. Soc. Am,", 41, 31-62, (1951).

(3) Gabaxopoulos G. A.. Evidence for the seat of strain-producing forces. "Ann. di Geofisica ", 18, 399-409, (1965).

(4) GuTExberat B. and Riciters C., Seismicily of the Earth and Associaled Lhenomena. Princeton Tuiversity Press. (1954).

(5) Matuzawa T., Study of Earthquakes. Cno Sloten, Tokyo Japan, 213, (1964).

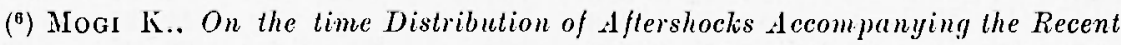
Major Earthquakes in and near Japan. "Bull. Earthq. Res. Inst.", 40, 107-124. (1962 a). 
(i) Mogi K., Study of elastic shocks caused by the fracture of heterogeneous materials and its relalions to earthquake phenomena. "Bull. Earthq. Res. Inst. " 40, 125-17t. (1962 b).

$\left({ }^{8}\right)$ Mogi K., Magnitude, frequency relation for elastic shocks accompanying fractures of various malerials and some related problems in earthquakes. "Bull. Earthq. Res. Inst." 40, \$31-853, (1962 c).

(9) Mogi K., The fracture of a semi-infinite body caused by an inner stress origin and its relation to the earlhquake phenomena (second paper). "Bul.t Larthq. Res. Inst.", 41, 595-614, (1963 a).

(10) MOGI K., Some discussions on aflershocks, foreshocks and earthquake swarms the fraclure of a semi-infinile body caused by an inner stress origin and its relation to the earlhquake phenomena. "Bull. Larthq. Res. Inst.", 41, 615-658, (1963 b).

(11) Papazacios B., Comsinakis P. and Drakopuulos J., P'reliminary Resulls of an investigation of the crustal structure in the region of (ireece. "Bull. Seism. Soc. Am." (in press), (1966).

(12) Pshexinov N. K., The problem of aflershocles (in Russian). "Geology and Geophysics", 1, 135-140, (1964).

(13) Riciren C., Elementary S'eismology, Freeman, Co., San Franciseo. 768. (1958).

(19) Suzuki Z., Nakamura K., Limuka K., Abe M., Hamaliuchi H., Isili ll.. Suzuki M., Yнманото K. and Suzuki K., On the aftershocks of Oga Earlhquake, May 7, 1964. "Science Reports of the Toloku University", 3, 146-163, (1965).

$\left.{ }^{15}\right)$ UTSU 'T., A Stalistical sludy on the Occurrence of Aftershochs "Geophysical magrazine "30, 4, 521-603, (1961). 